Portland State University

PDXScholar

Summer 9-5-2014

\title{
Controlling the Empire: Measuring Ethnic Residential Segregation in London, 2001-2011
}

Lindsay Joella Spell

Portland State University

Follow this and additional works at: https://pdxscholar.library.pdx.edu/open_access_etds

Part of the Civil Rights and Discrimination Commons, and the International and Area Studies Commons

Let us know how access to this document benefits you.

\section{Recommended Citation}

Spell, Lindsay Joella, "Controlling the Empire: Measuring Ethnic Residential Segregation in London, 2001-2011" (2014). Dissertations and Theses. Paper 1978.

https://doi.org/10.15760/etd.1978

This Thesis is brought to you for free and open access. It has been accepted for inclusion in Dissertations and Theses by an authorized administrator of PDXScholar. Please contact us if we can make this document more accessible: pdxscholar@pdx.edu. 
Controlling the Empire:

Measuring Ethnic Residential Segregation in London, 2001-2011

by

Lindsay Joella Spell

A thesis submitted in partial fulfillment of the

requirements for the degree of

\author{
Master of Science \\ in \\ Geography
}

Thesis Committee:

Martha Works, Chair

David Banis

Jason Jurjevich

Portland State University 2014 
(C) 2014 Lindsay Joella Spell 


\begin{abstract}
This research presents an overview of ethnic residential segregation in London, England, from 2001 to 2011 using four different methods of measurement. The purpose of the study was to both examine changes in the level of segregation among different ethnic groups between census dates and to compare various methods of measurement. Using the Index of Dissimilarity, Poulsen et al.'s (2001) typology classification and two different local statistics (Getis-Ord $G^{*}$ and Anselin Local Moran's I), the levels of concentration of the five main ethnic minority groups in London were measured for data from the 2001 and 2011 censuses. The five ethnic minority groups studied were: Black African, Black Caribbean, Indian, Pakistani and Bangladeshi. Of the five populations analyzed, only the Black Caribbean population showed any decrease in its overall level of segregation, while the other four all saw slight increases in segregation over the period. After comparing the four methods used, it was determined that while all offer a different perspective on the segregation of groups across space, the Anselin Local Moran's I statistic provides the most detailed result of variation in concentration across space.
\end{abstract}




\section{Dedication}

For Gramps, who always knew I'd get it done. 


\section{Acknowledgements}

This research would not have been possible were it not for any number of people in my life who encouraged and supported me throughout this process. I must begin by thanking my amazing family for their endless optimism that I would indeed finish and finally earn the degree I've been working toward for so long. My mom has been a patient listener for many months while I work things out on the phone whether she understood me or not, so thank you. And to my Dad, what can I say? Your Excel skills have been invaluable and I would have no results at all if not for your FaceTime tutoring sessions while I figured out how to work with mountains of census data. Daniel and Dawn, thank you for your many words of encouragement and for reminding me that a good thesis is a done thesis. Thank you so much to Martha for staying with me through changing circumstances and being so willing to guide me through this process. David and Jason, thanks to you for agreeing to be on my committee despite your already packed schedules. To all of the many friends and family members I haven't mentioned, you are very much appreciated and I would not have made it this far without each and every one of you! 


\section{TABLE OF CONTENTS}

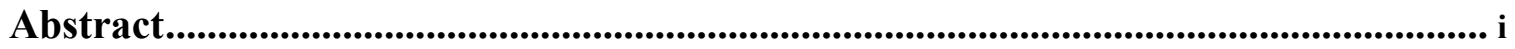

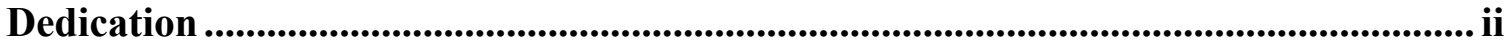

Acknowledgements ................................................................................................... iii

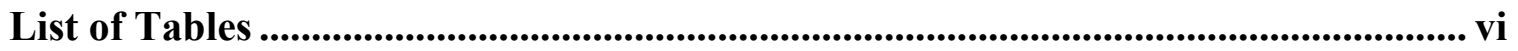

List of Figures............................................................................................................................... vii

List of Acronyms ................................................................................................ ix

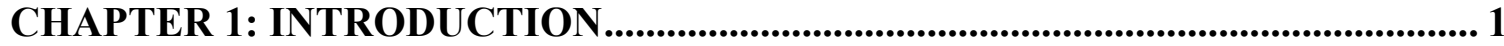

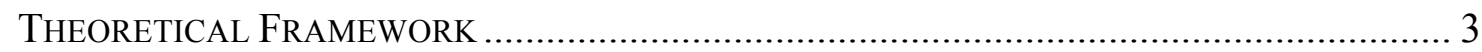

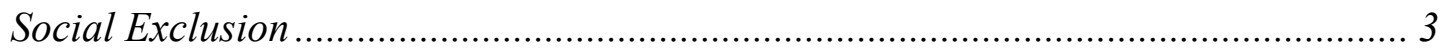

Vulnerability of Immigrant Populations .......................................................... 7

CHAPTER 2: BACKGROUND ............................................................................9

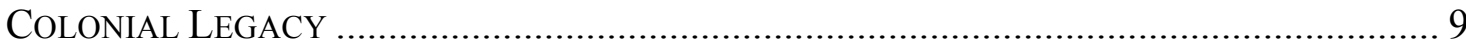

MAJOR IMMIGRANT STREAMS TO THE UNITED KINGDOM …........................................ 11

EVOLUTION OF BRITISH IMMIGRATION POLICY ....................................................... 14

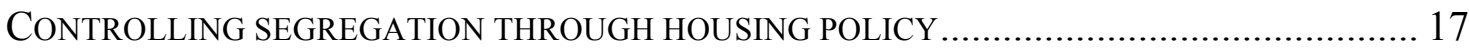

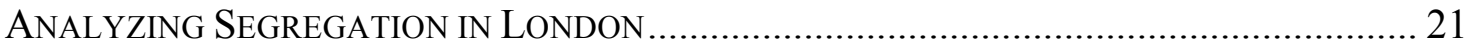

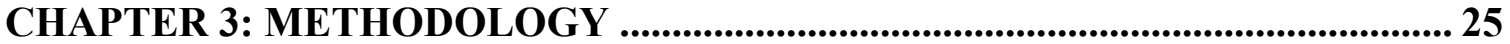

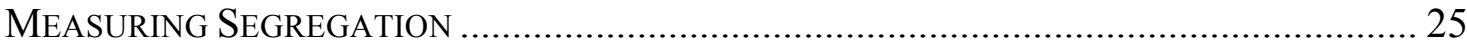

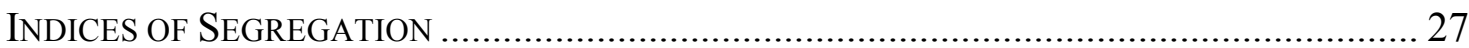

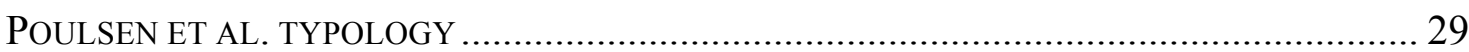

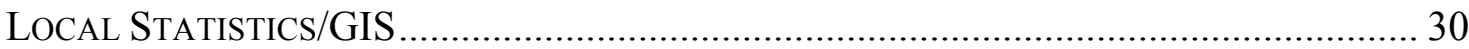

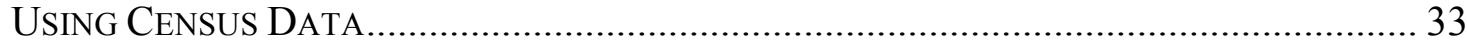

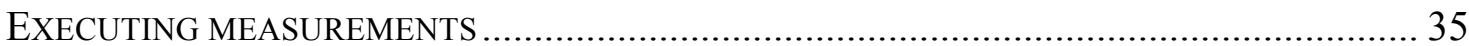

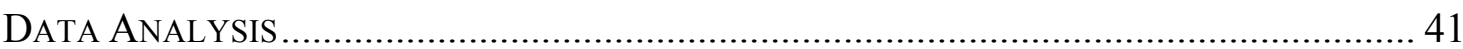

CHAPTER 4: RESULTS/ANALYSIS ............................................................ 42

Changes In The White/British Population.......................................................... 45

Changes IN THE Afro-CaribBEAn PopUlation ...................................................... 48

Changes IN THE South Asian Population............................................................. 58

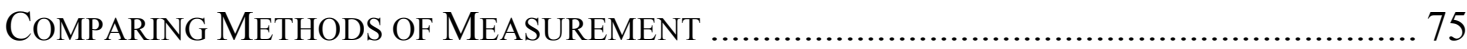

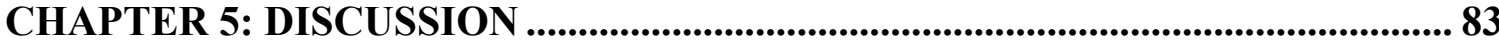

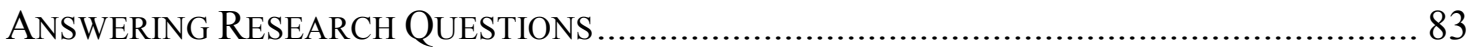

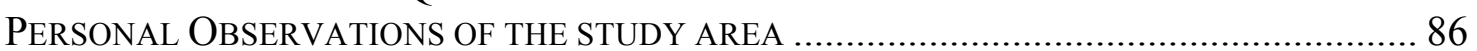

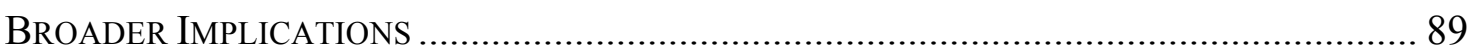




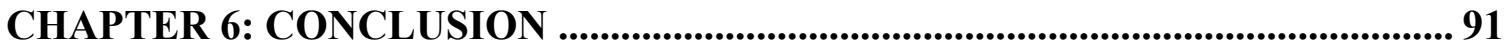

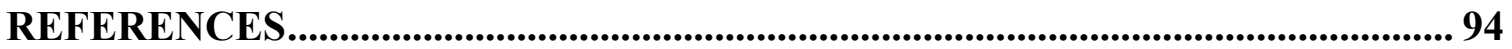

APPENDIX A: ENGLAND CENSUS QUESTIONNAIRE, ETHNICITY QUESTION 2001 \&2011 ............................................................................... 98 


\section{List of Tables}

1. Master Legend for Results Maps......................................... 43

2. Population Estimates for England by ethnic group, 2001 and 2011 censuses......44

3. Population Estimates for London by ethnic group, 2001 and 2011 censuses......44

4. Proportion of total population living in London, 2001 and 2011 censuses......... 44

5a. White/British population in statistically significant Output Areas, $G^{*} \ldots \ldots \ldots . . .47$

5b. White/British population in statistically significant Output Areas, $I \ldots \ldots \ldots \ldots \ldots 47$

6a. Black African population in statistically significant Output Areas, $G^{*} \ldots \ldots \ldots . . .53$

6b. Black African population in statistically significant Output Areas, $I$.............53

7a. Black Caribbean population in statistically significant Output Areas, $G^{*} \ldots \ldots . .57$

7b. Black Caribbean population in statistically significant Output Areas, $I \ldots \ldots \ldots . .57$

8a. Indian population in statistically significant Output Areas, $G^{*} \ldots \ldots \ldots \ldots \ldots \ldots 6$

8b. Indian population in statistically significant Output Areas, $I \ldots \ldots \ldots \ldots \ldots \ldots \ldots 63$

9a. Pakistani population in statistically significant Output Areas, $G^{*} \ldots \ldots \ldots \ldots \ldots \ldots 67$

9b. Pakistani population in statistically significant Output Areas, $I \ldots \ldots \ldots \ldots \ldots \ldots . \ldots 67$

10a. Bangladeshi population in statistically significant Output Areas, $G^{*} \ldots \ldots \ldots \ldots 71$

10b. Bangladeshi population in statistically significant Output Areas, $I$.............71

11a. Percent of group population living in areas of high or low concentration.......75

11b. Change in percentage of group living in areas of high or low concentration... 75 


\section{List of Figures}

1. The United Kingdom - With Study Area Highlighted......................... 3

2. Net Migration in the United Kingdom, 1962-2009 ........................... 9

3. Extent of the British Empire, 1921........................................ 10

4. Greater London Output Districts.......................................... 36

5a. Greater London Output Areas, 2001 Census................................ 37

5b. Greater London Output Areas, 2011 Census................................... 38

6a. Local Statistics Results for the White/British Population, 2001...............46

6b. Local Statistics Results for the White/British Population, 2011................46

7a. Poulsen et al. typology Results for the Black Population, 2001................. 48

7b. Poulsen et al. typology Results for the Black Population, 2011 ................. 49

8a. Index of Dissimilarity Results for the Black African Population, 2001 .......... 50

8b. Index of Dissimilarity Results for the Black African Population, 2011......... 51

9a. Local Statistics Results for the Black African Population, 2001 ............... 52

9b. Local Statistics Results for the Black African Population, 2011...............52

10a. Index of Dissimilarity Results for the Black Caribbean Population, 2001 ..... 54

10b. Index of Dissimilarity Results for the Black Caribbean Population, 2011 .....55

11a. Local Statistics Results for the Black Caribbean Population, 2001............56

11b. Local Statistics Results for the Black Caribbean Population, 2011.............56

12a. Poulsen et al. typology Results for the South Asian Population, 2001..........58

12b. Poulsen et al. typology Results for the South Asian Population, 2011..........59

13a. Index of Dissimilarity Results for the Indian Population, 2001 ...............60

13b. Index of Dissimilarity Results for the Indian Population, 2011.............. 60

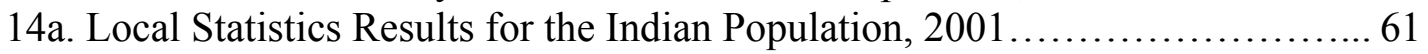

14b. Local Statistics Results for the Indian Population, 2011..................... 62

15a. Index of Dissimilarity Results for the Pakistani Population, 2001............ 64

15b. Index of Dissimilarity Results for the Pakistani Population, 2011............ 64

16a. Local Statistics Results for the Pakistani Population, 2001...................65

16b. Local Statistics Results for the Pakistani Population, 2011..................66 66

17a. Index of Dissimilarity Results for the Bangladeshi Population, 2001.......... 68

17b. Index of Dissimilarity Results for the Bangladeshi Population, 2011..........68

18a. Local Statistics Results for the Bangladeshi Population, 2001 ................69

18b. Local Statistics Results for the Bangladeshi Population, 2011................70

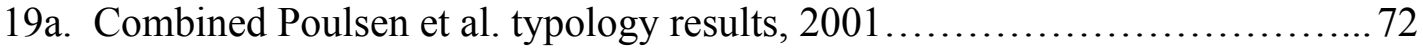

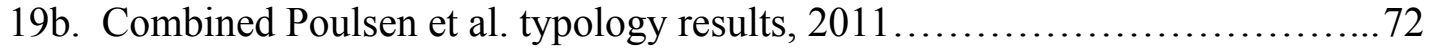

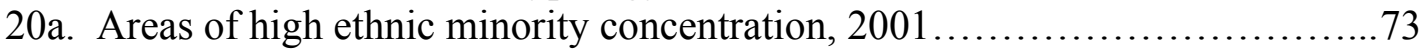

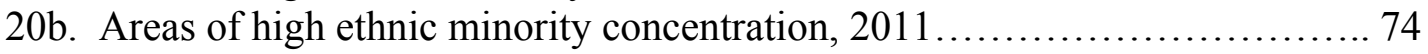


21. Comparing methods, Poulsen et al. typology \& Index of Dissimilarity........76

22. Comparing methods, Getis-Ord $G^{*} \&$ Index of Dissimilarity.................78

23. Comparing methods, Anselin Local Moran's $I \&$ Index of Dissimilarity...... 78

24. Comparing methods, Poulsen et al. Typology \& Anselin Local Moran's $I \ldots 80$

25. Comparing methods, Poulsen et al. Typology \& Getis-Ord $G^{*} \ldots \ldots \ldots \ldots \ldots . \ldots 0$

26. Comparing Methods, Anselin Local Moran's $I \&$ Getis-Ord $G^{*} \ldots \ldots \ldots \ldots \ldots 81$

27. Graffiti in Elephant \& Castle......................................... 86

28. Demolition of a council housing facility in Elephant \& Castle ................ 87

29. Afro-Caribbean centric high street in Peckham.......................... 88

30. Public service advertisement in Barking................................ 89 


\section{List of Acronyms}

$\begin{array}{ll}\text { CBL } & \text { Choice-based Letting } \\ \text { CUKC } & \text { Citizen of the United Kingdom and Colonies } \\ G^{*} & \text { Getis-Ord } G^{*} \text { statistic } \\ \text { GIS } & \text { Geographic Information Systems } \\ \text { HH } & \text { High-High Cluster } \\ \text { HL } & \text { High-Low Cluster } \\ I & \text { Moran's } I \text { statistic } \\ \text { ID } & \text { Index of Dissimilarity } \\ \text { LH } & \text { Low-High Cluster } \\ \text { LL } & \text { Low-Low Cluster } \\ \text { LQ } & \text { Location Quotient } \\ \text { NCW } & \text { New Commonwealth } \\ \text { OA } & \text { Output Area } \\ \text { UK } & \text { United Kingdom } \\ \text { US } & \text { United States }\end{array}$




\section{Chapter 1: Introduction}

As more migrants make their new home in the UK, concerns about the levels of ethnic residential segregation among the immigrant population have arisen in both the political and social scientific spheres. Examinations of ethnic residential segregation from a quantitative perspective are the first step in ensuring that the needs of an already vulnerable population can be adequately met. While not all segregation at the residential level is harmful and at times is even a matter of choice on the part of the ethnic minority population in question, areas of concentration need to be identified before other questions as to whether such segregation is also resulting in deprivation or exclusion can be addressed.

In this study, I will use a series of measurements to examine ethnic residential segregation in the greater London area across two census periods: 2001 and 2011. The research will provide a visualization of how the city's ethnic minority population changed/moved in the first decade of the twenty-first century and will also be an opportunity to compare the methods of measurement themselves.

Before addressing the specific aims of this research, it should be noted that particularly in the area of ethnic residential segregation, the way in which research questions are framed can have a significant impact on the results of the study. Johnston et al. (2005) write, "In almost all areas of social science, the results of a piece of research depend on how the questions were phrased and how the relevant concepts were defined and measured. This is certainly the case with ethnic residential segregation, a concept that has a number of (at least implied) definitions and a series of quantitative measures linked to them" (1226-1227). Thus a great deal of consideration has gone into deciding which 
measures of segregation to use and how those measures might impact the results. With this in mind, the research questions I seek to address are:

- How did levels of ethnic residential segregation in the greater London area change between 2001 and 2011 ?

- Have planning policies promoting "community cohesion" been successful in their goal of decreasing levels of segregation?

- How does changing the method of measurement impact the pattern of and therefore the interpretation of segregation cartographically?

It is my assertion that while the areas of segregation throughout the city have shifted or moved, levels of segregation have not significantly decreased despite efforts to the contrary. I also believe that the more advanced methods of measurement utilizing Geographic Information Systems (GIS) technologies will produce a more nuanced and accurate view of segregation across the study area than the traditional measurement of using a single number index.

The study area for this research is the Greater London Area (Figure 1). Due to the nature of the calculations being performed, analysis will be measured at two scales. The Index of Dissimilarity will be calculated at the district level using the thirty-three local authority districts in the London area. Local statistics will be performed at the Output Area level, of which there are approximately 25,000 in London. The method for analysis will be discussed in further detail following background sections on theories of social exclusion and the role of British colonialism in establishing a potentially vulnerable ethnic minority population in the United Kingdom. 


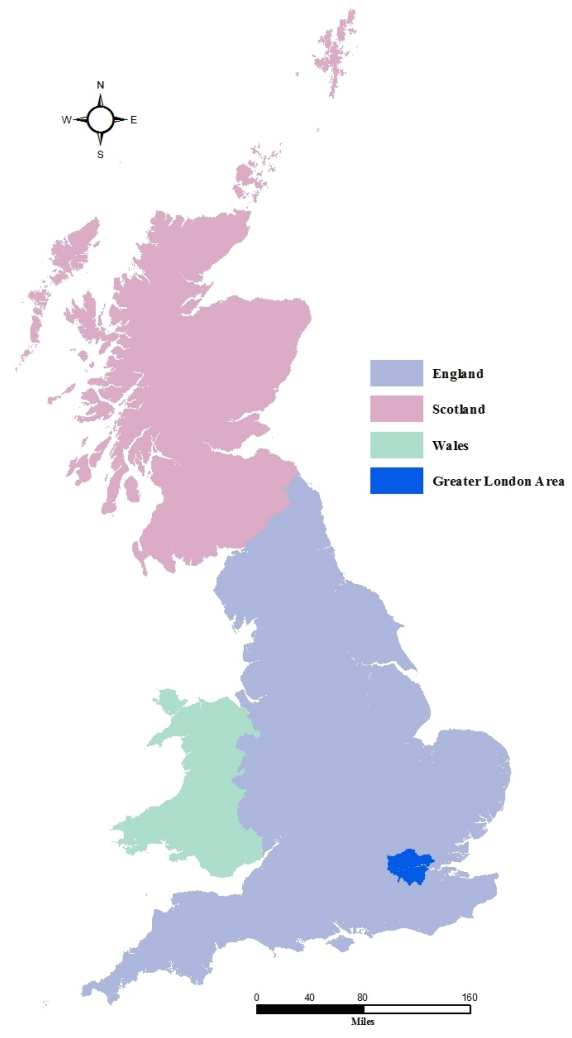

Figure 1: The United Kingdom - with study area highlighted Source: Office of National Statistics, Contains National Statistics data (C) Crown copyright and database right 2013, Contains Ordnance Survey data (C) Crown copyright and database right 2013

\section{Theoretical Framework - Social exclusion}

In most academic discourse, segregation is used to describe a community in which one group of residents is highly concentrated to the detriment of said residents. Segregation is the result of many underlying socioeconomic dynamics and goes beyond spatial concentration. In many cases, high levels of segregation are indicative of processes that both create and perpetuate not only spatial separation, but also social exclusion.

Geographers have a long history of examining landscapes in order to see how human activity and policy have created them. In the latter decades of the twentieth century, geographers started investigating landscapes for indicators of social exclusion. 
As with many social theories, there are several definitions for social exclusion. One broad definition is as follows: "Social exclusion operates to prevent people from participating in the mainstream activities of society and accessing the standards of living enjoyed by the rest of society" (Taket et al. 2009, 10). According to Trudeau and McMorran, "Concern about social exclusion was excited within geography by multiple tears in the social fabric of societies throughout the world, including the end of colonization, the rise of civil rights movements, the arrival of third world migrants in first world locations, widening gaps between rich and poor, and the increasing feminization of labor" $(2011,437)$.

The United Kingdom is an example of a society that experienced many of the phenomena mentioned, particularly the end of colonization and the arrival of migrants from less developed countries. The ways in which different groups are excluded from a landscape as well as how marginalized peoples experience exclusion in society have gained particular interest from many geographers since the 1990s (Trudeau and McMorran 2011). These manifestations of exclusion on the landscape are not uniform across space and can be seen in different ways in different countries. In the United Kingdom, much of this exclusion can be seen in the patterns of concentration within the ethnic minority community.

Social exclusion in application can be a somewhat ambiguous concept, but at its core it involves the processes through which certain portions of a population are excluded from various aspects of local society. It is a process that works in two ways: pushing people out of a community and actively working to keep others from coming in (Fangen 2010). There are practices that are known to produce social exclusion, but are not reproduced identically across space. The historically homogeneous nature of a society 
like Britain's lends itself to "a variety of exclusionary practices to maintain conformity, purify space, and push non-conforming elements to the margins" (Trudeau and McMorran 2011, 441). The groups that are most likely to experience social exclusion may be different in different societies, but there are groups that are more likely than others to be excluded. Groups that are at risk for exclusion are "those with limited opportunities for financial advancement, newcomers to a community and persons who transgress the ideologies or dominant moral code of a community" (Taket et al. 2009, 19). In the case of Britain, ethnic minority groups have all of the above characteristics to varying degrees.

In the UK, one of the places where these practices are most evident is in the housing sector. For their study on housing allocation practices and exclusion in the UK, Pawson and Kintrea (2002) identified the two key ways social housing allocation is used to perpetuate social exclusion: the first being the methods by which households are denied access to housing outright and the second involves the ways that the housing system controls the distribution of housing resources to those who are granted access to them. The housing system provides a method by which different expressions of social exclusion are disseminated throughout the community. National housing policies put into practice locally create varying levels of exclusion for different ethnic minorities throughout Britain. Pawson and Kintrea point to the ways that housing contributes to other forms of exclusion: “...housing processes have the potential to be a force for social exclusion by creating and maintaining social and spatial divisions and thereby providing barriers to jobs, education and other services" $(2002,646)$. 
One of the more visible results of social exclusion in Britain is the segregation of ethnic minorities in some of the most deprived neighborhoods in the country. The system of allocating social housing drives the high levels of ethnic minority concentration in undesirable locations. While akin to housing projects in the United States in many ways, social housing is much more prevalent in the UK and includes approximately one in four households in Britain (Peach 1999). In a report on sustainable communities, the Office of the Deputy Prime Minister defines social housing as "Housing provided by Registered Social Landlords or the local authority at a rent lower than market rent" (Sustainable Communities, 80). The ethnic minority population is overrepresented in social housing across the country (Manley and van Ham 2011). This leads to an intensification of social exclusion because the most disadvantaged people are spatially segregated in the worst housing (Pawson and Kintrea 2002). Thus the effects of social exclusion are manifested on the landscape. More details as to how the social housing sphere operates and at times drives ethnic segregation will be discussed in the next chapter.

Many people studying issues of segregation use the experience of the United States as something of a barometer for evaluating the severity of segregation in other countries. After decades of studying segregation throughout the world, the US still stands as an extreme example of ethnic residential segregation. When looking at differences between segregation in the United States and the United Kingdom, Deborah Phillips writes, "The intensity and extent of ethnic segregation may be lower than in the USA, but it may be argued that there are similar processes at work that have implications for the marginalisation and exclusion of settled minority groups and newly arriving migrants" $(2010,221)$. The establishment of segregation as a visible sign of social exclusion 
enables us to ask what specifically leads to changing levels of ethnic segregation. It may be that segregation is caused by structural processes like the welfare system or policies aimed at integrating immigrants into society, and it may also be more political factors such as the immigration policies themselves that are contributing to high levels of ethnic minority exclusion in the UK (Pawson and Kintrea 2002). Once these potential contributors to exclusion and in turn, segregation, are recognized, a thorough examination of changing levels of segregation can provide guidance as to what may have changed in those realms that may have contributed to varying levels of ethnic concentration.

\section{Vulnerability of Immigrant Populations}

There are many different ways to approach issues such as segregation and social exclusion. These issues can be examined in the context of race, ethnicity, religion or socio-economic status, all with different connotations and results. But while they are all different aspects of society, they share a common thread: vulnerability. Attempts to measure and study segregation are predominantly done to address the needs of a vulnerable population. One of the most vulnerable groups in any society is the immigrant or ethnic minority population. Due to their oftentimes low social standing, they are vulnerable to disadvantages not experienced by the majority population. As Stewart writes, “...there are various types and causes of vulnerability: vulnerability as entitlement problems, vulnerability as powerlessness and vulnerability through appropriation and exploitation" $(2005,500)$. The UK's government, in one of a series of reports seeking to address issues of social exclusion, labels the ethnic minority population as a group at particular risk due to its vulnerability (ODPM 2004). 
Once the immigrant population has been acknowledged as being vulnerable to discrimination and social exclusion, it then becomes important to accurately locate those areas with high concentrations of vulnerable residents. In the case of London and many other large metropolitan centers, a high number of the most vulnerable portions of the population are relegated to the lowest quality housing throughout the city. Knox points out that various vulnerable populations have continued to concentrate in inner-cities across the UK and in many cases these areas have a large number of residents from a particularly vulnerable group, that of New Commonwealth immigrants (1989).

A brief history of British colonialism provides context for understanding why immigrants arrived in the UK, the UK's relationship with its ethnic minority population and what steps have been taken to control both immigration and segregation since the major migration waves began following World War II. 


\section{Chapter 2: Background and Context}

\section{Colonial Legacy}

For much of the last four centuries, the United Kingdom has predominantly been a country of emigration. British citizens took sail and colonized countries across the globe in the name of their King and/or Queen and in that way established the UK as a country of persistent emigration, which it still is today (though not at the same levels) (Layton-Henry 1994). Even with waves of new migrants arriving after World War II, the UK did not experience a year with net immigration, with more people coming into the country than leaving it, until 1985 (Figure 2). This long period as a colonial superpower instilled the British population with a sense that UK, and especially English, citizens were superior and more powerful than those of the colonies.

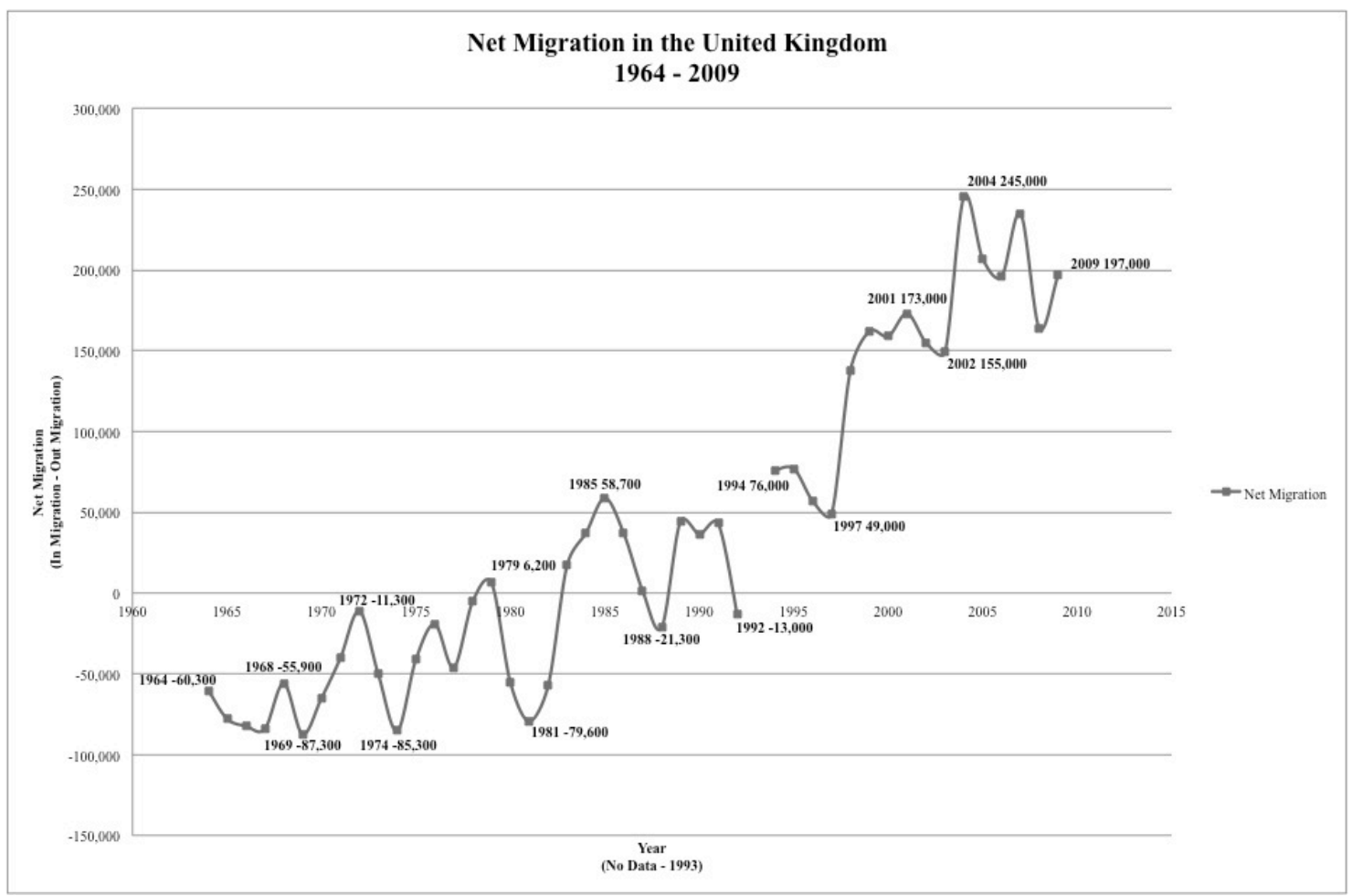

Figure 2: Net Migration in the United Kingdom, 1962-2009

Source: UN Department of Economic and Social Affairs - Population Division (C) Copyright United Nations 2011 (http://esa.un.org/unmigration/MigrationFlows.aspx) 
Britain's colonial legacy is central to understanding how the UK has handled the waves of immigrants it has received since World War II and how those individuals are treated once they settle in Britain. The vast majority of all immigrants/ethnic minorities living in the UK hail from New Commonwealth (NCW) countries, which are "the group of former colonial states and dependencies, almost all non-European, which elected to remain within the Commonwealth when they were granted independence from 1947 onwards" (Coleman 1995, 155) (Figure 3).

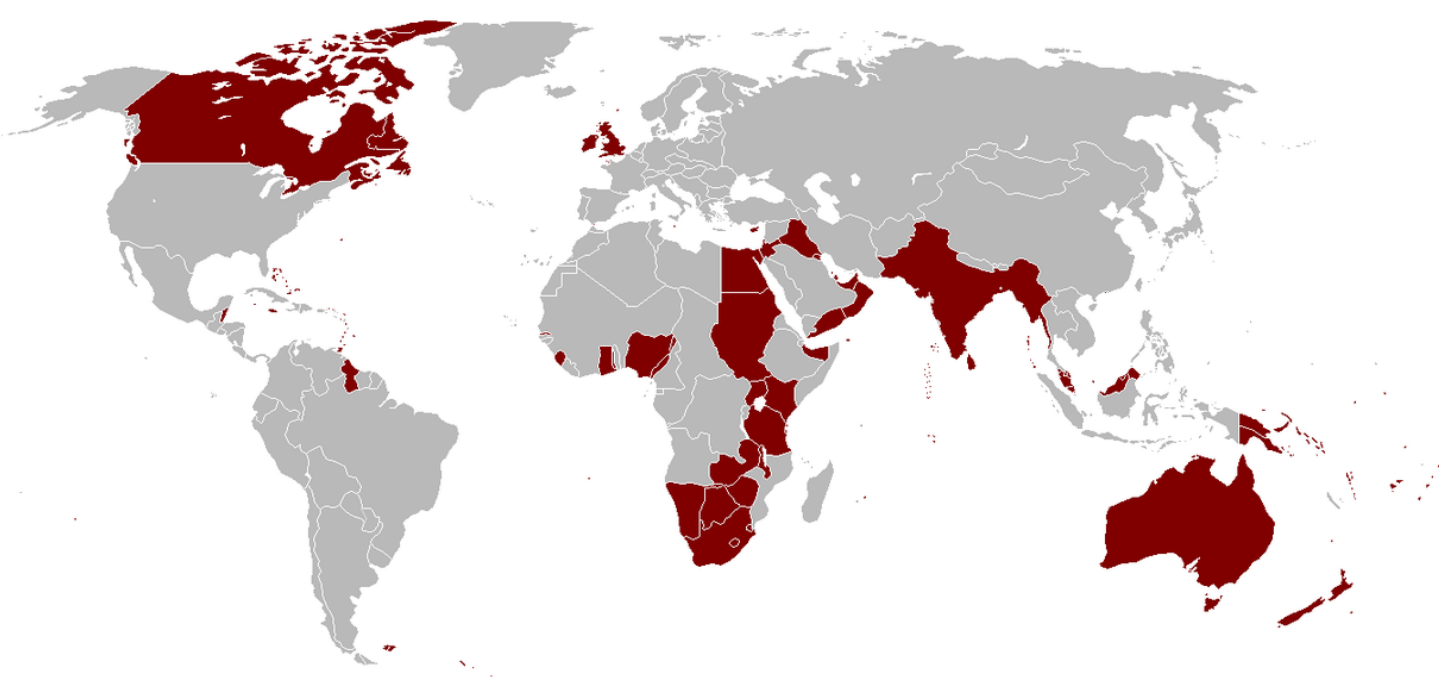

Figure 3: Extent of the British Empire, 1921

Source: http://commons.wikimedia.org/wiki/File:British_Empire_1921.png

As the ethnic minority population grew and colonial holdings were lost, the national identity of Britain seemed, in the view of the native population, to be in danger. The huge empire that Britain once counted as hers was shrinking and its significance on the world stage was in decline (Phillips and Karn 2001). Looking for somewhere to place blame for these occurrences, many Britons pointed to the recently arrived immigrants, many of whom were coming from lands that Britain had once called her own. The idea of 
a British identity and common British values was being threatened and immigration was blamed (Wolton 2006).

But the loss of its colonies did not diminish the country's feelings of authority that coincided with being a colonial power. As Layton-Henry writes, "Three centuries of imperial superiority and authority over African, Asian and Caribbean colonies had imbued not only the British public but especially the elite with feelings of European superiority and nonwhite inferiority" $(1994,275)$. As continued high levels of NCW immigration threatened these sentiments, they became manifest in expressions of racism toward the newly arrived ethnic minority population. Phillips and Karn write, "the colonial association of black subordination and white domination has given greater strength to racist sentiments in the case of the New Commonwealth and Pakistan population" $(1991,80)$.

As continued levels of high NCW immigration threatened these sentiments, they became manifest in expressions of racism toward the newly arrived ethnic minority population. Ethnic minorities were labeled as outsiders who were uprooting the national sense of cohesion previously shared among the population (Phillips 2006). Before moving forward, it is important to address terminology for a moment. In the UK, "the term immigrant has been generally replaced by the term ethnic minority, now universally employed by government and in most cases of the media to refer to immigrants and to their United Kingdom-born children" (Coleman 1995, 157).

\section{Major Immigrant Streams to the United Kingdom}

The ethnic minority population grew exponentially in the second half of the twentieth century. Totaling only 50,000 people in 1951, the ethnic minority population in 
the UK increased to 3 million people by 1991 (Peach 1999). Much of the immigration came from NCW locales and began in the post-World War II era with three primary migration waves starting with groups from the Caribbean and Africa, followed by immigrants from India and Pakistan, and concluding with the arrival of groups from Bangladesh. The Caribbean migrant wave began almost immediately following the war and was at its peak from 1955 to 1964 (Peach 1999). Their arrival, along with migrations from former colonies in Africa, established a sizeable black population for the first time in the British Isles (James 2004). Afro-Caribbean migrants settled in large urban areas throughout England and Wales and as chain migration began, with families reuniting in Britain, different areas emerged as centers for different groups within the larger community. Among these migrants, there were discernable patterns based on islands of origin, with groups from Leeward and Windward islands settling in one area of the city, those from Jamaica settling in another (Peach 1999).

The second major wave of migrants came from India and Pakistan, with the peak lasting from 1964 to 1974 (Peach 1999). While most of the Indian migrants came from India directly, almost a third of the Indian population in the UK is comprised of East African Indians who were forced to leave Africa in the late 1960s after policies of Africanisation were enacted (Peach 1999). The final major wave came from Bangladesh and was later than the previous two, peaking from 1980 to 1985 (Peach 1999). Despite the cultural differences among the three South Asian ethnic groups, all three displayed similar patterns of settlement throughout the country. Unlike the Afro-Caribbean population, which stayed in urban cores, the Indian and Pakistani migrants settled in textile centers in northern England (Phillips and Karn, 1991). The Bangladeshi 
population became ultra-centralized in London, specifically in the borough of Tower Hamlets. As of the 2011 Census, just over half of the Bangladeshi population of England lives in London, with 37 percent of the population living in Tower Hamlets alone. Much like those of Afro-Caribbean origin, the growing communities of South Asian immigrants soon became distinguishable based on country of origin, with areas comprised of Indian residents differing from those of Bangladeshi or Pakistani backgrounds (Phillips and Karn 1991).

As previously mentioned, the first major arrival of NCW migrants came shortly after the end of World War II. Throughout the conflict, many colonial citizens were brought to the UK as laborers to keep the war machine moving. When the war ended, those laborers were sent back to their home countries, but upon arriving home and finding struggling economies, many laborers decided to go back to the UK (Money 1997). During these initial phases of immigration, there were several government agencies and private companies that encouraged the trend, heavily recruiting individuals from NCW countries to migrate to Britain. British Transport and the National Health Service were two entities that prompted a steady stream of workers migrating from former colonies to settle in the UK (Phillips and Karn 1991).

Part of the impetus for this new era of immigration was the relative ease with which New Commonwealth citizens could move to the United Kingdom. After the establishment of the Commonwealth, the 1948 British Nationality Act for the first time distinguished between people who were citizens of the United Kingdom and the Colonies (CUKC) and those that were citizens of the Commonwealth (Money 1997). This distinction did not, however, affect the rights of Commonwealth citizens in the United 
Kingdom. They were able to move freely throughout all of the British territories and only needed to reside in the UK for twelve months to attain British citizenship (Money 1997). These policies would soon change drastically, but from 1948 to 1962, citizens of the $\mathrm{NCW}$ were able to move to Britain without significant bureaucratic difficulty. Immigration continued to increase in the years after the war, particularly from NCW countries. From 1951 to 1966, NCW migrants made up $60 \%$ of the increase in Britain's foreign-born population (Money 1997). As more migrants arrived from the New Commonwealth, the mostly white population of the UK was introduced to a wide array of new cultural and religious practices along with languages and racial groups that had rarely if at all been seen in the country previously (Coleman 1995). These additions to British society were steadily increasing in number and their presence was beginning to be viewed as a problem. The United Kingdom was experiencing growth in ways it had never seen and according to Money, "The change in structural conditions - high and rising immigration in concentrated areas, combined with local unemployment, immigrant access to social services, and crowding of public facilities - was reflected in growing opposition to immigration in the affected communities" $(1997,703)$. Many members of the majority white population were not pleased with the changes they were seeing, and policies to reflect this displeasure came in 1962, just fourteen years after the initial waves of immigration began.

\section{Evolution of British Immigration Policy}

A nation's immigration policy is largely a reflection of how that nation perceives its immigrant population. In the United Kingdom, rising levels of immigration brought increasingly restrictive immigration legislation, which was indicative of the UK's 
colonial past and the increasing unpopularity of migrant groups amongst the native population. In his examination of immigration policy moving into the twenty-first century, Douglas Massey points to three factors that seem to determine immigration policy in receiving countries. The first is the country's economic standing. While it has not been established which portions of the economy are most pertinent, the overall condition of the economy will guide immigration policy (Massey 1999). Times of good economic health will have immigration policy that is looser than times of poor economic health, which typically result in more restrictive immigration regimes. The second is how many immigrants a country is receiving, when migrant flows are high, more restrictive policy will likely result (Massey 1999). The third determinant of immigration policy is linked to the ideological position of society at that point in time - countries experiencing times of social cohesion will have more restrictive immigration laws while countries that are expanding and encouraging widespread trade will have more relaxed laws (Massey 1999).

In the post-war period, with countries like the United Kingdom experiencing unprecedented levels of immigration, politicians were forced to accept that they would now have to "permanently incorporate millions of migrants into their social, political and cultural institutions" (Schierup, Hansen and Castles 2006, 28). While policymakers were beginning to recognize the need for revamped immigration policy, the public at large was expressing its displeasure with having migrant groups in their neighborhoods. Most of the opinions expressed through public polls and the media centered on the perceived disadvantages of immigration and called for stricter immigration laws (Layton-Henry 1994). Prior to changing the law, postwar governments began using informal methods to 
inhibit immigration. Those methods included attempting to persuade the Indian government to stop issuing passports to those wishing to migrate (Layton-Henry 1994). Such methods were unsuccessful and policymakers turned to the rule of law to restrict and reduce immigration.

The 1962 Commonwealth Immigration Act for the first time created a distinction between those who held a British passport issued in the UK and those who held one issued elsewhere in the Empire and started the process of bringing former imperial subjects under immigration controls (Wolton 2006). The timing of this legislation is worth noting, for while many immigration laws are passed in times of underemployment, the 1962 Act was introduced in a time of full employment, when economists were predicting a shortage of labor (Money 1997). When examined through the lens of Massey's major determinants of immigration policy, the United Kingdom's introduction of restrictive legislation came as a result of immigration being largely disliked by the native white population. Immigration and the issues that come with it were so heavily politicized in the years following the war that it created an imposing restriction on lawmakers (Layton-Henry 1994).

The next major change in immigration policy came in 1971, when Conservatives gained control of the government and "revamped the immigration control system and brought $\mathrm{NCW}$ immigration in line with the more restrictive alien immigration control system" (Money 1997, 707). The 1971 Immigration Act removed the previous distinction between immigrants coming from $\mathrm{NCW}$ countries and immigrants from other non-NCW countries, making it much more difficult for $\mathrm{NCW}$ immigrants to settle permanently in 
Britain (Couper and Santamaria 1984). But even after the implementation of tighter immigration controls, new migrants continued flowing into the UK.

As immigration continued, new ethnic minority communities established themselves throughout Britain. Chain migration served to reinforce the patterns of settlement shown by the initial wave of immigrants (Phillips and Karn 1991). These patterns consisted of "continuing residential concentration, segregation, and deprivation, with a growing overrepresentation within the poorest areas" for the NCW population (Phillips and Karn 1991, 68). From the outset, ethnic minorities were living in highly segregated areas and as the ethnic minority population grew, concerns about the impact of such segregation began to arise. As with many issues in society, different groups throughout Britain gave different explanations and complaints about ethnic residential segregation. Deborah Phillips writes, "ethnic segregation has been sensationalised by the media, and politicised by both the Right and the Left; for the Right it has provided substance for calls for immigration control, whereas for the Left it has often been used as a symbol of racism and ethnic inequality" $(2006,26)$. With growing numbers of ethnic minorities establishing permanent homes in the UK, much of the discussion regarding immigrant communities turned from immigration itself to how the immigrants were settling within the country.

\section{Controlling segregation through housing policy}

The United Kingdom's history as a country of emigration meant it was not prepared for the wave of migrants that arrived in the last half of the twentieth century. The reaction to these new arrivals by the public was mostly negative and did not improve as the minority population continued to grow with each decade. By the 1990s the 
realization was made that "the migrations of the 1945-73 boom period, together with new migrations since the 1980s, were leading to large-scale settlement and ethnic community formation" (Schierup, Hansen \& Castles 2006, 23). This resulted in continued public concern regarding the immigrant population and its presence in Britain.

Much of the dislike for the immigrant community has been linked to racism due to the fact that most of the immigrant population is nonwhite. According to Money, "NCW immigrants were resented because of their colour but also because of a growing immigrant presence. This was because 'coloured' rather than 'white' immigration was expanding and because it was more concentrated than the 'white' immigration" (1997, 715). The emergence of racial tension and discriminatory housing practices led to several attempts to discourage discrimination throughout the 1960s and 1970s (Phillips and Karn 1991). But antidiscrimination legislation and government policies promoting a multicultural society did not discourage the widely held notion that ethnic minority groups were self-segregating and did not want to be fully engaged in British society (Phillips 2006).

After spending the latter decades of the twentieth century encouraging a spirit of multiculturalism throughout the United Kingdom, tensions between ethnic minorities and the native British population came to a head in 2001, when riots broke out in the city of Bradford in northern England. The primary participants in the riots were young British Muslims, the majority of whom were of South Asian descent (Phillips 2006). The events made headlines and the ethnically concentrated areas in Bradford were subsequently characterized with other large areas of ethnic minority concentration (e.g. London), and were then "largely portrayed in negative terms and were seen as synonymous with high 
levels of social deprivation, poverty and drugs, and crime" (Phillips 2006, 28). After the riots, the government commissioned panels to look into the cause of the riots and how future riots might be prevented. The reports that followed concluded that the segregation of the ethnic minority community was the root cause of the riots and recommended new policies to promote an increase in the incorporation of ethnic minorities into greater British society. Deborah Phillips writes, “the government's strategy for building harmony in multiethnic Britain has been founded on the ideology of 'community cohesion,' which is explicitly linked to a desegregationist project" $(2006,37)$.

Thus the government's support of multiculturalism turned into a promotion of "community cohesion" aimed primarily at decreasing the levels of ethnic residential segregation throughout the United Kingdom. The new agenda promoting cultural cohesion rather than multiculturalism attempted to define where diversity begins and ends and gave politicians the opportunity to openly attack the notion of Britain as a multicultural society (Burnett 2007). In 2007, shortly before he would become Prime Minister, Gordon Brown said the following in a piece for the Daily Telegraph: "Continually failing to emphasise what bound us together as a country, multiculturalism became an excuse for justifying separateness and then separateness became a tolerance of - and all too often a defence of - greater exclusivity" (quoted in Johnston 2007, np).

Once community cohesion became the official position of the government, the question then became how to implement policies to enforce it. The idea of community cohesion is grounded in the idea that integration at a societal level will be increased by a greater amount of residential mixing among different ethnic groups, which would then lead to a greater sense of shared values and identity (Phillips 2006). In practice, this new 
approach resulted in "a range of policies that seek to address integration through the managed settlement of new arrivals and the improvement of settled groups' housing circumstances" (Phillips 2010, 214). Many of the ethnic minorities targeted by these policies were encouraged to move away from their established communities despite limits on their social and spatial mobility (Phillips 2010).

Due to the large section of the ethnic minority population living in social housing across the country, changes to allocation policy were deemed the most effective method for increasing community cohesion. As van Ham and Manley point out,

The social sector can play a crucial role in [community cohesion] as it is one of the few sectors of the housing market where the government can directly influence the outcomes. Creating mixed neighbourhoods requires government intervention through housing policy by either informing neighbourhood tenure mix - mixing owners and renters - or by influencing the ethnic and socio-economic mix of tenants in social housing through the allocation system of social housing $(2009,408)$.

The practice of social housing allocation has been contributing to ethnic segregation patterns in the UK since at least the 1950s (Manley and van Ham 2011). Thus when the government decided to address ethnic segregation via community cohesion, the policy avenue chosen was housing policy.

Choice-based letting (CBL) was introduced as a pilot program in 2001 and gave individuals eligible for social housing a choice in where they would like to live rather than relying on social landlords to assign housing directly (Pawson et al. 2006). In this way, the government hoped to address previous concerns regarding social exclusion and vulnerability across the country with the hope that when given more choice ethnic minority families would choose to live in less segregated areas (ODPM 2004). This new 
approach to housing allocations was seen "as a tool to create less isolated, socially mixed, sustainable communities" (Pawson and Kintrea 2002, 663).

The 2006 Government-issued report entitled "Monitoring the Longer Term Impact of Choice Based Lettings," aimed to examine the results the first five years of the program. One of the impacts examined is how, if at all, CBL impacted ethnic minority segregation. In looking at a series of areas in large cities throughout England, the report states, "In most of the areas analysed, however, CBL appears to have resulted in a degree of deconcentration for both Afro-Caribbean and South Asian communities. These results suggest that CBL may help perpetuate the general trend of gradual minority ethnic residential dispersal" (DCLG 2006, 117). The veracity of this statement will be examined following the results for this study.

Ultimately, the aim of community cohesion is lessen to ethnic minority segregation due to the fear that ethnic clusters will result in some sort of revolt against British society. But this fear is not expressed in the institution of new policy. Instead the push by the government to create a cohesive community is labeled as being an attempt to alleviate poverty and social exclusion in the ethnic minority community (Phillips 2010). These decisions are being made from a place of apprehension about the motives of the ethnic minority community, not out of a desire to create a truly integrated and unified society.

\section{Analyzing Segregation in London}

A comprehensive review of all work done on ethnic residential segregation and its measurement would require several volumes, thus for the purposes of this work, I am reviewing only a select number of studies that directly correlate with the forthcoming 
analysis. John Stillwell conducted one such study in 2010. In "Ethnic population concentration and net migration in London," Stillwell used Location Quotients to look at the relative concentration of specific minority groups across London to assess the effects migration had on levels of segregation across the study area. The Location Quotient (LQ) he used took the ethnic population of a chosen ward divided by the total population of the ward and then divided that number by the total ethnic population of London divided by the population of London. For the purposes of this study, any LQ's less than one resulted in an underrepresented population and any LQ's over one resulted in an overrepresented population (Stillwell 2010). His results show that while the Afro-Caribbean migrant groups are more numerous in London, the South Asian population is more highly concentrated in different areas of the city (Stillwell 2010).

Any review of research in the field of ethnic residential segregation, particularly regarding methodologies, must include the work of Michael Poulsen, Ron Johnston and James Forrest. Their numerous collective pieces on the subject brought a renewed vigor to the study of ethnic residential segregation through their use of multiple methods as well as the development of a new segregation typology. In one of their most recent studies, Poulsen et al. studied ethnic residential segregation in London using local statistics (2011). Through that study, they were able to demonstrate some of the weaknesses of the sole use of traditional indices to measure segregation. In that report, the authors state, "[I]ndices tell us something about the geography of Bangladeshi residential patterns within London, therefore, but say nothing about either the intensity to which Bangladeshis are clustered in particular parts of London (i.e. in neighbouring output areas)" (Poulsen et al. 2011, 639). The results of that study point to a London that 
is dominated by areas of white concentration with smaller areas categorized as ethnic enclaves, inhabited by a variety of ethnic groups (Poulsen et al. 2011).

In 2007 Brimicombe adapted methods previously used by Poulsen, Johnston and Forrest to examine ethnic segregation as well as religion in London. His decision to use London as a study area is indicative of why many others have decided to study segregation in the city as well. As he points out (referring to results of the 2001 Census), "The geographical distribution of the $12.5 \%$ ethnic minority population is highly concentrated... only $9 \%$ of White British live in London, $44 \%$ of the ethnic minority population live there (15\% of the population in England and Wales live in London)" (Brimicombe 2007, 884). In order to create the most accurate picture of ethnic residential segregation as possible, Brimicombe opted to use methods other than indices to measure segregation for his study, instead deciding to use a variation of the Poulsen et al. Typology for his analysis (2007). The results of this study once again showed that many ethnic minorities were living in some amount of segregation, but not all groups were experiencing it in the same way. In his view, some of the ethnic minority groups were benefiting from their segregation, but others were trapped in areas of pronounced disadvantage (Brimicombe 2007).

Another pair of scholars who have published numerous studies regarding ethnic residential segregation is van Ham and Manley (2009) (2011). Their recent work has focused primarily on how changes in social housing allocation in Britain have impacted ethnic segregation. The decision to analyze segregation in this view was in large part influenced by the large proportion of ethnic minorities living in social housing in the United Kingdom. At the time of the 2001 Census, $31 \%$ of the ethnic minority population 
in London lived in social housing (van Ham and Manley 2009). When choice-based letting was introduced to the social housing sector, many people worried that allowing individuals to have some amount of choice in where they lived would lead to an increase in ethnic segregation (van Ham and Manley 2009). Through the use of several metrics to measure segregation, the study found that for the most part the addition of choice to social housing did not necessarily increase segregation but rather caused it to shift. The analysis reports, "The ethnic minority population tends to either stay in neighbourhoods with a high percentage of ethnic minorities or move to neighbourhoods with a high percentage of ethnic minorities" (van Ham and Manley 2009, 415). 
Chapter 3: Methodology

\section{Measuring Segregation}

Whenever one is endeavoring to examine and understand segregation, it is important to recognize the very prominent role that humans play in the segregation of space. It is not a purely spatial event; it is deeply rooted in the choices and actions of the people living in the area in question. As Kaplan and Woodhouse write, "segregation must be conceived as a multilayered phenomenon, a process that victimizes some groups while possibly liberating others. Whatever the causes or consequences of ethnic segregation, it has the potential of redefining the ethnic experience altogether" $(2004,583)$. In another paper looking at ethnic segregation, Kaplan and Woodhouse point out that the ways in which segregation is defined and controlled is largely dependent on the location in question. How segregation is viewed and examined is impacted greatly by each country's history and feelings toward ethnicity (Kaplan and Woodhouse 2005).

In their definitive study on the elements of segregation, Massey and Denton wrote:

Specifically, we hold that residential segregation is a global construct that subsumes five underlying dimensions of measurement, each corresponding to a different aspect of spatial variation: evenness, exposure, concentration, centralization, and clustering. Each of these distributional characteristics has different social and behavioral implications and each represents a different facet of what researchers have called 'segregation' $(1988,283)$

In order to develop a comprehensive understanding of the processes and effects of segregation, it is helpful to examine each of the five dimensions of segregation as defined by Massey and Denton. Under this paradigm, the term evenness involves looking at how 
two different social groups are distributed throughout a city; it is not an absolute measurement but a relative one involving at least two distinct groups (Massey and Denton 1988). The next element of segregation is exposure. This term involves the amount of contact one group is likely to have with members of another group; it is measured by looking at how much minority and majority groups physically meet each other through the sharing of residential space (Massey and Denton 1988). The third dimension is concentration, the examination of how much space a minority group occupies relative to the size of the entire area being studied, when one group occupies a small proportion of the total urban area, it is said to be concentrated (Massey and Denton 1988). Next is centralization, or how close to the urban core a particular group is situated (Massey and Denton 1988). The last dimension of segregation defined is clustering, or how many of the areal units inhabited by the minority group in question are contiguous (Massey and Denton 1988). With an understanding of the different ways segregation manifests spatially, we can now look at the ways in which researchers have defined it conceptually.

In one of Johnston et al.'s numerous studies on the subject of ethnic residential segregation and its measurement, they describe two understandings of segregation at a macro-level. The first is segregation as a pattern description or "the degree to which members of different groups live apart from each other" $(2009,92)$. The second is segregation as a process description, or "the processes by which such spatial separation is generated" $(2009,92)$. In the analysis for this research, segregation as a pattern description is the focus with the hope that eventually this type of work will lead to a more comprehensive understanding of the processes of segregation. 


\section{Indices of Segregation}

Much of the literature regarding ethnic residential segregation involves a great deal of debate among scholars as to the best way to do it. Over the past two decades particularly, much of this debate has revolved around whether indices are an adequate measure of segregation in urban areas. While indices can be helpful tools in beginning to understand segregation from a macro-level, they are best used in situations of extreme segregation. As Poulsen et al. point out, "Single number indices identify the average situation without indication of associated degree of variation" $(2011,637)$. Despite their shortcomings, studies that utilize indices can be instructive and helpful, providing for a comparative analysis of different methods of measurement.

In their work on the dimensions of segregation, Massey and Denton wrote, "We argue that segregation is a multidimensional phenomenon that should be measured by a battery of indices rather than one single index" $(1988,312)$. It is my contention that indices are useful in providing an overall picture of segregation, but other methods are necessary to gain insight into the more minute details of segregation in an area. While indices can be helpful in gaining a cursory understanding of the general levels of segregation in an area, they often hide as much as they reveal.

In most studies of segregation, the aim is to discover how evenly a population group is distributed throughout space. Most research of this nature uses the Index of Dissimilarity (IDxy), which is looks at the distribution of two groups and is the percentage of group $x$ that would need to be redistributed to be identical to the 
distribution of group $y$ (Johnston et al. 2010). ID is found using the following equation:

$$
D=\frac{1}{2} \sum\left|\frac{N_{1 i}}{N_{1}}-\frac{N_{2 i}}{N_{2}}\right|
$$

where $N_{1 i}$ equals the population of Group 1 in the $i$ th tract, $N_{2 i}$ equals the population of Group 2 in the $i$ th tract, $N_{1}$ equals the total population of Group 1 in the city, and $N_{2}$ equals the total population of Group 2 in the city. The value of $\mathrm{D}$ is equal to the proportion of the minority (or majority) population that would have to be redistributed so that each areal unit would have exactly the same composition as the city as a whole (White 1983).

The difficulties of using indices such as ID to get an accurate picture of segregation will be addressed later, but it is still the most widely used measure of segregation. There are many indices and other measures for segregation that will not be addressed in the scope of this research, but regardless of the measure, it is important to recognize that one measure will never paint the entire picture of what processes are working to create segregation in an area. Segregation "does not stem from a single process, but from a complex interplay of many different social and economic processes that generate various constellations of outcomes interpreted as 'segregation'" (Massey and Denton 1988, 309).

Historically studies of segregation have relied heavily upon the aforementioned Index of Dissimilarity (ID). This index has been the primary tool for measuring segregation for decades despite its shortcomings. Indices like ID do not provide any information about the levels of segregation of one area in relation to others. According to Poulsen et al., "Only at the extremes (that is, either fully segregated or fully integrated) 
do these indices give a complete picture of the degree of residential concentration" (2001, 2081). Accordingly, indices do not provide any information regarding how much of a particular ethnic group lives in highly segregated areas, it only shows which areas are highly segregated (Johnston et al. 2009). When change is introduced into the equation, the sole use of indices as measurement can create further ambiguity. This is because in most cases, change is not uniform across space. Some areas may experience an increase in segregation, others may experience a decrease, and these changes will not be visible when using a single-number index like ID (Johnson et al. 2010). It is for these reasons that I have chosen to supplement the use of ID with other methods of measurement, in part to show how changing the method changes the result and also to provide as comprehensive a view of segregation as possible.

\section{The Poulsen et al. typology}

In their extensive work on measuring segregation, Johnston, Poulsen and Forrest developed a new system for classifying areas based on their levels of segregation. The typology classifies areas into one of six types based on three different components and provides a more distinctive approach to measuring evenness. The components used are derived from what Philpott (1978) and Peach (1996) proposed were the processes that result in ethnic residential segregation. Those components are:

1. the degree to which members of the dominant group, $X$, live apart from (share residential space with) members of groups $y$ and $z$.

2. the degree to which members of the minority groups $y$ and $z$ live apart from (share residential space with) members of the dominant group $X$

3. the degree to which members of the minority groups $y$ and $z$ live apart from (share residential space with) each other (Johnston et al. 2007). 
Taking into consideration the preceding three variables, Johnston et al. created six different categories for areas of a city, which are:

I. areas where members of the majority group, $X$, predominate, forming more than 80 percent of the total population

II. areas where members of the majority group, $X$, dominate, forming 50-80 percent of the total population, but members of ethnic groups $y$ and $z$ form a substantial minority.

III. areas where members of ethnic groups $y$ and $z$ dominate, forming 50-70 percent of the total population, but members of the majority group, $X$, form a substantial minority

IV. areas where members of ethnic groups $y$ and $z$ predominate, but neither group dominates the other

$\mathrm{V}$. areas where members of ethnic groups $y$ and $z$ predominate, forming 70 percent or more of the total, and one group is at least twice as large as the other

VI. areas where members of ethnic groups $y$ and $z$ predominate, forming 70 percent or more of the total, one group is at least twice as large as the other and at least 30 percent of that group's total population in the city lives in those areas. (Johnston et al. 2007).

In this model, areas categorized as Type I are those with the majority group being extremely segregated; areas labeled as Types IV-VI are also highly segregated, but in those cases it is the minority groups living in segregation. Type II and III areas show areas of relative ethnic integration (Johnston et al. 2009). Within the ethnically segregated areas, Type $\mathrm{V}$ are defined as ethnic enclaves, with one ethnic group dominant and Type VI are areas showing characteristics of ghettoization (Johnston et al. 2009). The purpose of this typology was to provide a more complete examination of segregation than is available through the use of single-number indices (Johnston et al. 2009). It still does not provide any details as to the extent of clustering in those areas where one ethnic group predominates, but the use of local statistics has made those evaluations possible (Johnston et al. 2009) 


\section{Local Statistics/GIS}

With the development of Geographic Information Systems (GIS) has come several new and innovative ways to look at and measure ethnic residential segregation. Many of the hurdles to performing comprehensive segregation analysis can be overcome using a variety of GIS tools. While there must always be room for some error and the ability to tailor results to meet a specific end, GIS offers researchers tools to look at segregation at a much finer scale and with more detail than was previously possible. For the purposes of this study, I will be using two tools to find areas of statistically significant clustering in London. There are two statistics in particular that are most helpful: Anselin Local Moran's I and Getis-Ord $G^{*}$ both of which are local statistics.

In his paper "Local Indicators of Spatial Association - LISA," Luc Anselin introduced the idea of using the previously established Moran's I statistic to look at local patterns. His reasoning for this is as follows, "by directly linking the local indicators to a global measure of spatial association, the decomposition of the latter into its observationspecific components becomes straightforward, thus enabling the assessment of influential observations and outliers" (Anselin 1995, 112). The basis for this development was the need to adapt global statistics for use in local situations, thus enabling researchers to find local patterns of clustering as well as outliers. Local statistics "serve a useful purpose in exploratory analysis of spatial data, potentially indicating local spatial clusters and forming the basis for a sensitivity analysis (outliers)" (Anselin 1995, 112). The equation for calculating Anselin Local Moran's I is as follows:

$$
I_{i}=\frac{x_{i}-\bar{x}}{S^{2}} \sum_{j=1, j \neq i}^{n} w_{i j}\left(x_{j}-\bar{x}\right)
$$


where is $x_{i}$ an attribute for feature $I, \bar{x}$ is the mean of the corresponding attribute, $w_{i j}$ is the spatial weight between feature $i$ and $j$, and:

$$
S_{i}^{2}=\frac{\sum_{j=1, j \neq i}^{n}\left(x_{j}-\bar{x}\right)^{2}}{n-1}-\bar{x}^{2}
$$

with $n$ equating to the number of features (ESRIc 2014). In terms of the five dimensions of segregation, Anselin Local Moran's I is primarily concerned clustering.

The second local statistic used in this research is Getis-Ord $G^{*}$. According to Getis and Ord, "The $G(d)$ statistic measures overall concentration or lack of concentration of all pairs of $\left(x_{i}, x_{j}\right)$ such that $i$ and $j$ are within $d$ of each other" (1992, 190). Used together, Anselin Moran's I and Getis-Ord $G^{*}$ measure and extrapolate two similar but different types of spatial autocorrelation. In their piece describing a new set of spatial statistics, Getis and Ord write, "When used in conjunction with a statistic such as Moran's $I$, [ $G$ statistics] deepen the knowledge of the processes that give rise to spatial association, in that they enable us to detect local 'pockets' of dependence that may not show up when using global statistics" $(1992,190)$. The equation for finding $G^{*}$ is as follows:

$$
G_{i}^{*}=\frac{\sum_{j=1}^{n} w_{i, j} x_{j}-\bar{X} \sum_{j=1}^{n} w_{i, j}}{S \sqrt{\frac{\left[n \sum_{j=1}^{n} w_{i, j}^{2}-\left(\sum_{j=1}^{n} w_{i, j}\right)^{2}\right]}{n-1}}}
$$

where $x_{j}$ is the attribute value for feature $j, w_{i, j}$ is the spatial weight between feature $i$ and $j, n$ is equal to the total number of features and:

$$
\bar{X}=\frac{\sum_{j=1}^{n} x_{j}}{n}
$$




$$
S=\sqrt{\frac{\sum_{j=1}^{n} x_{j}^{2}}{n}-(\bar{X})^{2}}
$$

The $G_{i}^{*}$ statistic is a z-score, so no further calculations are required (ESRIb 2014). This statistic is a measure of concentration across space and shows areas of high or low concentration.

As Anselin writes, "For $G i$ * statistic, a positive value indicates a spatial clustering of high values, and a negative value a spatial clustering of low values, while for the $I i$, a positive value indicates spatial clustering of similar values (either high or low), and negative values a clustering of dissimilar values (for example, a location with high values surrounded by neighbors with low values), as in the interpretation of the global Moran's I' (Anselin 1995, 102-103). In this way the use of both statistics can provide a more comprehensive measure of ethnic residential segregation in London.

\section{Using Census Data}

Different countries use a variety of methods for collecting and disseminating census data. In the case of the United Kingdom, the data comes from a decennial census. The different component countries of the UK do not participate in the same census. England and Wales have a combined census while Northern Ireland and Scotland have individual censuses. Despite different methods and some differences in format, the census for all four countries is taken on the same day which in 2001 was the $29^{\text {th }}$ of April and in 2001 was the $27^{\text {th }}$ of March.

The census data for this research was retrieved from the Office of National Statistics' Neighbourhood Statistics and Nomis websites, which provide geographic and tabular census data. In order to ensure that the entire London area was covered, census 
data was extracted using the London districts as a guide. For the 2001 census, ethnicity data was found in the Standard Tables, specifically "S101 Sex and age by ethnic group" (ONS 2013). The entirety of the table contains information not pertinent to this research, so only the following categories were extracted: All People, White - British, Asian or Asian British - Indian, Asian or Asian British - Pakistani, Asian or Asian British Bangladeshi, Black or Black British - Black Caribbean, and Black or Black British Black African. For the 2011 census, the ethnicity data was found in the Key Statistics tables for England and Wales, specifically "KS201EW - Ethnic Group" (ONS 2013). As with the 2001 data, the entire dataset was not required, so I extracted data only for the ethnic groups being used for the study. Those groups were: All Usual Residents, White: English/Welsh/Scottish/Northern Irish/British, Asian/Asian British: Indian, Asian/Asian British: Pakistani, Asian/Asian British: Bangladeshi, Black/African/Caribbean/Black British: African and Black/African/Caribbean/Black British: Caribbean.

There are two main challenges with studying British census data over time: changing definitions and changing areal collection units. The first problem, definitions, results in part from the fact that a question regarding ethnicity was not introduced in the England/Wales Census until 1991. While questions of ethnicity were tested as early as 1961, the question was not introduced in the official census until 1991 (Brimicombe 2007). Thus the only way to study the ethnic minority population via census data prior to 1991 is to look at answers to questions regarding country of birth. The other definitional problem stems from changes made to the options given to respondents in successive censuses. The labeling of ethnic groups is not without its challenges, and the census has undergone changes to the available choices in both the 2001 and 2011 censuses. These 
changes make it much more difficult to compare any one ethnic group across time, as some respondents may have changed their self-identification as the list of possibilities changed. The census questionnaire allows respondents to select more than one ethnicity, which is then reported as a Mixed category. For the purposes of this study, I chose to only include those records for single ethnic groups rather than both single and multiple ethnicity results. To view the ethnicity question portion of the census for both 2001 and 2011 see Appendix A.

The second issue in using British census data is one of spatial units. As with ethnic group classifications, the spatial units for data collection have changed in each successive census from 1991 to 2011. The most drastic change came between 1991 and 2001, when the previously smallest areal unit of wards was broken down into Output Areas. This change reduced the smallest census area by a third, which makes any direct comparisons between data from 1991 and 2001 difficult and potentially very misleading (Simpson 2007). Output Areas were established as the smallest spatial units in the census with an average population of 300 people per unit in the 2001 census (van Ham and Manley 2009). In 2001, the average population of Output Areas in England was 300 and in 2011 that number rose slightly to an average population of 374 residents.

\section{Executing Measurements}

The British government has put substantial effort into making sure that raw data is accessible for the general public, which made the task of retrieving large amounts of census data possible. Unfortunately, the boundary datasets did not correspond directly with the population datasets, which led to many attempts to draw out the population data for the London area from countrywide datasets. The method I settled on for making sure 
the datasets were comprehensive was to query the data by district. There are thirty-three districts constituting the Greater London Area (Figure 4). Using the list of Greater London Districts, I was able to collect all of the ethnic group data by Output Area for both 2001 and 2011 as previously discussed.
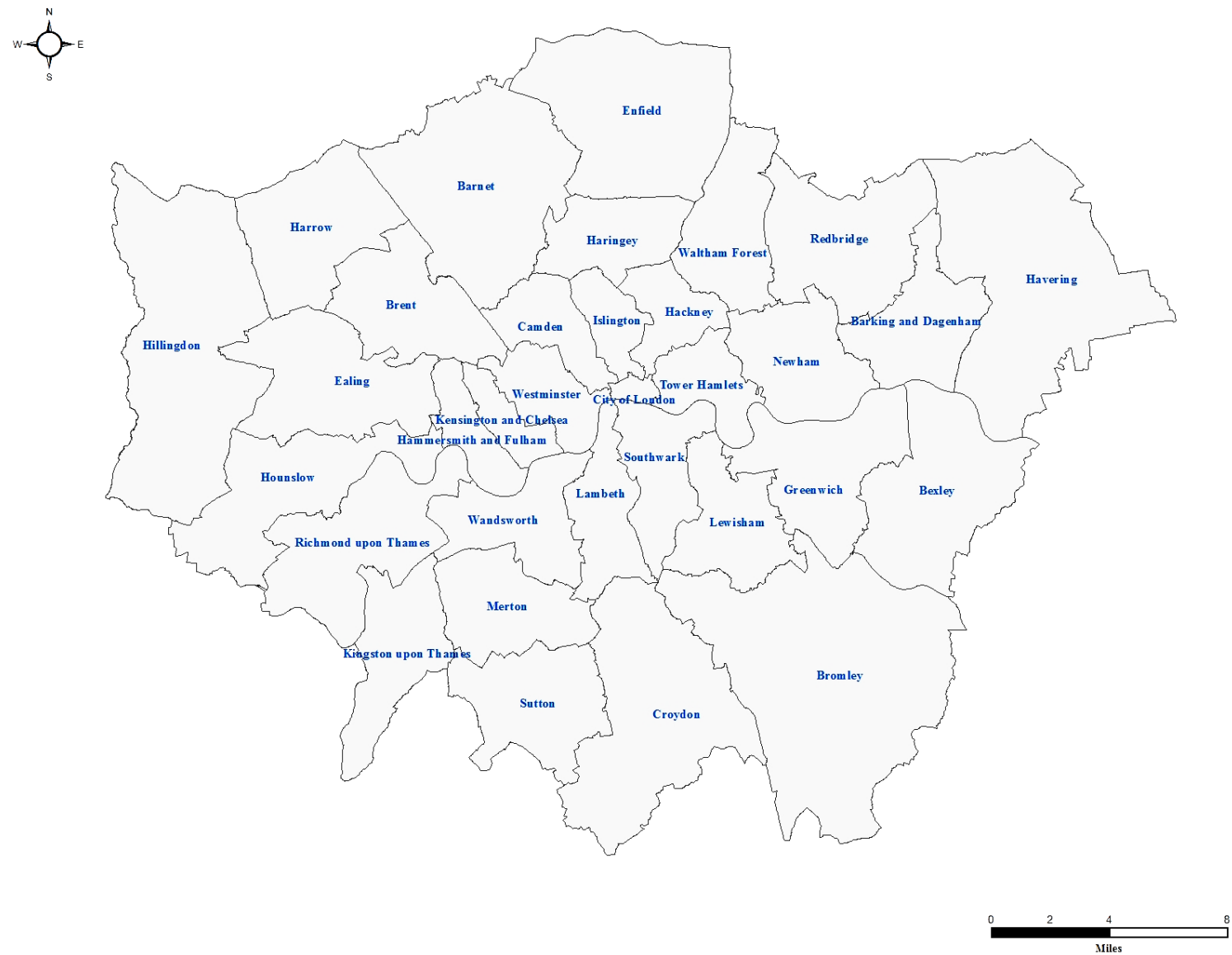

Figure 4: Greater London Districts

Source: Office of National Statistics, Contains National Statistics data $(C)$ Crown copyright and database right 2013, Contains Ordnance Survey data $\odot$ Crown copyright and database right 2013

After the Output Area geometry and census datasets were retrieved, there were several steps to be taken before the census data could be brought into a GIS environment. My first action was to export all of the OA codes for both 2001 and 2011 from ArcMap into Excel. The OA codes were the only link between the geographic and numeric datasets. Using a vlookup in Excel, the census data was matched to the OA codes from 
the shapefiles and then the census tables were brought into ArcMap where they were joined with the corresponding Output Area dataset.

The focus of this analysis is on the 2001 and 2011 censuses, both of which used Output Areas for their smallest areal unit (Figures 5a and 5b). There were changes made to a number of OAs between 2001 and 2011, making direct comparison of all OAs more difficult. In 2011, 25,295 OAs comprised the Greater London area. The following is a breakdown of the status of how, if at all, they were changed from the OAs used for the 2001 census: 23,633 were unchanged, 67 were merged with another OA, 1,566 were split into multiple OAs due to an increase in population, and 28 were removed.

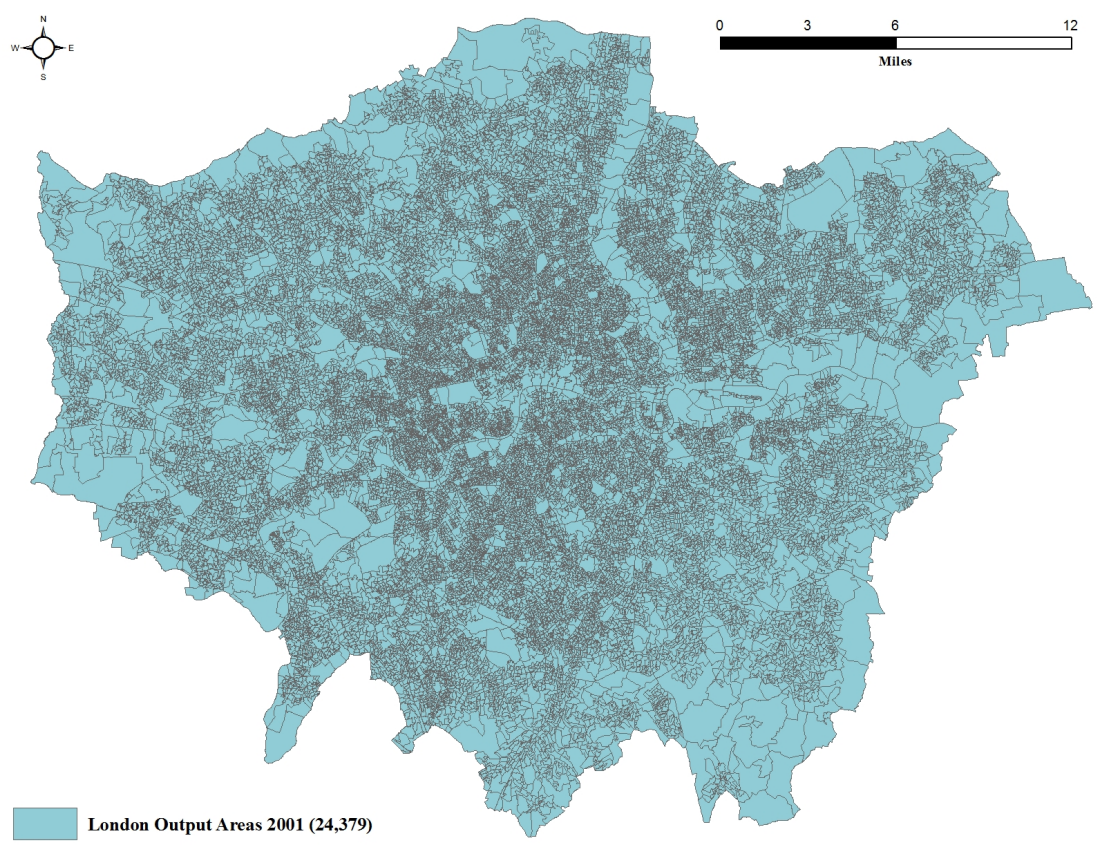

Figure 5a: Greater London Output Areas, 2001 Census

Source: Office of National Statistics, Contains National Statistics data (C) Crown copyright and database right 2013, Contains Ordnance Survey data (C) Crown copyright and database right 2013 


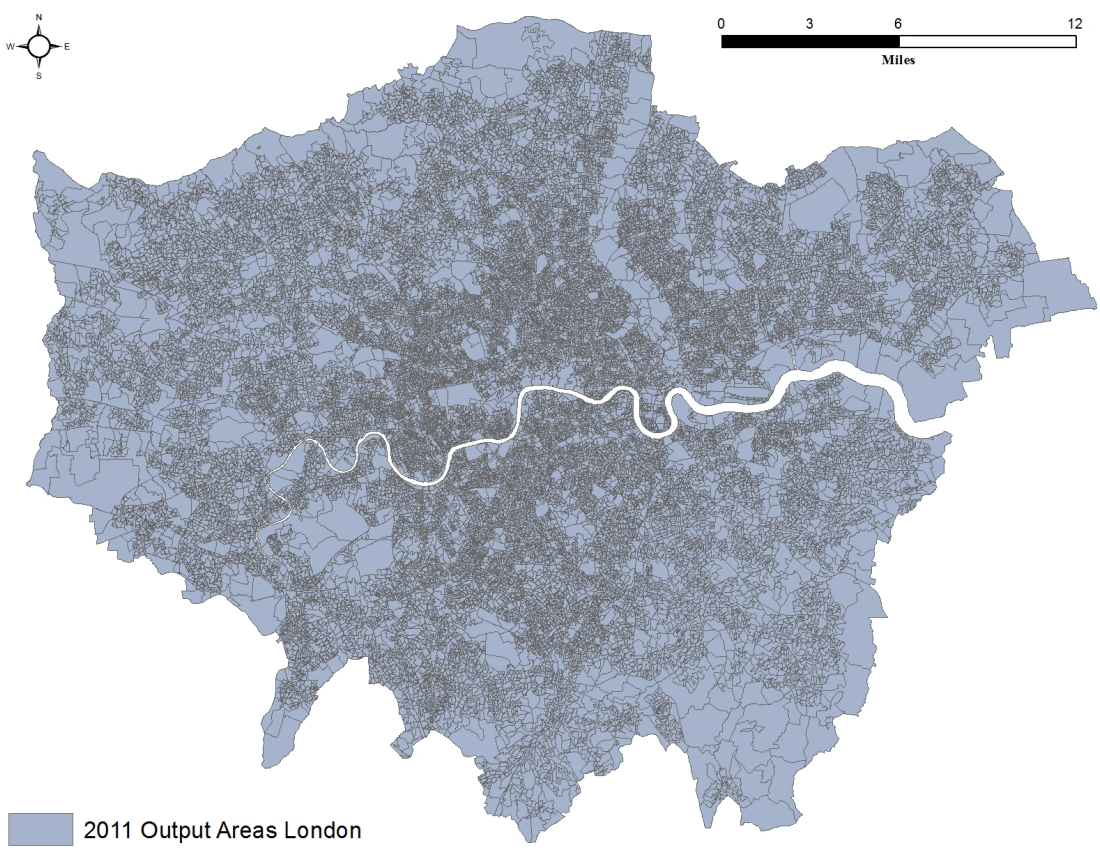

Figure 5b: Greater London Output Areas, 2011 Census

Source: Office of National Statistics, Contains National Statistics data (C) Crown copyright and database right 2013, Contains Ordnance Survey data @ Crown copyright and database right 2013

The next step involved finding an appropriate distance band for use in the local statistics. A distance band is a set distance used to analyze each feature within the context of their neighbors located within that distance (ESRIa2014, np). To find the correct distance band, Global Moran's I was calculated and the resulting z-scores were analyzed to find a distance band that would ensure that all features had at least eight neighbors. The distance band at which the z-score dipped was the threshold, in this case 2000 meters, which was then used as the distance band for all further analysis. This means that the results are comparing each data record with those values neighboring it within 2000 meters.

Once the distance band was set, the two local statistics were run for each ethnic group for both census years, resulting in twenty-four sets of results. The first method was 
Hot Spot Analysis, which uses the Getis-Ord $G^{*}$ statistic to identify statistically significant hot and cold spots across an area. According to ESRI, "To be a statistically significant hot spot, a feature will have a high value and be surrounded by other features with high values as well. The local sum for a feature and its neighbors is compared proportionally to the sum of all features; when the local sum is very different from the expected local sum, and that difference is too large to be the result of a random chance, a statistically significant z-score results" (ESRIb 2014, np). The results for Hot Spot Analysis are given as z-scores, with hot and cold spots being categorized with 99\% confidence of significance, $95 \%$ or $90 \%$ confidence of significance. For the purposes of the numerical analysis, I am considering only those Output Areas with a 99\% confidence of significance as either hot or cold spots.

The second method was Cluster and Outlier Analysis, which uses Anselin Local Moran's I to find areas of clustering of high or low values as well as outliers, where a group of high or low values is surrounded by the opposite values. ESRI states, "In effect, [the tool will] indicate whether the apparent similarity (a spatial clustering of either high or low values) or dissimilarity (a spatial outlier) is more pronounced than one would expect in a random distribution" (ESRIc 2014, np). In addition to z-scores, the results of the tool also categorize each feature according to the type of cluster it is. The categories are: cluster of high values (HH), cluster of low values (LL), an outlier where a high value is surrounded by low values (HL), or an outlier where a low value is surrounded by high values (LH) (ESRIc 2014). Features can also be statistically insignificant in which case they are not given a type classification 
The tabular results were then exported back into Excel for further analysis. The GIS-calculated results for each statistic and each group were exported individually by ethnic group, year and statistic. The other methods of measurement, the Index of Dissimilarity and the Poulsen et al. typology, were both computed outside ArcMap and imported via table join, much like the raw census data, to enable a cartographic examination of the results. The calculations for the Index of Dissimilarity were performed in Excel. ID was calculated for each ethnic group against the White/British population by District before being transferred back into ArcMap. Due to the nature of $I D$, it could not be performed at the Output Area level and thus the smallest areal unit to calculate the index came at the district level.

In order to perform the Poulsen et al. typology, I utilized software designed to make the computation of indices of residential segregation more accessible. In their paper outlining the purposes and uses of GeoSeg Analyzer, Apparicio et al. describe their goals in creating this software:

"Following a review of existing applications, we defined three important criteria for developing a new application. First, we sought to develop an application that would be easy to use but that would integrate a large number of residential segregation indices. Second, we intended the application to be independent rather than integrated in a GIS (ArcGIS, MapInfo, Quantum GIS, etc.) or statistical software (Stata, SAS, R, etc.), in order to limit the burden to the user. Third, we intended to develop free and open-source software" $(2013,4)$.

In this software, I was able to use the Poulsen et al. typology to categorize Output Areas in London according to two broad ethnic groups: Asian, which included the Indian, Pakistani and Bangladeshi populations, and Black, which consisted of the Black African and Black Caribbean populations, for the 2001 and 2011 censuses. 


\section{Data Analysis}

Both a visual analysis of the maps produced for each measure as well as a numerical analysis of the results for the local statistics were performed. The factors considered in the visual analysis included looking at how the patterns of clustering, evenness and concentration changed from 2001 to 2011 within each ethnic group, and how the patterns shown by each measure differed when comparing the same dataset. Overall, the general patterns between the two local statistics remained fairly consistent within each ethnic group. The Cluster and Outlier analysis allows for visualizing outliers at the same localized level, which produces a more fragmented result while the Hot Spot analysis result is more simplified across space. What may appear to be a large Hot Spot according to Getis-Ord $G^{*}$ might also contain Output Areas considered outliers according to Anselin Local Moran's I. Thus when taken together, the two measures can provide a very nuanced picture of ethnic concentration in an area. The datasets being analyzed would result in a table with over 800,000 records for each ethnic group. Thus, the numeric results of this analysis are presented in summary tables for each ethnic group, year and statistic, along with how the results changed over time both in terms of Output Areas and raw population. 


\section{Chapter 4: Results \& Analysis}

The results of this study are separated into two types of analysis. The first is an examination of the portion of the ethnic minority population living in areas that are either highly or lowly segregated throughout the Greater London area from 2001 to 2011 . The second is how changing the method of measurement changes the result both visually and quantitatively. The visual analysis of the cartographic results may not be conclusive, but they can provide insight into how results from different measures might be perceived by the general public. Even small manipulations in classification within the maps can change the result drastically and thus change how that map is interpreted.

For purposes of accessibility, the following page is a master legend for all of the levels of analysis along with a short explanation of what the different classifications within each map type denote (Table 1). 
Table 1: Master Legend for Results Maps

\begin{tabular}{|c|c|c|}
\hline Legend Item & Label & Explanation \\
\hline \multicolumn{3}{|l|}{ Local Statistics Results } \\
\hline & High Concentration & $\begin{array}{l}\text { All Output Areas classified as either Hot } \\
\text { Spots by } G^{*} \text { or HH clusters by } I \text {, indicating } \\
\text { areas of statistically high concentration of the } \\
\text { ethnic group being analyzed }\end{array}$ \\
\hline & Low Concentration & $\begin{array}{l}\text { All Output Areas classified as either Cold } \\
\text { Spots by } G^{*} \text { or LL clusters by } I \text {, indicating } \\
\text { areas of statistically low concentration of the } \\
\text { ethnic group being analyzed. }\end{array}$ \\
\hline & $\begin{array}{l}\text { High-Low Outlier } \\
\text { Cluster }\end{array}$ & $\begin{array}{l}\text { OAs classified as a HL cluster by } I \text {. Indicates } \\
\text { an area with a statistically high population of } \\
\text { the group in question surrounded by } \\
\text { statistically low values of that group. }\end{array}$ \\
\hline & $\begin{array}{l}\text { Low-High Outlier } \\
\text { Cluster }\end{array}$ & $\begin{array}{l}\text { OAs classified as a LH cluster by } I \text {. Indicates } \\
\text { an area with a statistically low population of } \\
\text { the group in question surrounded by } \\
\text { statistically high values of that group. }\end{array}$ \\
\hline \multicolumn{3}{|l|}{ Typology Results } \\
\hline & Type I & $\begin{array}{l}\text { Areas where the majority group forms more } \\
\text { than } 80 \% \text { of the total population }\end{array}$ \\
\hline & Type II & $\begin{array}{l}\text { Areas where the majority group makes up 50- } \\
80 \% \text { of the population, but members of } \\
\text { minority groups in question form a substantial } \\
\text { minority }\end{array}$ \\
\hline & Type III & $\begin{array}{l}\text { Areas where members of ethnic minority } \\
\text { groups form } 50-70 \% \text { of the total population, } \\
\text { but members of the majority form a } \\
\text { substantial minority. }\end{array}$ \\
\hline & Type IV & $\begin{array}{l}\text { Areas where members of ethnic minority } \\
\text { groups form } 70 \% \text { of the total population \& } \\
\text { one minority group is at least twice as large as } \\
\text { the other(s) }\end{array}$ \\
\hline & Type V & $\begin{array}{l}\text { Areas where ethnic minority groups form } 70 \% \\
\text { or more of the total population, one minority } \\
\text { group is at least twice as large as the other(s) } \\
\text { and at least } 30 \% \text { of the group's total } \\
\text { population lives in those areas. }\end{array}$ \\
\hline \multicolumn{3}{|l|}{$\begin{array}{c}\text { Index of Dissimilarity } \\
\text { Results }\end{array}$} \\
\hline $\begin{array}{l}21-30 \\
31-40 \\
41-50 \\
51-60 \\
61-70 \\
71-80 \\
81-90 \\
91-100\end{array}$ & 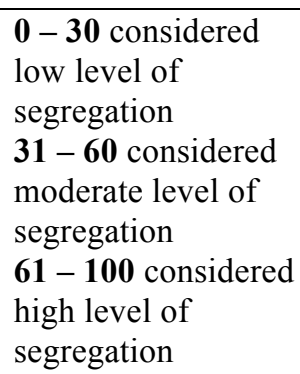 & $\begin{array}{l}\text { Higher values indicate districts with higher } \\
\text { levels of segregation, where a larger } \\
\text { proportion of the minority group in question } \\
\text { would need to relocate to be evenly } \\
\text { distributed with the majority population across } \\
\text { that district. } \\
\text { Color Ramp Source: } \\
\text { Colors from www.ColorBrewer.org by Cynthia A. } \\
\text { Brewer, Geography, Pennsylvania State University. }\end{array}$ \\
\hline
\end{tabular}


Prior to looking at the results for the individual ethnic groups in question, a look at how population levels changed overall in both England and London can be helpful for providing some context as to how much of any one group lives in the study area (Tables 2, 3 and 4). The tables indicate that while raw population counts show a decrease only in the White/British population between census dates, all groups examined saw a decrease in the proportion of their population living in London, with the Black African population seeing over one fifth of its population leaving the area between 2001 and 2011.

Table 2: Population Estimates for England by ethnic group, 2001 and 2011 censuses Source: Office of National Statistics, Contains National Statistics data

(C) Crown copyright and database right 2013

\begin{tabular}{|l|r|r|r|r|r|r|r|}
$\begin{array}{c}\text { England } \\
\text { Population }\end{array}$ & \multicolumn{1}{|c|}{ All } & White/British & Indian & Pakistani & Bangladeshi & \multicolumn{1}{c|}{$\begin{array}{c}\text { Black } \\
\text { African }\end{array}$} & $\begin{array}{c}\text { Black } \\
\text { Caribbean }\end{array}$ \\
\hline $\mathbf{2 0 0 1}$ & $49,138,831$ & $42,747,136$ & $1,028,546$ & 706,539 & 275,394 & 475,938 & 561,246 \\
\hline $\mathbf{2 0 1 1}$ & $53,012,456$ & $42,279,236$ & $1,395,702$ & $1,112,282$ & 436,514 & 977,741 & 591,016 \\
\hline Change & $3,873,625$ & $-467,900$ & 367,156 & 405,743 & 161,120 & 501,803 & 29,770 \\
\hline
\end{tabular}

Table 3: Population estimates for London by ethnic group, 2001 and 2011 censuses

Source: Office of National Statistics, Contains National Statistics data

(C) Crown copyright and database right 2013

\begin{tabular}{|l|r|r|r|r|r|r|r|}
$\begin{array}{c}\text { London } \\
\text { Population }\end{array}$ & \multicolumn{1}{|c|}{ All } & White/British & Indian & Pakistani & Bangladeshi & $\begin{array}{c}\text { Black } \\
\text { African }\end{array}$ & $\begin{array}{c}\text { Black } \\
\text { Caribbean }\end{array}$ \\
\hline $\mathbf{2 0 0 1}$ & $7,246,467$ & $4,352,243$ & 439,275 & 143,130 & 153,923 & 379,371 & 344,083 \\
\hline $\mathbf{2 0 1 1}$ & $8,173,941$ & $3,669,284$ & 542,857 & 223,797 & 222,127 & 573,931 & 344,597 \\
\hline Change & 927,474 & $-682,959$ & 103,582 & 80,667 & 68,204 & 194,560 & 514 \\
\hline
\end{tabular}

Table 4: Proportion of total population living in London, 2001 and 2011 censuses

Source: Office of National Statistics, Contains National Statistics data

(C) Crown copyright and database right 2013

\begin{tabular}{|l|r|r|r|r|r|r|r|}
$\begin{array}{c}\text { \% of Total } \\
\text { Group Pop in } \\
\text { London }\end{array}$ & All & White/British & Indian & Pakistani & Bangladeshi & $\begin{array}{c}\text { Black } \\
\text { African }\end{array}$ & $\begin{array}{c}\text { Black } \\
\text { Caribbean }\end{array}$ \\
\hline $\mathbf{2 0 0 1}$ & 14.75 & 10.18 & 42.71 & 20.26 & 55.89 & 79.71 & 61.31 \\
\hline 2011 & 15.42 & 8.68 & 38.89 & 20.12 & 50.89 & 58.70 & 58.31 \\
\hline Change & 0.67 & -1.50 & -3.81 & -0.14 & -5.01 & -21.01 & -3.00 \\
\hline
\end{tabular}




\section{Changes in the White/British Population}

Before examining the population results for different ethnic groups, it is helpful to understand the distribution of the majority White/British population throughout the city. In order to avoid any discrepancies due to changes in Output Area geometry, the results for the local statistics were generalized by classification. All of the Output Areas classified as either a Hot Spot or HH cluster were combined in one layer with Cold Spot and LL clusters in another in ArcMap. This was done to facilitate finding an accurate accounting of the number of people living in those areas. The outlier OAs were kept separate to highlight the variations across space revealed by Anselin Local Moran's $I$. The maps show that the ring of high concentration that almost completely encircled London in 2001 was broken in several more places by 2011. Visually it appears that the overall population living in areas classified as highly concentrated shifted in some places but did not noticeably decrease between the census dates (Figures 6a and 6b). 


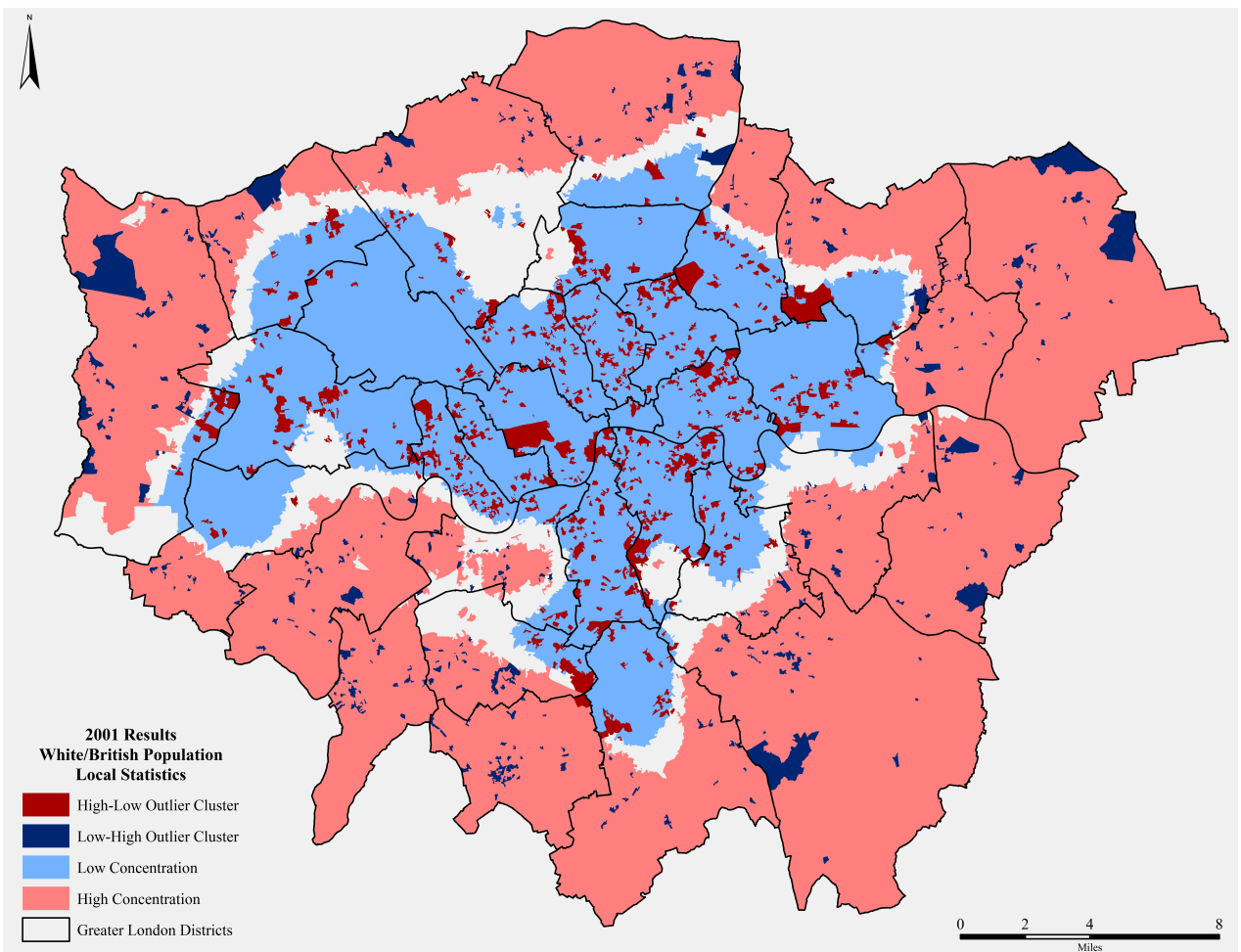

Figure 6a: Local Statistics Results for the White/British Population, 2001

Source: Office of National Statistics, Contains National Statistics data $($ Crown copyright and database right 2013, Contains Ordnance Survey data (C) Crown copyright and database right 2013

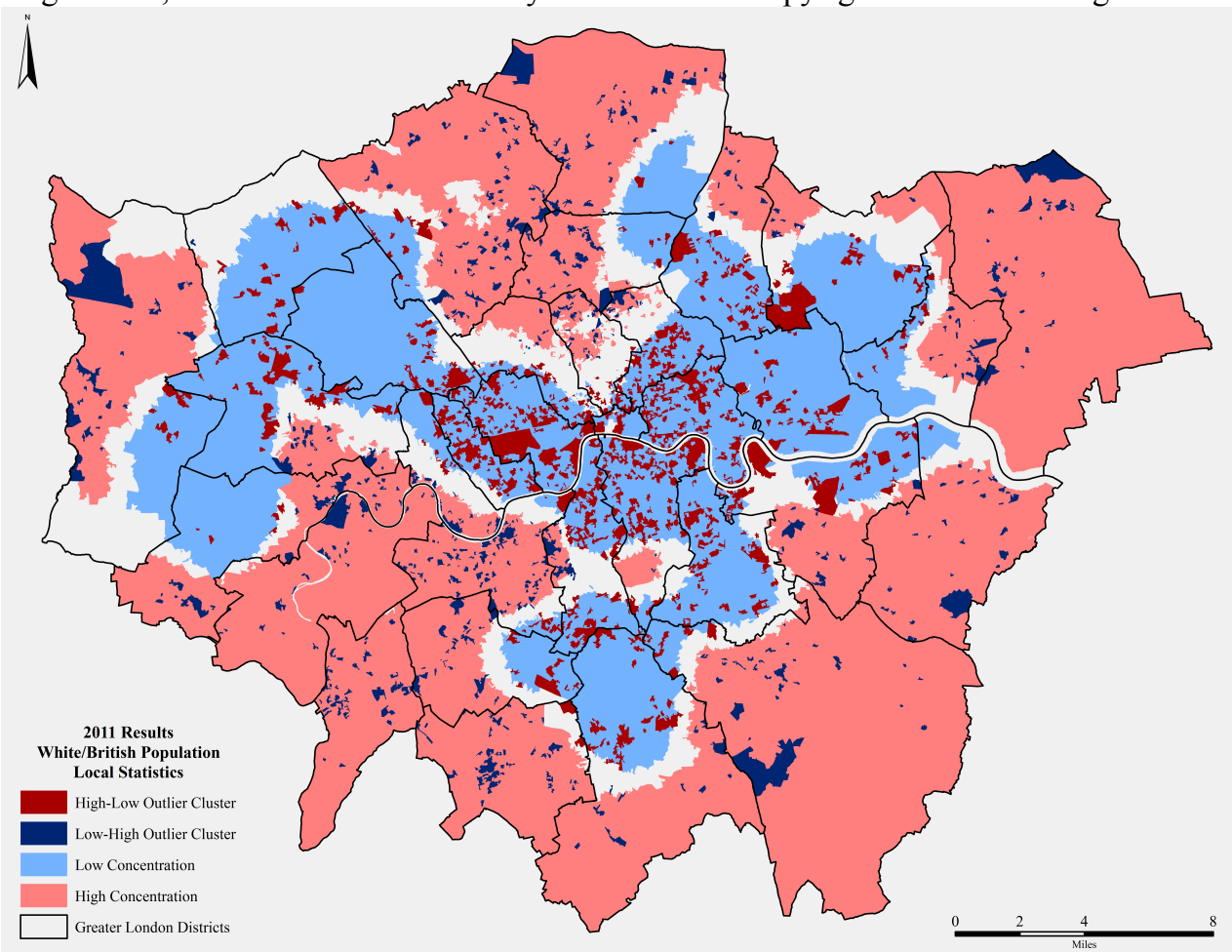

Figure 6b: Local Statistics Results for the White/British Population, 2011

Source: Office of National Statistics, Contains National Statistics data $\odot$ Crown copyright and database right 2013, Contains Ordnance Survey data (C) Crown copyright and database right 2013 
For further analysis of exactly how the White/British population changed over the study period, the number of White/British people living in areas classified as statistically significant is shown in two separate tables, one with the results according to Getis-Ord $G^{*}$ and one according to Anselin Local Moran's I (Tables 5a and 5b).

Table 5a: White/British population in statistically significant Output Areas and change in population 2001-2011, Getis-Ord $G^{*}$

Source: Office of National Statistics, Contains National Statistics data

(C) Crown copyright and database right 2013

\begin{tabular}{|c|c|c|c|c|}
\cline { 2 - 5 } \multicolumn{1}{c|}{} & Hot Spot & $\begin{array}{c}\text { \% Group } \\
\text { Population }\end{array}$ & Cold Spot & $\begin{array}{c}\text { \% Group } \\
\text { Population }\end{array}$ \\
\hline $\mathbf{2 0 0 1}$ & $2,102,676$ & 48.31 & $1,674,670$ & 38.48 \\
\hline $\mathbf{2 0 1 1}$ & $2,395,702$ & 48.35 & $1,663,049$ & 33.56 \\
\hline Change & 293,026 & 0.04 & $-11,621$ & -4.91 \\
\hline
\end{tabular}

Table 5b: White/British population in statistically significant Output Areas and change in population 2001-2011, Anselin Local Moran's I

Source: Office of National Statistics, Contains National Statistics data

(C) Crown copyright and database right 2013

\begin{tabular}{|c|c|c|c|c|}
\cline { 2 - 5 } \multicolumn{1}{c|}{} & $\begin{array}{c}\text { High } \\
\text { Cluster }\end{array}$ & $\begin{array}{c}\text { \% Group } \\
\text { Population }\end{array}$ & Low Cluster & $\begin{array}{c}\text { \% Group } \\
\text { Population }\end{array}$ \\
\hline $\mathbf{2 0 0 1}$ & $1,778,837$ & 40.87 & $1,055,462$ & 24.25 \\
\hline $\mathbf{2 0 1 1}$ & $1,841,306$ & 37.16 & 884,017 & 17.84 \\
\hline Change & 62,469 & -3.71 & $-171,445$ & -6.41 \\
\hline
\end{tabular}

While the absolute number of White/British residents living in highly

concentrated areas increased over time, the proportion of that group's population living in said areas either increased very slightly or decreased between 2001 and 2011. Both statistics show that the raw number and proportion of the group's population living in areas of low concentration decreased over time. With either measure, there is still a large portion of the group that lives in an area without any significant clustering, though the areas of highest and lowest concentration cover most of the city. 
Changes in the Afro-Caribbean Population

Before the changes across the Black African and Black Caribbean communities are addressed individually, the Poulsen et al. typology shows a general picture of the distribution of these groups across the city and how that distribution may have changed over time (Figures $7 \mathrm{a}$ and $7 \mathrm{~b})$.

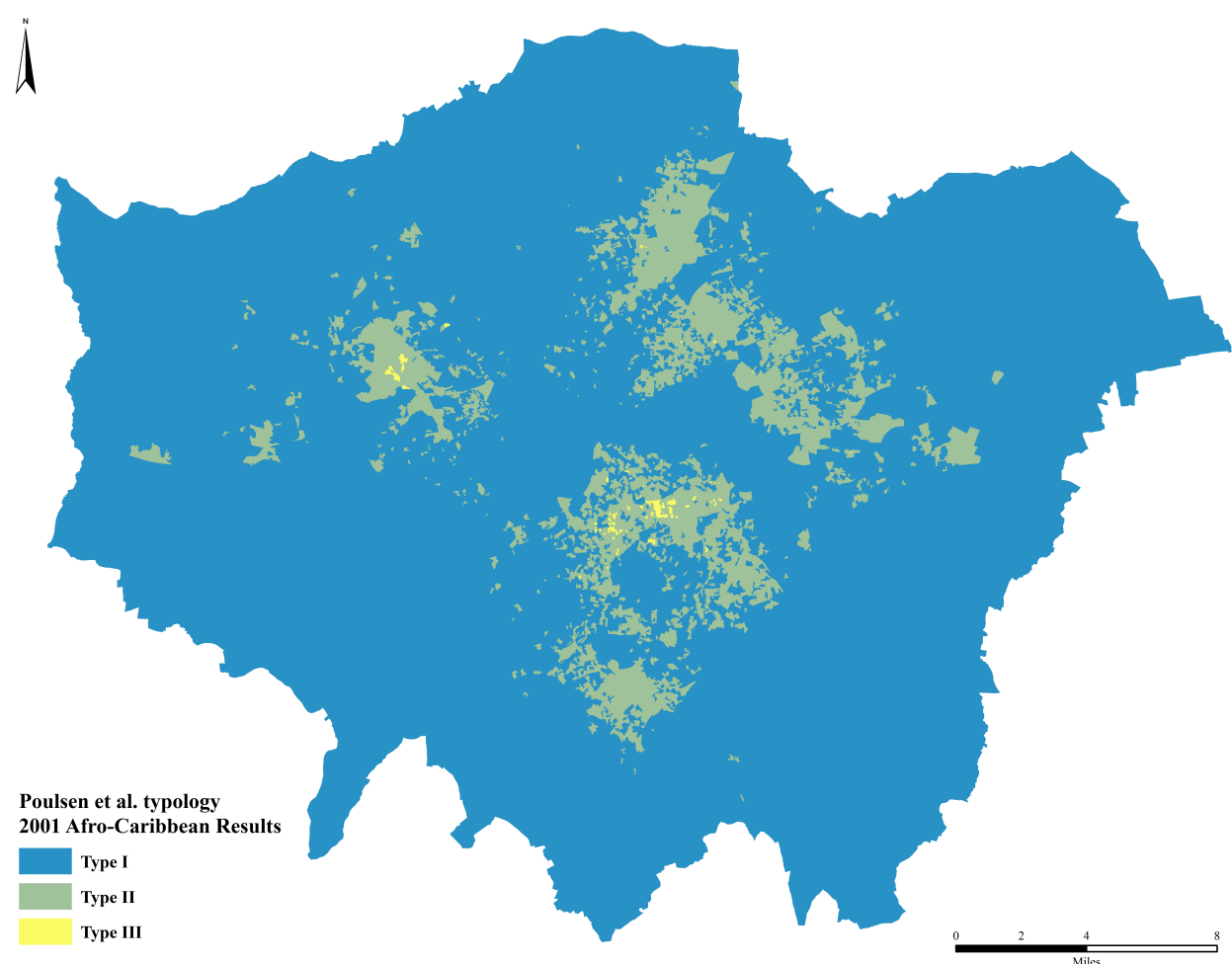

Figure 7a: Poulsen et al. typology Results for the Black Population, 2001

Source: Office of National Statistics, Contains National Statistics data $\mathbb{C}$ Crown copyright and database right 2013, Contains Ordnance Survey data (C) Crown copyright and database right 2013 


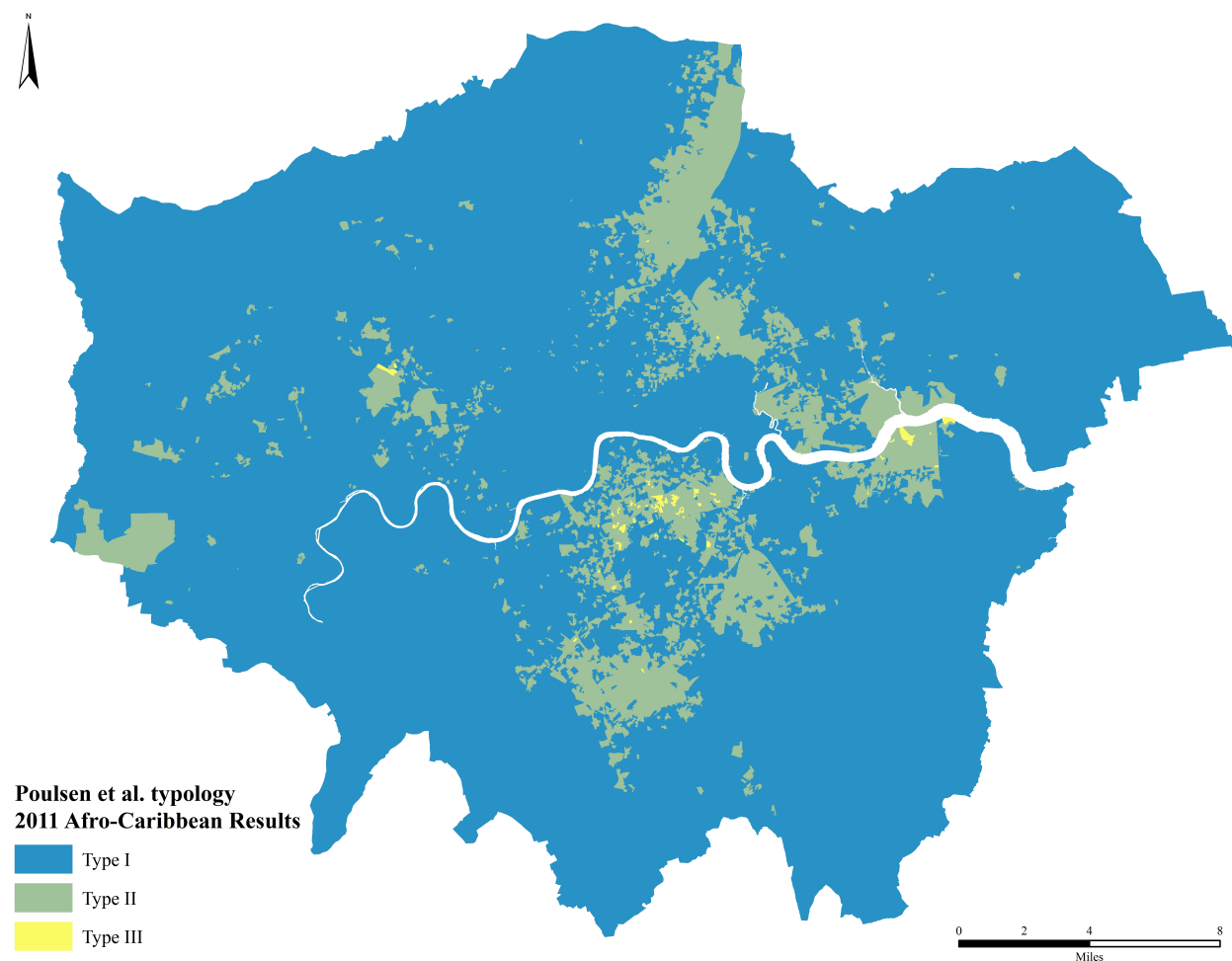

Figure 7b: Poulsen et al. typology Results for the Black Population, 2011

Source: Office of National Statistics, Contains National Statistics data (C) Crown copyright and database right 2013, Contains Ordnance Survey data C Crown copyright and database right 2013

These results show that there seem to be three fairly centralized areas of high levels of segregation for the Black population in London. This pattern is consistent with the original settlement patterns of these two migrant groups and does not show evidence of great change since the post-war period. While the maps show some shifting of these areas of high segregation, there was not a significant increase of segregation across the city.

After establishing what appears to be the general pattern of segregation for the Black African and Black Caribbean populations, the other measures were calculated. First was the Black African population, beginning with the Index of Dissimilarity and followed by the local statistics. Due to the nature of the measure, the ID could not be calculated at the Output Area level. Thus the results for ID are at the district level. All of 
the Output Areas composing each district were used for this calculation. The results for ID are very broad, as can be seen in the maps for the Black African population's results (Figures $8 \mathrm{a}$ and $8 \mathrm{~b}$ ). The range of values for each year decreased between census dates indicating an overall decrease in the level of segregation across the city. Newham, the district with the lowest value in 2001 retained that distinction in 2011, but the district with the highest value shifted from Richmond upon Thames to City of London.

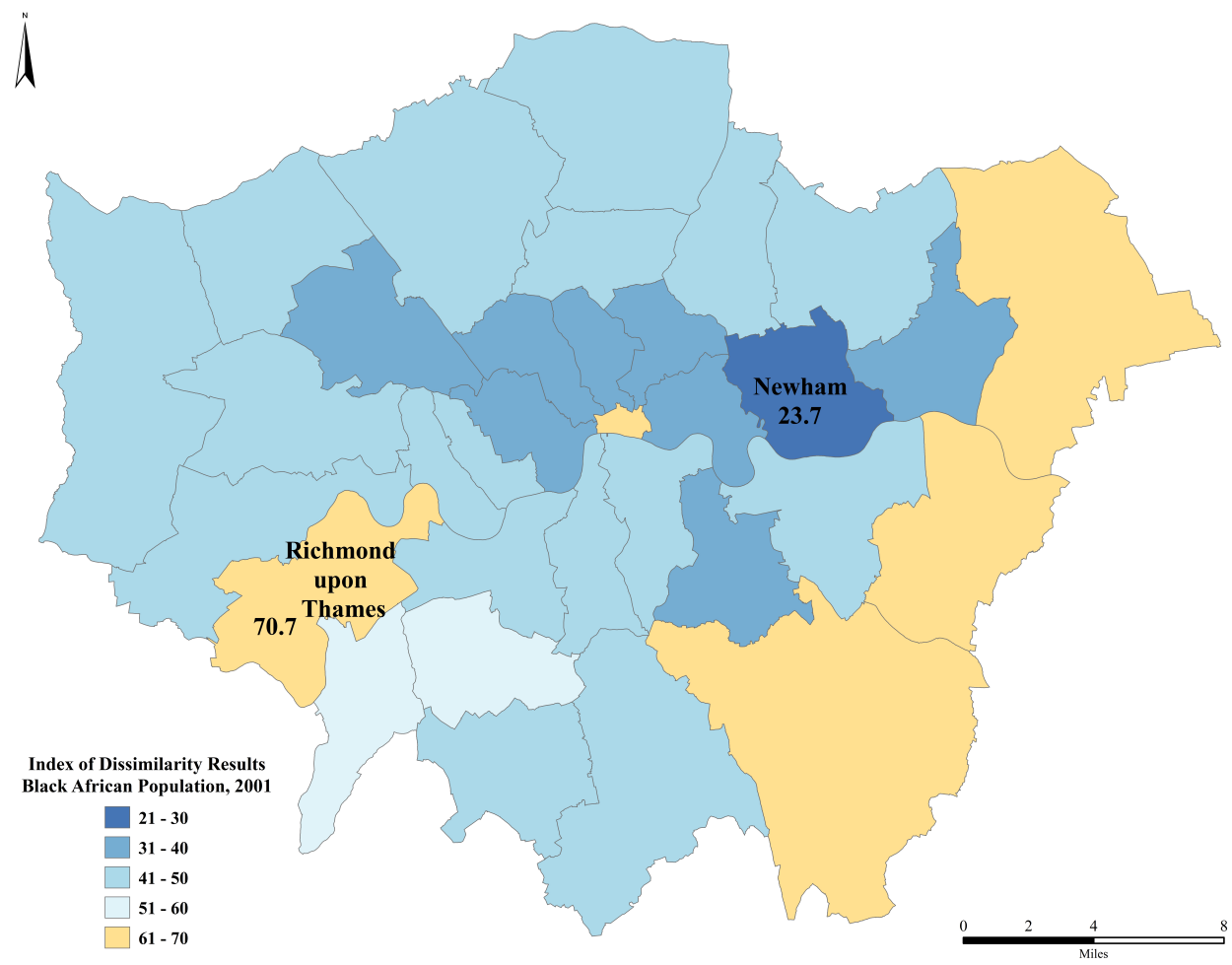

Figure 8a: Index of Dissimilarity Results for the Black African Population, 2001 Source: Office of National Statistics, Contains National Statistics data $($ C Crown copyright and database right 2013, Contains Ordnance Survey data (C) Crown copyright and database right 2013 


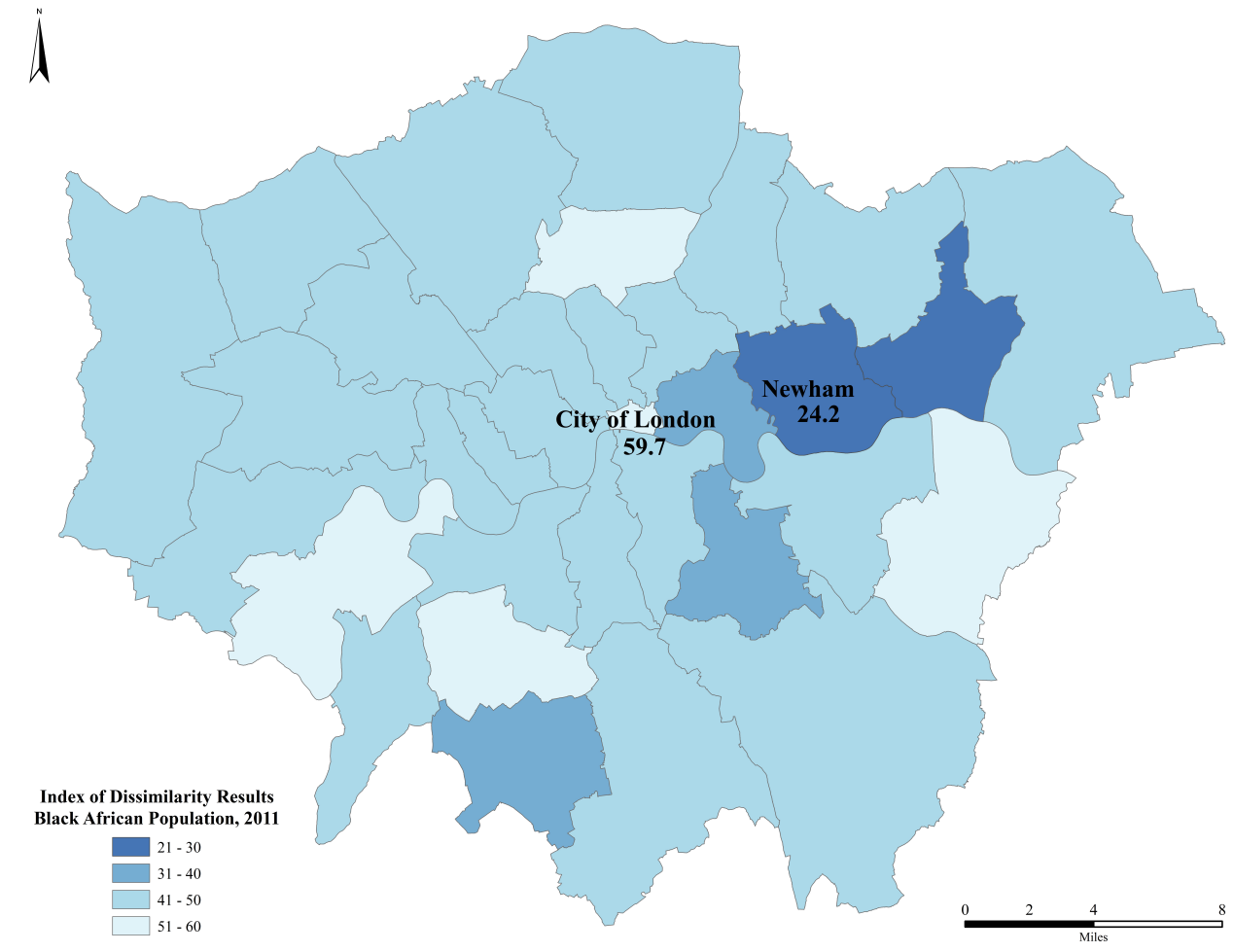

Figure 8b: Index of Dissimilarity Results for the Black African Population, 2011

Source: Office of National Statistics, Contains National Statistics data $\subset$ Crown copyright and database right 2013, Contains Ordnance Survey data $\mathbb{C}$ Crown copyright and database right 2013

The generalized maps for the two local statistics show that the overall area of high concentration in the Black African population grew outward over time from areas that were already highly concentrated (Figures 9a and 9b). There also are more High-Low outliers throughout the city, indicating areas where there is a significant Black African population surrounded by areas with significantly low Black African populations. Only further studies can reveal if what are outliers according to 2011 census data will or have become larger areas of concentration. The areas classified as Low-High outliers in 2001 remained much the same in 2011. This would indicate pockets of high segregation where there is a significantly low number of Black African residents surrounded by areas with a high number of Black African residents forming pockets of low values in the midst of highly segregated areas. 


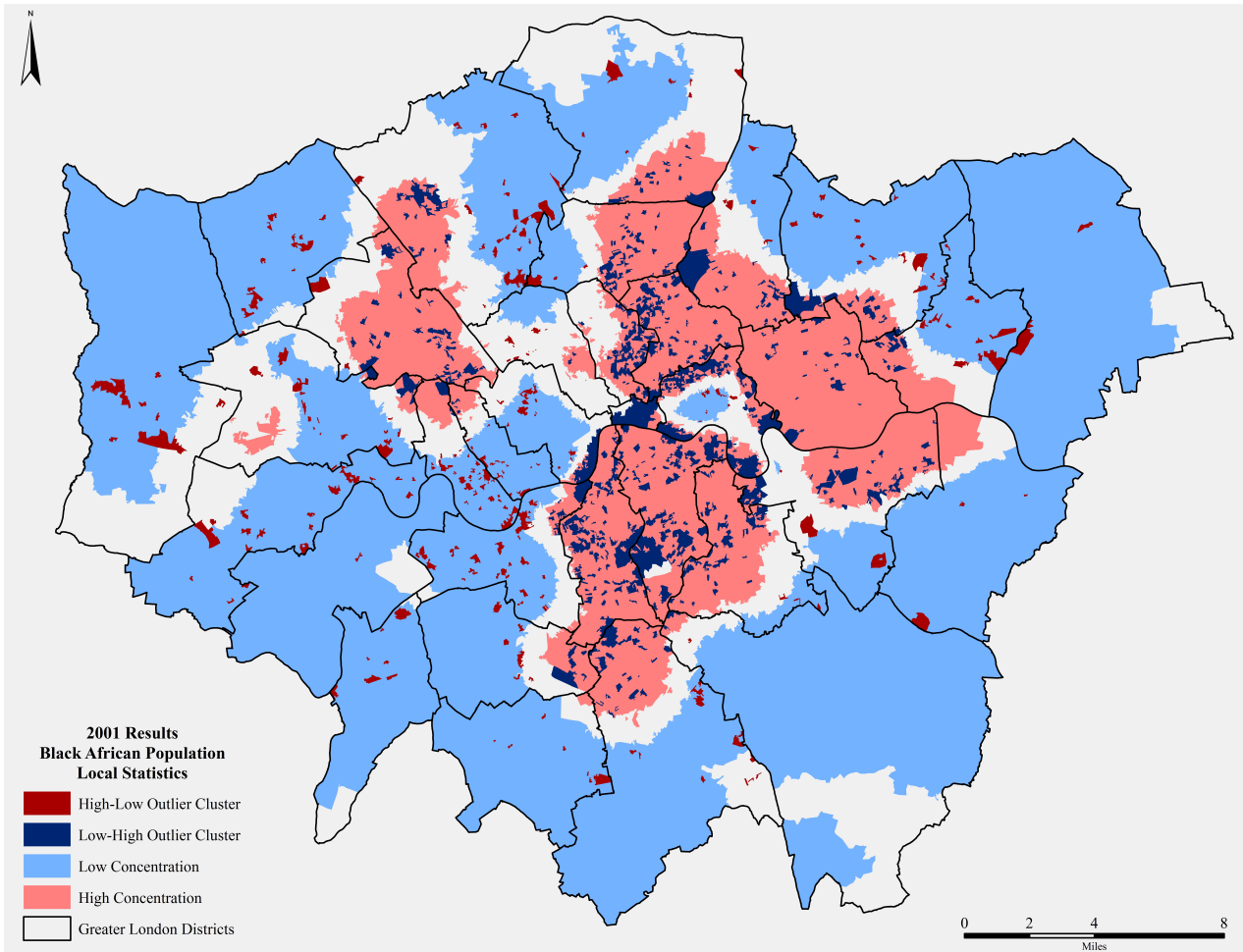

Figure 9a: Local Statistics Results for the Black African Population, 2001

Source: Office of National Statistics, Contains National Statistics data $\odot$ Crown copyright and database right 2013, Contains Ordnance Survey data (C) Crown copyright and database right 2013

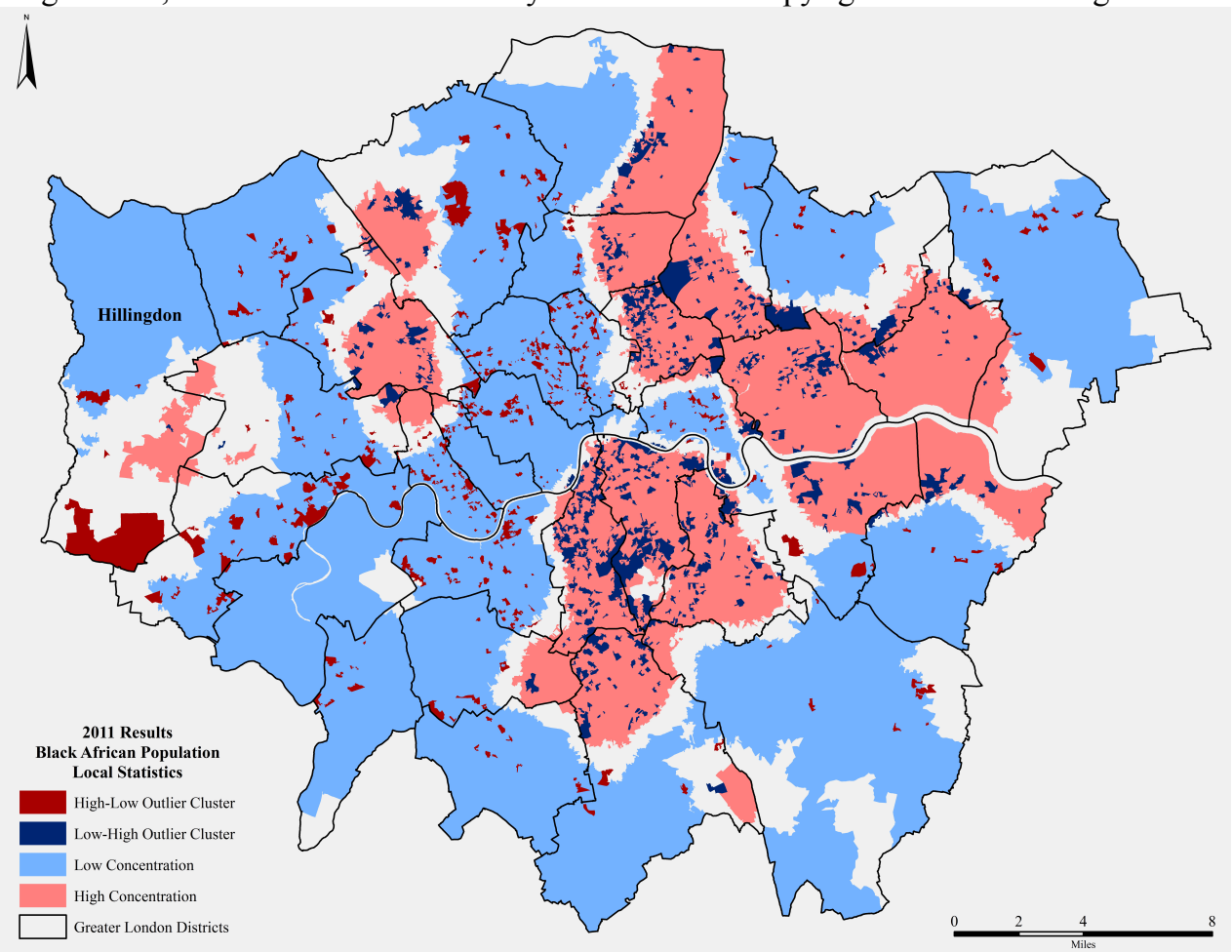

Figure 9b: Local Statistics Results for the Black African Population, 2011

Source: Office of National Statistics, Contains National Statistics data $($ Crown copyright and database right 2013, Contains Ordnance Survey data (C) Crown copyright and database right 2013 
As with the White/British population, the visual pattern of shifting and growing segregation among the Black African population can only be confirmed by examining the quantitative results (Tables $6 \mathrm{a}$ and $6 \mathrm{~b}$ ). When looking at the number of Black African residents living in hot spots or $\mathrm{HH}$ clusters, it would be easy to conclude that segregation in this group increased between 2001 and 2011. But in this case the more significant numbers are the proportions of the group's population living in highly concentrated areas. According to both statistics, there was a decrease in the overall portion of the Black African community living in an area that is considered highly segregated. Once again the exact values for each of these classifications varies by statistic, but the consistency of the portion of the group in highly clustered areas provides evidence to suggest that the overall level of segregation for the Black African population decreased between census dates.

Table 6a: Black African population in statistically significant Output Areas and change in population 2001-2011, Getis-Ord $G^{*}$

Source: Office of National Statistics, Contains National Statistics data (C) Crown copyright and database right 2013

\begin{tabular}{|c|c|c|c|c|}
\hline & Hot Spot & $\begin{array}{c}\text { \% Group } \\
\text { Population }\end{array}$ & Cold Spot & \% Group Population \\
\hline $\mathbf{2 0 0 1}$ & 243,556 & 64.20 & 6,042 & 1.59 \\
\hline $\mathbf{2 0 1 1}$ & 357,838 & 62.21 & 131,471 & 22.86 \\
\hline Change & 114,282 & -1.99 & 125,429 & 21.27 \\
\hline
\end{tabular}

Table 6b: Black African population in statistically significant Output Areas and change in population 2001-2011, Anselin Local Moran's I

Source: Office of National Statistics, Contains National Statistics data (C) Crown copyright and database right 2013

\begin{tabular}{|c|c|c|c|c|}
\hline & High Cluster & $\begin{array}{c}\text { \% Group } \\
\text { Population }\end{array}$ & Low Cluster & \% Group Population \\
\hline $\mathbf{2 0 0 1}$ & 211,849 & 55.84 & 19,235 & 5.07 \\
\hline $\mathbf{2 0 1 1}$ & 306,850 & 53.35 & 40,108 & 6.97 \\
\hline Change & 95,001 & -2.49 & 20,873 & 1.90 \\
\hline
\end{tabular}


The other minority group in the Black population is the Black Caribbean community. Much like the Black African group, the ID results show an overall decrease in the range of values, which indicates a general decrease in the levels of segregation throughout the city (Figures 10a and 10b).

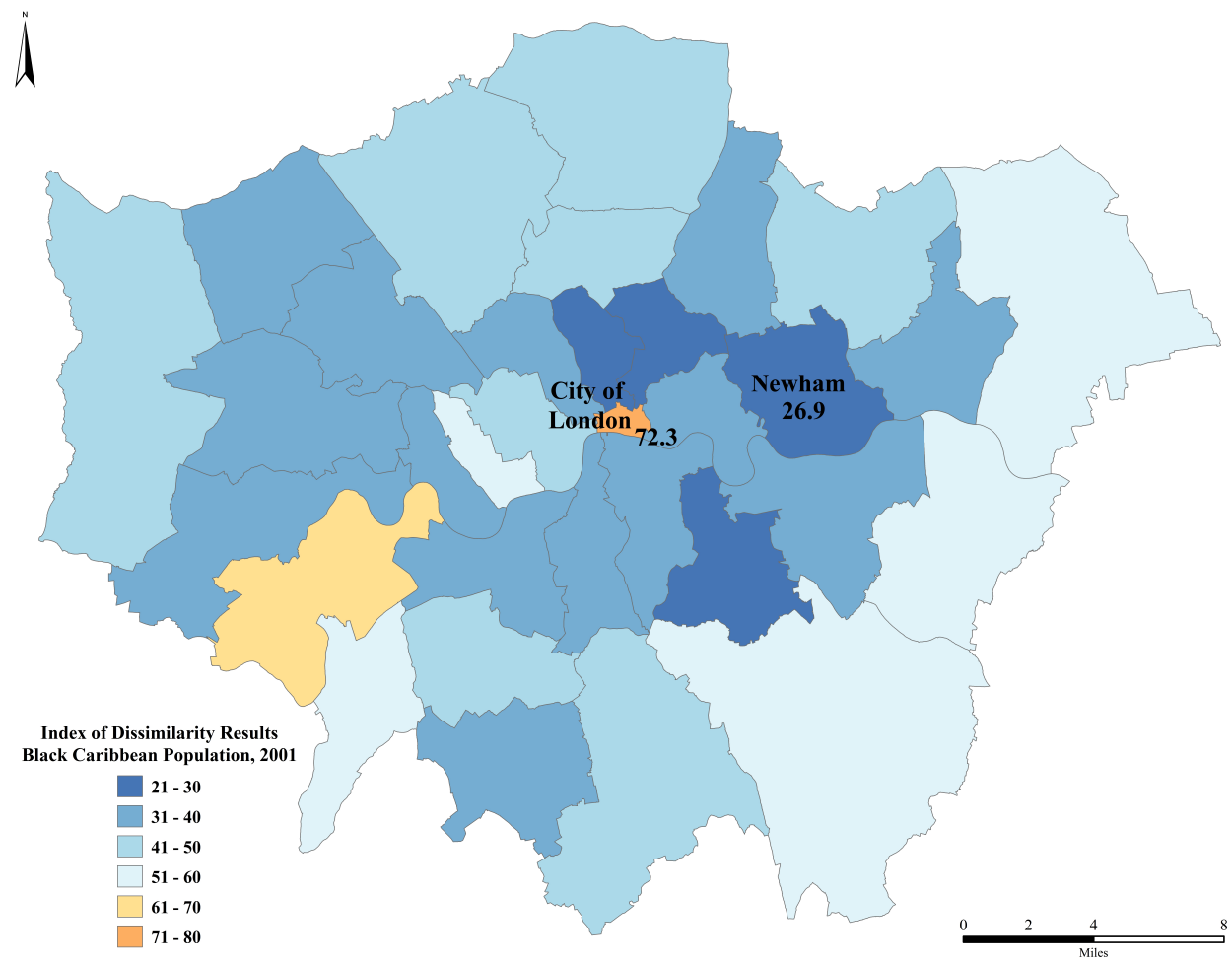

Figure 10a: Index of Dissimilarity Results for the Black Caribbean Population, 2001

Source: Office of National Statistics, Contains National Statistics data $($ C Crown copyright and database right 2013, Contains Ordnance Survey data (C) Crown copyright and database right 2013 


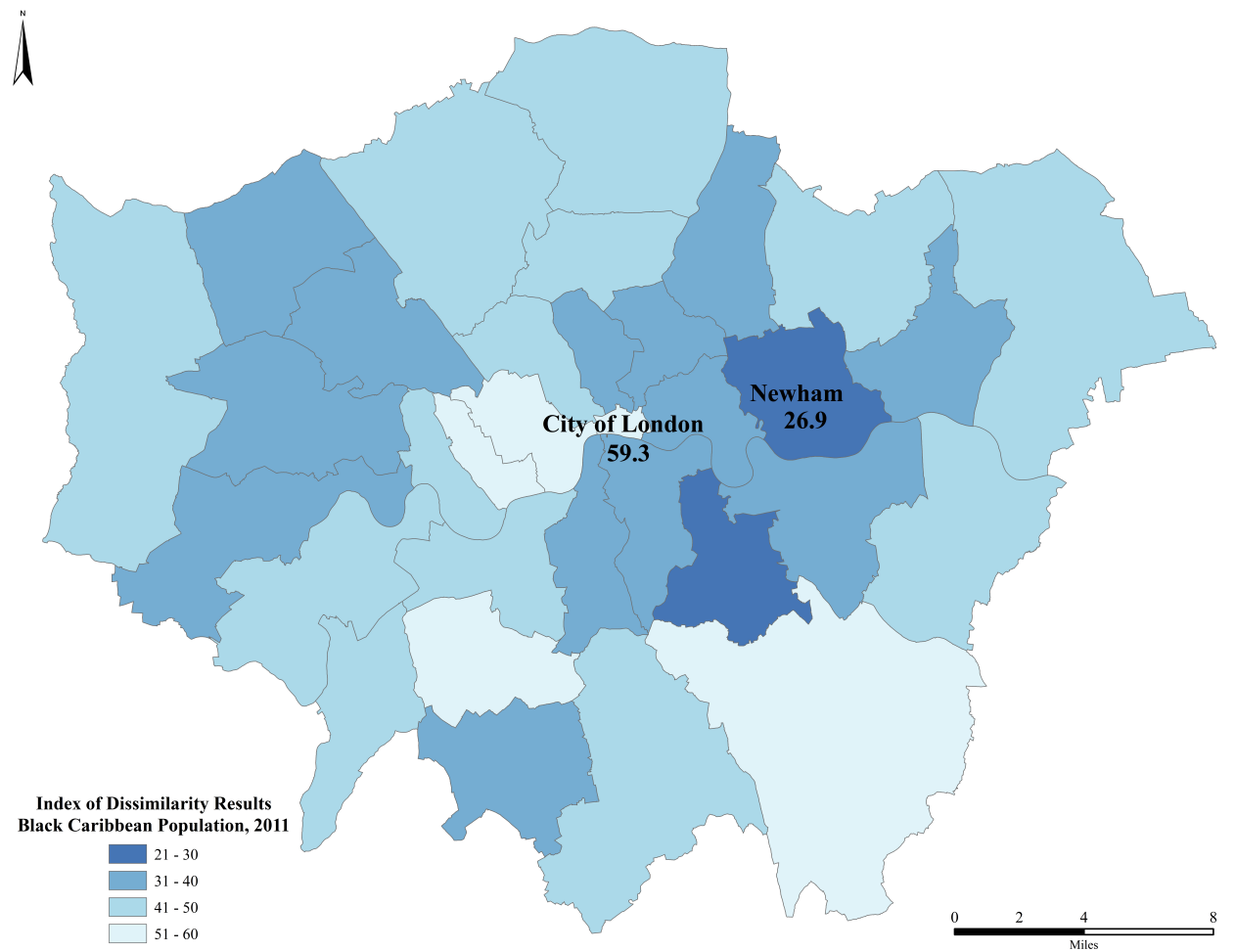

Figure 10b: Index of Dissimilarity Results for the Black Caribbean Population, 2011

Source: Office of National Statistics, Contains National Statistics data (C) Crown copyright and database right 2013, Contains Ordnance Survey data (C) Crown copyright and database right 2013

The local statistics results portray a pattern of segregation within the Caribbean community that seems to have stayed relatively stable over the study period (Figures 11a and 11b). But as with the Black African results, the number of High-Low outliers increased throughout the city, highlighting areas that may become more segregated in the future. There are also pockets of Low-High outliers in both years, with a large area in the southern part of Southwark. 


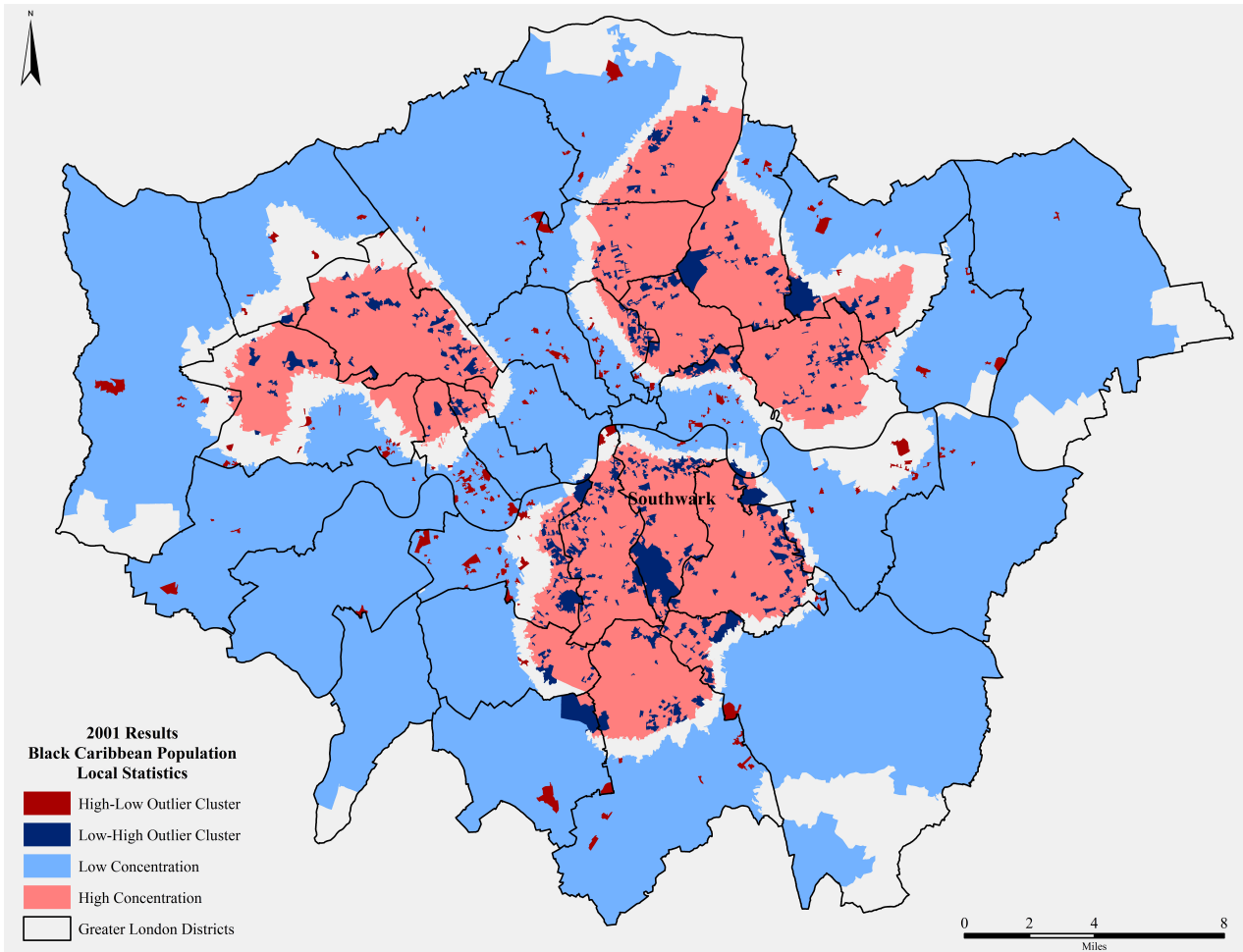

Figure 11a: Local Statistics Results for the Black Caribbean Population, 2001

Source: Office of National Statistics, Contains National Statistics data $\odot$ Crown copyright and database right 2013, Contains Ordnance Survey data (C) Crown copyright and database right 2013

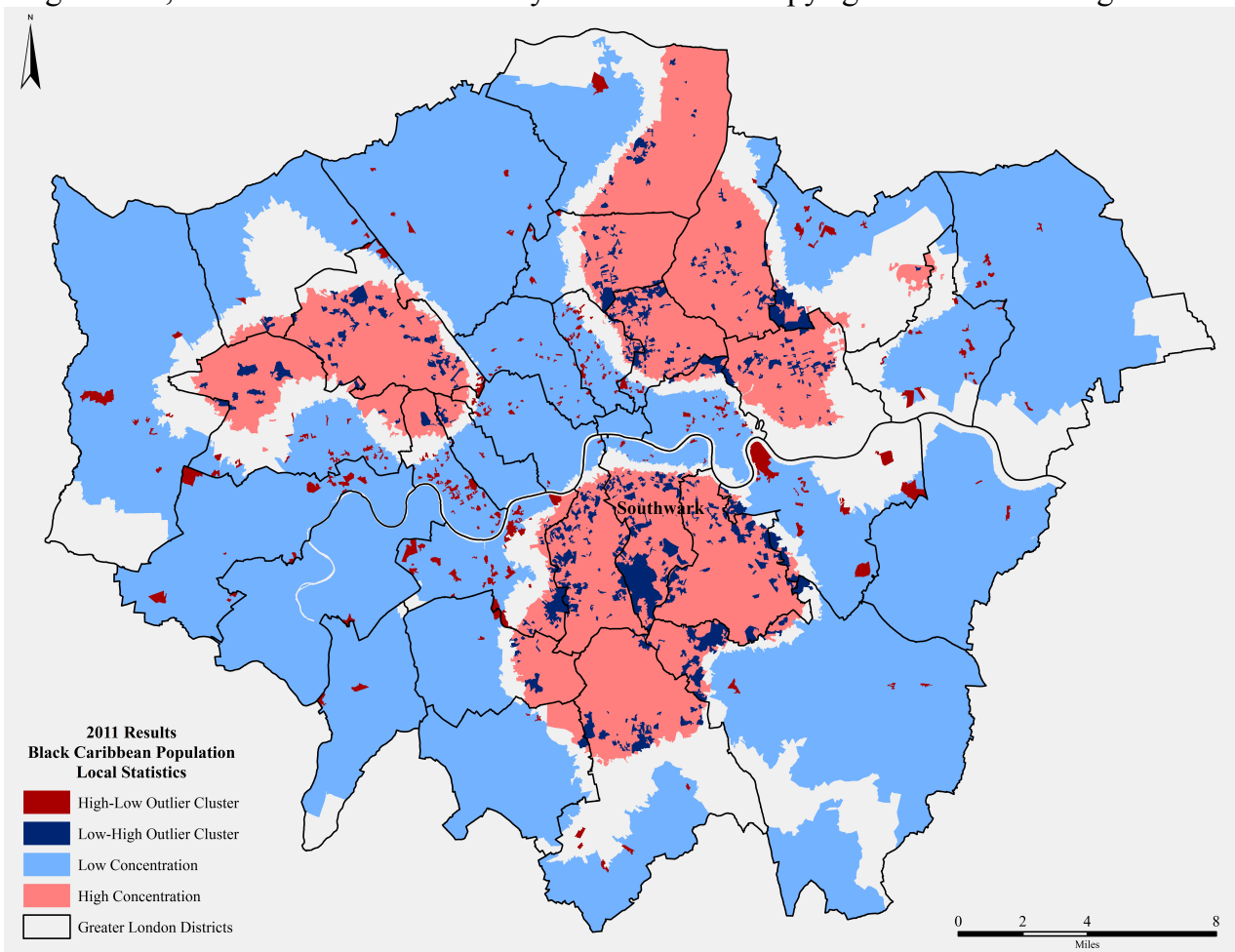

Figure 11b: Local Statistics Results for the Black Caribbean Population, 2011

Source: Office of National Statistics, Contains National Statistics data $(\subset$ Crown copyright and database right 2013, Contains Ordnance Survey data (C) Crown copyright and database right 2013 
Since the maps do not show large changes in the level of segregation for the Black Caribbean population, the numeric results provide more insight into how the population may have shifted over time (Tables $7 \mathrm{a}$ and $7 \mathrm{~b}$ ). When the populations of areas of highest and lowest concentration are examined, it is revealed that the Black Caribbean population saw a decrease in both the number of residents living in highly segregated areas and the percentage of the group's total population living in high segregation. There were also increases in the number and proportion of the Black Caribbean population living in areas of low concentration, but that change was not nearly as large as the decrease in highly segregated areas. This suggests that much of the approximately $5 \%$ of the population that is no longer living in a highly segregated area moved not into areas of significantly low segregation, but into areas with no significant clustering of any kind.

Table 7a: Black Caribbean population in statistically significant Output Areas and change in population 2001-2011, Getis-Ord $G^{*}$

Source: Office of National Statistics, Contains National Statistics data

(C) Crown copyright and database right 2013

\begin{tabular}{|c|c|c|c|c|}
\hline & Hot Spot & $\begin{array}{c}\text { \% Group } \\
\text { Population }\end{array}$ & Cold Spot & $\begin{array}{c}\text { \% Group } \\
\text { Population }\end{array}$ \\
\hline $\mathbf{2 0 0 1}$ & 244,764 & 71.14 & 56,794 & 16.51 \\
\hline $\mathbf{2 0 1 1}$ & 223,900 & 64.84 & 66,374 & 19.22 \\
\hline Change & $-20,864$ & -6.30 & 9,580 & 2.71 \\
\hline
\end{tabular}

Table 7b: Black Caribbean population in statistically significant Output Areas and change in population 2001-2011, Anselin Local Moran's I

Source: Office of National Statistics, Contains National Statistics data

(C) Crown copyright and database right 2013

\begin{tabular}{|c|c|c|c|c|}
\hline & High Cluster & $\begin{array}{c}\text { \% Group } \\
\text { Population }\end{array}$ & Low Cluster & $\begin{array}{c}\text { \% Group } \\
\text { Population }\end{array}$ \\
\hline $\mathbf{2 0 0 1}$ & 218,197 & 63.41 & 26,504 & 7.70 \\
\hline $\mathbf{2 0 1 1}$ & 200,625 & 58.10 & 27,259 & 7.89 \\
\hline Change & $-17,572$ & -5.31 & 755 & 0.19 \\
\hline
\end{tabular}




\section{Changes in the South Asian Population}

Moving to the South Asian population, consisting of groups from India, Pakistan and Bangladesh, I once again started with calculating the Poulsen et al. typology for all three before continuing to the individual measures. This measure reveals the main hubs of South Asian population throughout the city with one in the western portions of the city and one in the northeastern area of the city. The areas of highest concentration seem to have grown significantly between 2001 and 2011, though it is impossible to discern from these maps which of the three population groups increased in concentration or if all three saw an increase (Figures 12a and 12b).

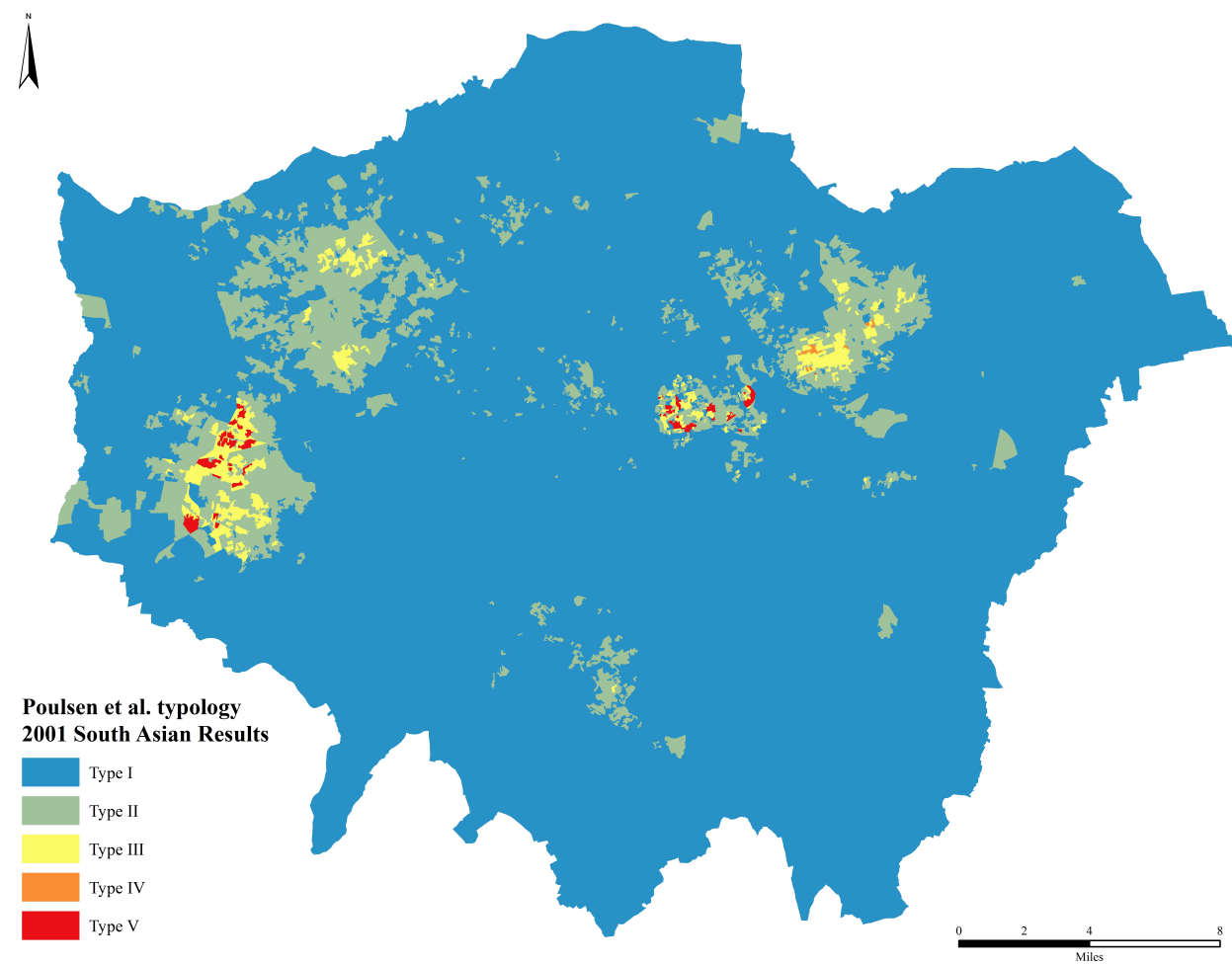

Figure 12a: Poulsen et al. typology Results for the South Asian Population, 2001

Source: Office of National Statistics, Contains National Statistics data (C) Crown copyright and database right 2013, Contains Ordnance Survey data (C) Crown copyright and database right 2013 


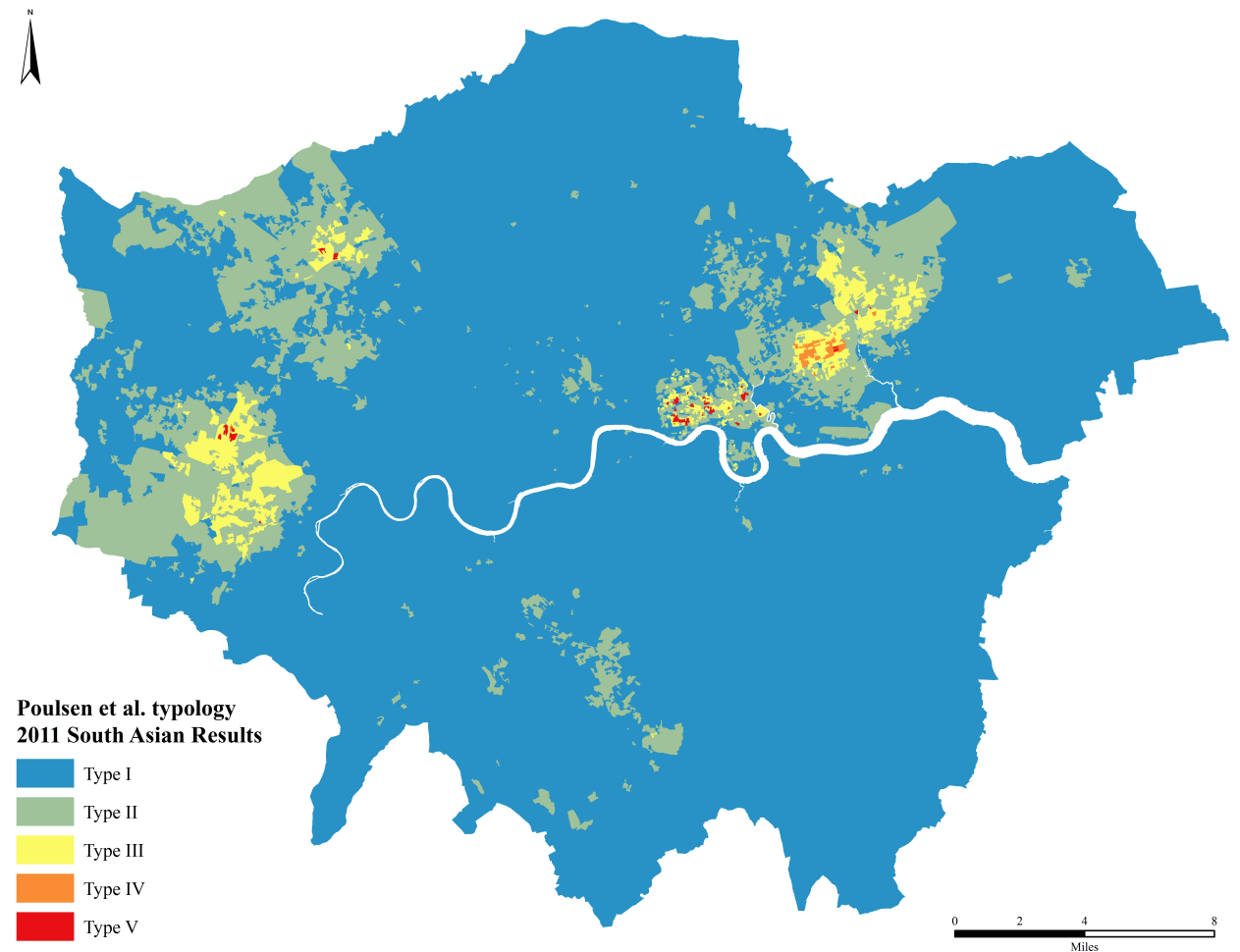

Figure 12b: Poulsen et al. typology Results for the South Asian Population, 2011

Source: Office of National Statistics, Contains National Statistics data $\odot$ Crown copyright and database right 2013, Contains Ordnance Survey data (C) Crown copyright and database right 2013

The first of the South Asian groups examined is the Indian population, which is the largest ethnic minority group in England. The Index of Dissimilarity results show the districts with the highest levels of segregation. The district of Hounslow has long been home to a large Indian population and is shown to be highly segregated in both 2001 and 2011 according to ID. The range of values actually increased over the study period, suggesting areas with increases and decreases in the overall level of segregation over time (Figures 13a and 13b). 


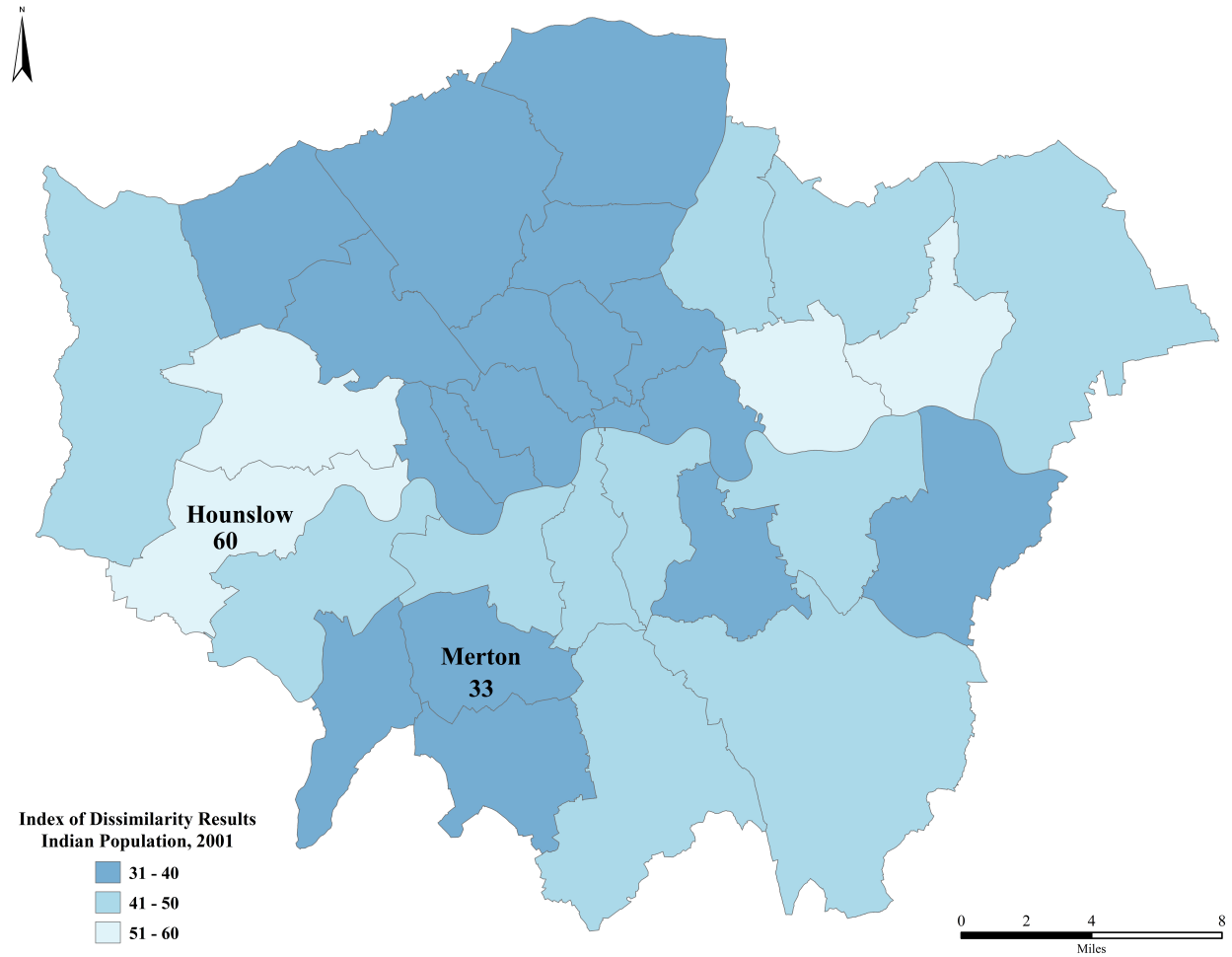

Figure 13a: Index of Dissimilarity Results for the Indian Population, 2001

Source: Office of National Statistics, Contains National Statistics data $\odot$ Crown copyright and database right 2013, Contains Ordnance Survey data (C) Crown copyright and database right 2013

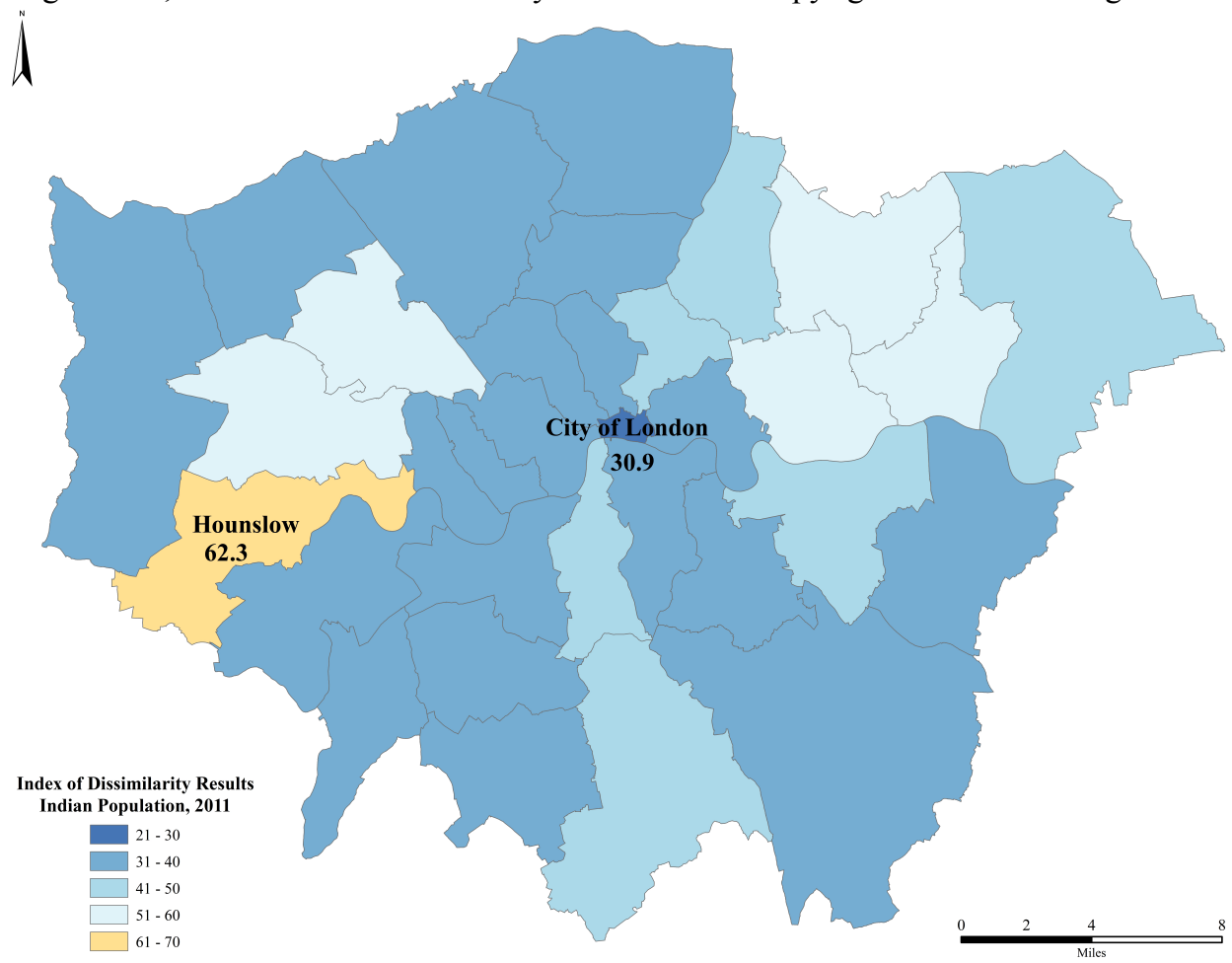

Figure 13b: Index of Dissimilarity Results for the Indian Population, 2011

Source: Office of National Statistics, Contains National Statistics data $($ Crown copyright and database right 2013, Contains Ordnance Survey data (C) Crown copyright and database right 2013 
The local statistic maps for the Indian population, an overall increase in the area of the city classified as highly segregated. There were shifts in some areas and the hot spot area in Barnet has separated from the larger hot spot area encompassing Brent, Ealing and Hounslow. The small hot spot that appeared in Greenwich in 2001 shrank considerably by 2011, while the large hot spot to the north of Greenwich grew over that time. Unlike the two Black groups, the Indian population did not see a significant change in the location and number of outlier areas throughout the city. Both High-Low and LowHigh outlier areas remained fairly consistent. One of the largest changes in the map result is seen in the growth of the biggest area of Indian population concentration in the western areas of the city even further west to the far edges of the London area in Hillingdon (Figures 14a and 14b).

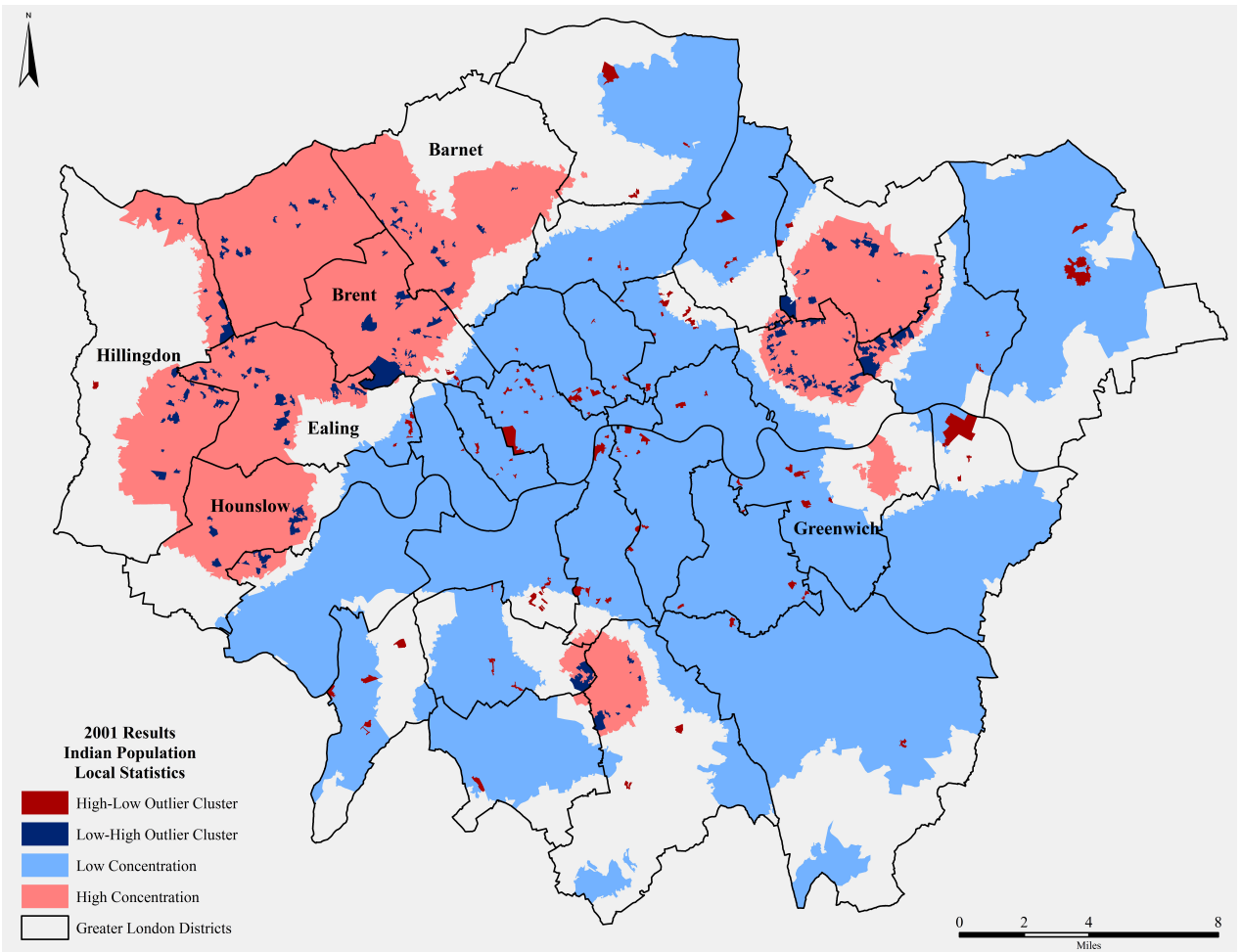

Figure 14a: Local Statistics Results for the Indian Population, 2001

Source: Office of National Statistics, Contains National Statistics data $($ Crown copyright and database right 2013, Contains Ordnance Survey data (C) Crown copyright and database right 2013 


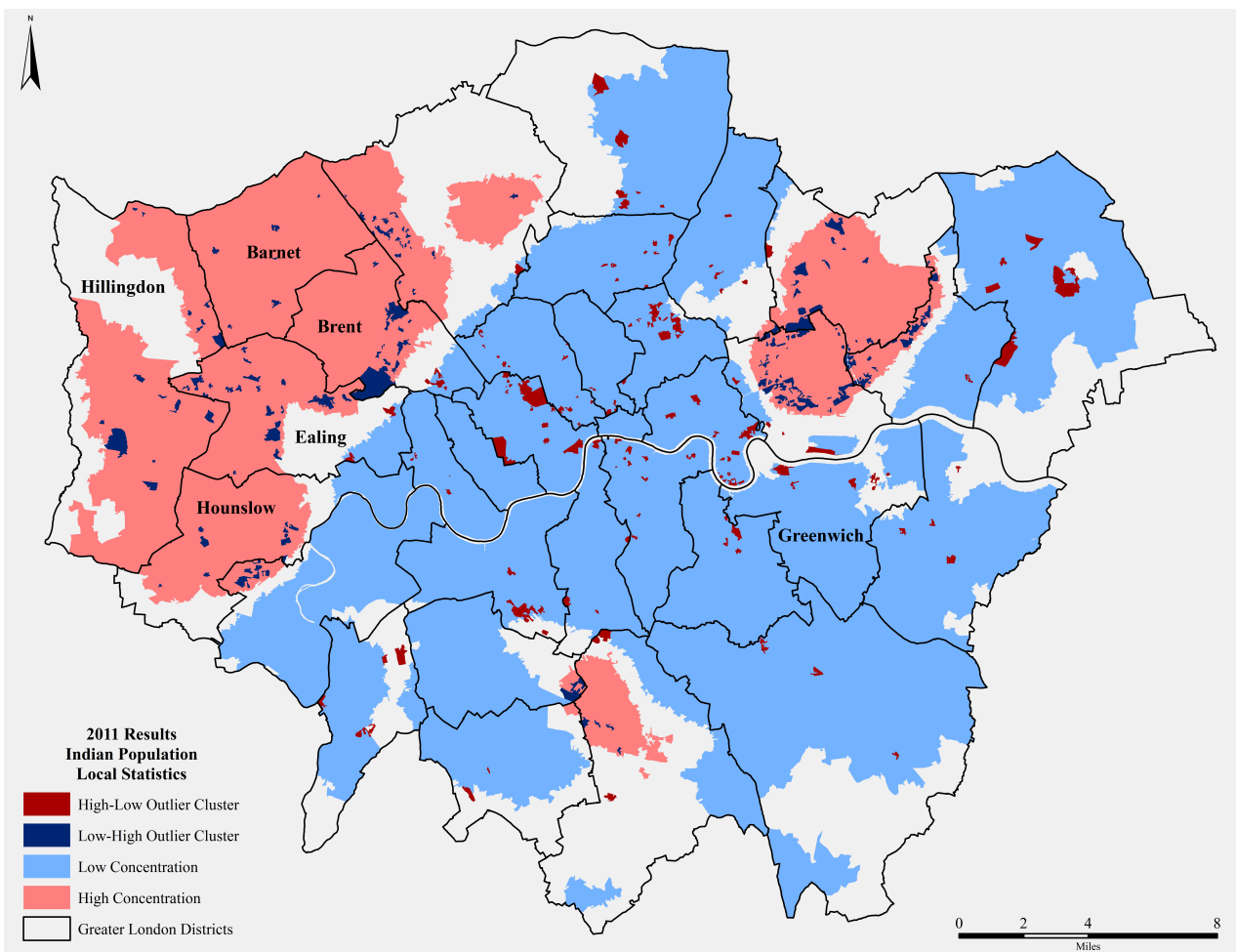

Figure 14b: Local Statistics Results for the Indian Population, 2011

Source: Office of National Statistics, Contains National Statistics data (C) Crown copyright and database right 2013, Contains Ordnance Survey data (C) Crown copyright and database right 2013

The tabular results for the Indian population show only slight changes in the level of segregation across the population between 2001 and 2011 (Tables 8a and 8b). While there is some discrepancy between the two statistics in terms of the portion of the Indian population living in a highly concentrated area, both statistics show an overall increase in the number of people living in areas of both high and low levels of concentration.

Regardless of the statistic, the Indian population did not see a significant change in distribution between 2001 and 2011. While there were shifts geographically in parts of the city, the overall level of segregation among the Indian community stayed relatively the same. 
Table 8a: Indian population in statistically significant Output Areas and change in population 2001-2011, Getis-Ord $G^{*}$

Source: Office of National Statistics, Contains National Statistics data

(C) Crown copyright and database right 2013

\begin{tabular}{|c|c|c|c|c|}
\hline & Hot Spot & $\begin{array}{c}\text { \% Group } \\
\text { Population }\end{array}$ & Cold Spot & $\begin{array}{c}\text { \% Group } \\
\text { Population }\end{array}$ \\
\hline $\mathbf{2 0 0 1}$ & 281,881 & 64.17 & 89,056 & 20.27 \\
\hline $\mathbf{2 0 1 1}$ & 349,252 & 63.89 & 125,190 & 22.90 \\
\hline Change & 67,371 & -0.28 & 36,134 & 2.63 \\
\hline
\end{tabular}

Table 8b: Indian population in statistically significant Output Areas and change in population 2001-2011, Anselin Local Moran's I

Source: Office of National Statistics, Contains National Statistics data

(C) Crown copyright and database right 2013

\begin{tabular}{|c|c|c|c|c|}
\hline & High Cluster & $\begin{array}{c}\text { \% Group } \\
\text { Population }\end{array}$ & Low Cluster & $\begin{array}{c}\text { \% Group } \\
\text { Population }\end{array}$ \\
\hline $\mathbf{2 0 0 1}$ & 258,901 & 58.94 & 25,390 & 5.78 \\
\hline $\mathbf{2 0 1 1}$ & 323,283 & 59.14 & 38,876 & 7.11 \\
\hline Change & 64,382 & 0.20 & 13,486 & 1.33 \\
\hline
\end{tabular}

The initial settlement patterns of the Pakistani population were very similar to that of their Indian counterparts. However, the measures calculated for the group individual indicate that while the general areas of concentration are similar to the Indian population, the intensity of concentration is higher for the Pakistani population. The range of values for ID show an overall decrease in the areas of highest segregation, but the low values did not differ greatly between census years (Figures 15a and 15b). 


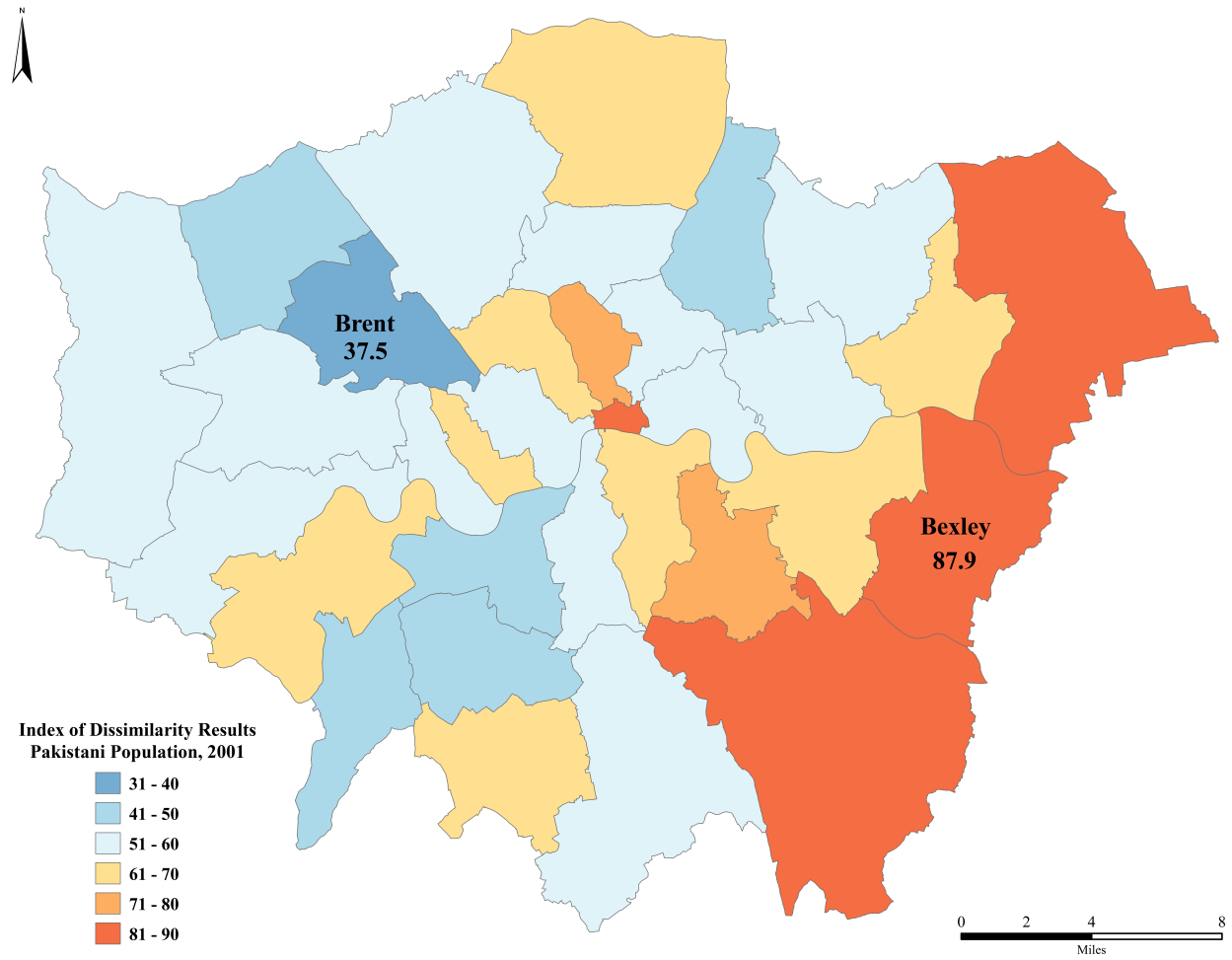

Figure 15a: Index of Dissimilarity Results for the Pakistani Population, 2001

Source: Office of National Statistics, Contains National Statistics data $\odot$ Crown copyright and database right 2013, Contains Ordnance Survey data C Crown copyright and database right 2013

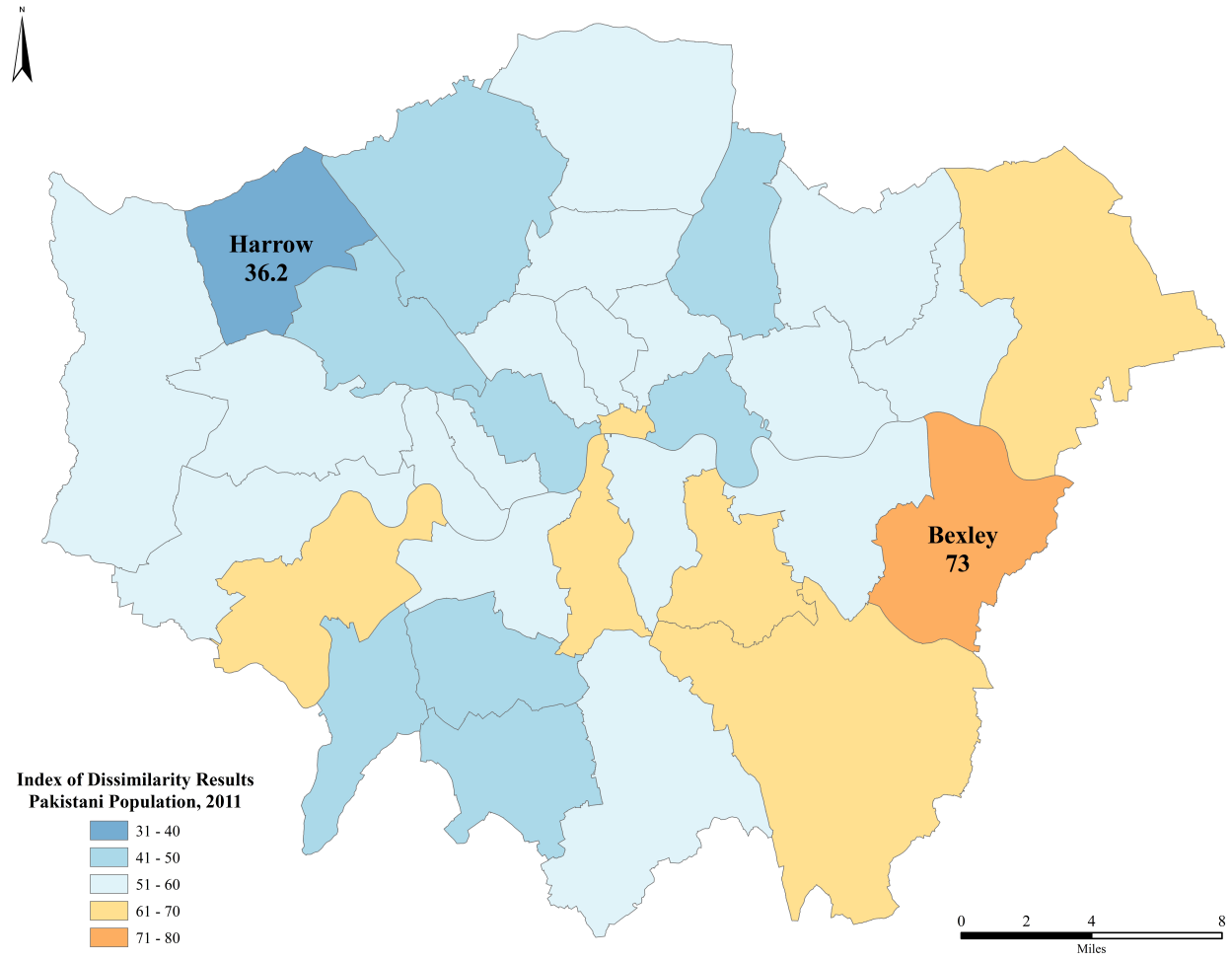

Figure 15b: Index of Dissimilarity Results for the Pakistani Population, 2011

Source: Office of National Statistics, Contains National Statistics data $(\subset$ Crown copyright and database right 2013, Contains Ordnance Survey data (C) Crown copyright and database right 2013 
The local statistics once again provide more detail as to how the Pakistani population is distributed across London and where it is most highly concentrated. Visually the patterns of highest and lowest concentration did not change dramatically between 2001 and 2011. Much like the other groups, there were small shifts in previously established areas of high clustering and some areas seemed to grow in size. The most significant change in the cartographic result is the disappearance of the High-Low outlier in the western district of Hillingdon. The area appeared within a fairly large cold spot in 2001 but by 2011 much of that cold area was no longer statistically significant and the HL outlier was no longer classified as such (Figures 16a and 16b).

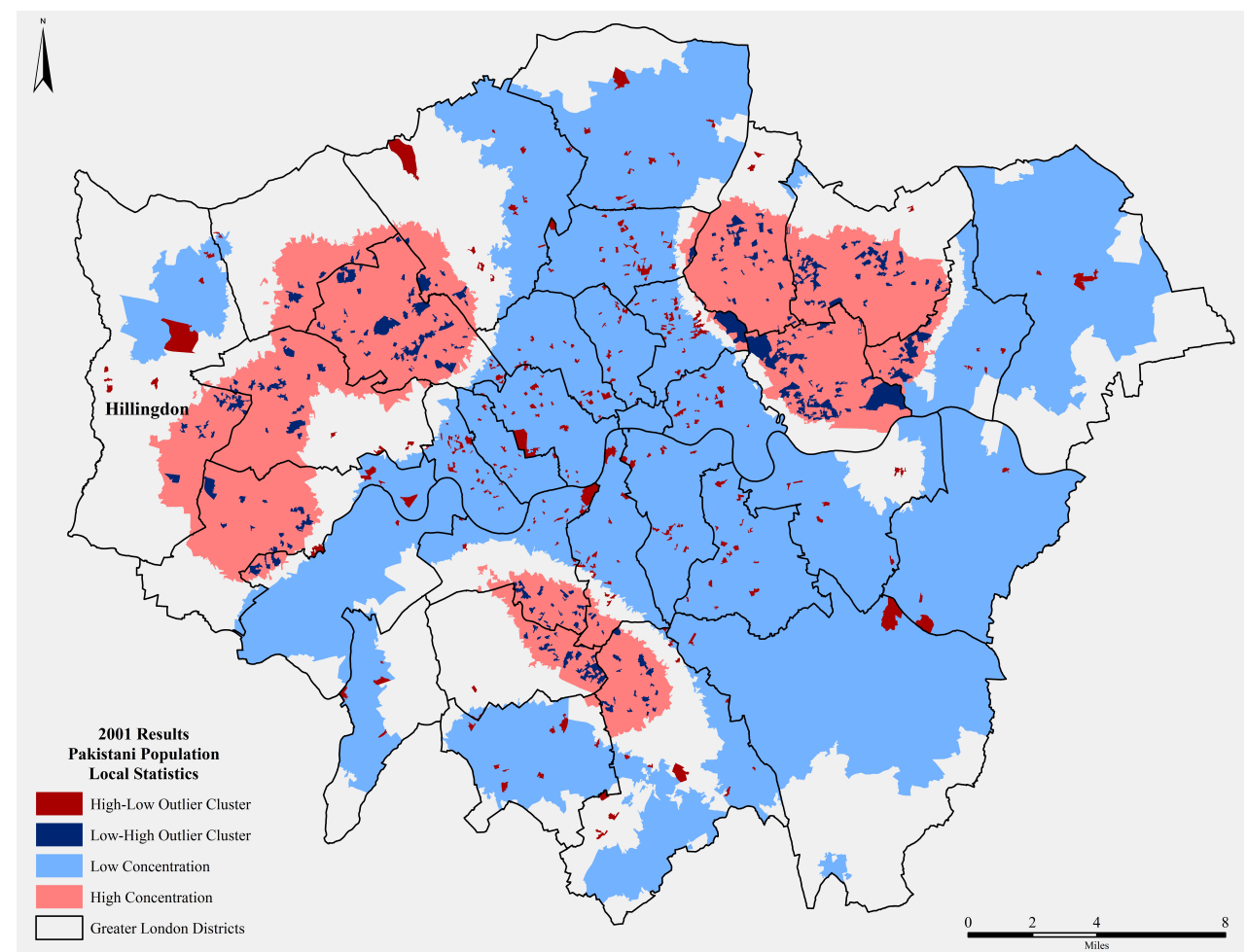

Figure 16a: Local Statistics Results for the Pakistani Population, 2001

Source: Office of National Statistics, Contains National Statistics data $\mathbb{C}$ Crown copyright and database right 2013, Contains Ordnance Survey data (C) Crown copyright and database right 2013 


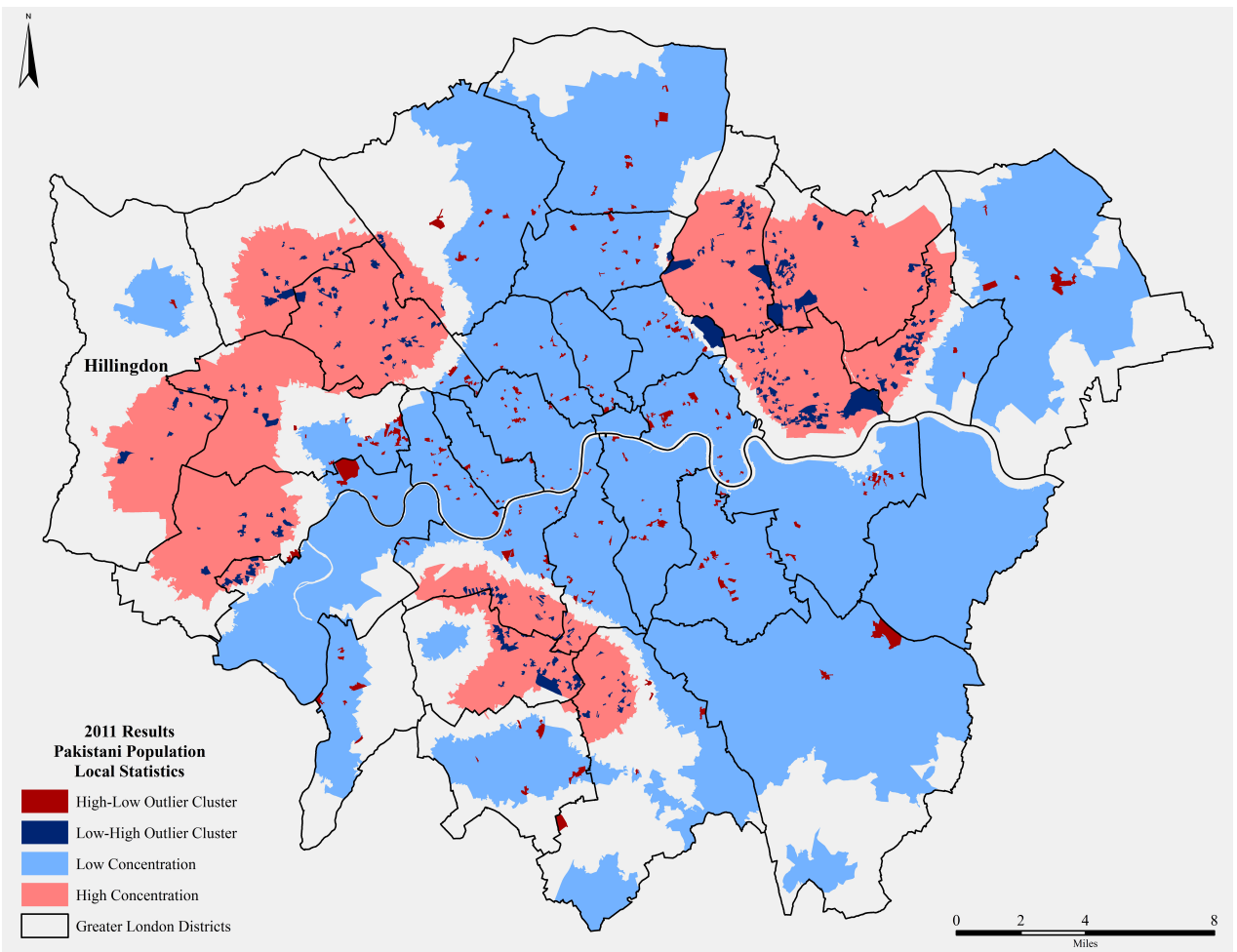

Figure 16b: Local Statistics Results for the Pakistani Population, 2011

Source: Office of National Statistics, Contains National Statistics data $($ Crown copyright and database right 2013, Contains Ordnance Survey data C Crown copyright and database right 2013

The tabular results for the Pakistani population shows an overall increase in both the number of people in the community living in areas of high concentration as well as the proportion of the group's total London Population. The statistics agree on all measures except the percentage of the Pakistani population living in cold spots. While according to $I$ there was an approximately 3 percent increase in the portion of the population living in low value clusters, $G^{*}$ shows a 1.19 percent decrease in the portion of the population living in a cold spot. For the purposes of this study, it is more important that both measures show an overall increase in the level of segregation within the Pakistani population from 2001 to 2011 (Tables 9a and 9b). 
Table 9a: Pakistani population in statistically significant Output Areas and change in population 2001-2011, Getis-Ord $G^{*}$

Source: Office of National Statistics, Contains National Statistics data

(c) Crown copyright and database right 2013

\begin{tabular}{|c|c|c|c|c|}
\hline & Hot Spot & $\begin{array}{c}\text { \% Group } \\
\text { Population }\end{array}$ & Cold Spot & $\begin{array}{c}\text { \% Group } \\
\text { Population }\end{array}$ \\
\hline $\mathbf{2 0 0 1}$ & 94,764 & 66.21 & 25,884 & 18.08 \\
\hline $\mathbf{2 0 1 1}$ & 159,679 & 71.08 & 37,948 & 16.89 \\
\hline Change & 64,915 & 4.87 & 12,064 & -1.19 \\
\hline
\end{tabular}

Table 9b: Pakistani population in statistically significant Output Areas and change in population 2001-2011, Anselin Local Moran's I

Source: Office of National Statistics, Contains National Statistics data

(C) Crown copyright and database right 2013

\begin{tabular}{|c|c|c|c|c|}
\hline & High Cluster & $\begin{array}{c}\text { \% Group } \\
\text { Population }\end{array}$ & $\begin{array}{c}\text { Low } \\
\text { Cluster }\end{array}$ & $\begin{array}{c}\text { \% Group } \\
\text { Population }\end{array}$ \\
\hline $\mathbf{2 0 0 1}$ & 87,733 & 61.30 & 144 & 0.10 \\
\hline $\mathbf{2 0 1 1}$ & 146,487 & 65.21 & 7,236 & 3.22 \\
\hline Change & 58,754 & 3.91 & 7,092 & 3.12 \\
\hline
\end{tabular}

The final ethnic minority group considered for this study is the Bangladeshi population. Of all the groups examined, the Bangladeshi population is by far the most concentrated. As previously discussed, over half of the Bangladeshi population in all of England lives in London and over a third lives in the Tower Hamlets district alone. Due to the intensive nature of the clustering seen in the Bangladeshi population, even a broad measure like the Index of Dissimilarity reveals the areas of highest concentration. The example of the Bangladeshi population also reveals one of the weaknesses of displaying ID cartographically (Figures 17a and 17b). Due to the fact that the range of values for the Bangladeshi population begins with 44.1 in 2001 and 41.2 in 2011, a map showing the results would seem to imply that those areas with the lowest classification have low values of segregation when in fact even in the least segregated districts in the city almost half of the Bangladeshi or British/White population would need to be moved in order to create an even distribution across space. 


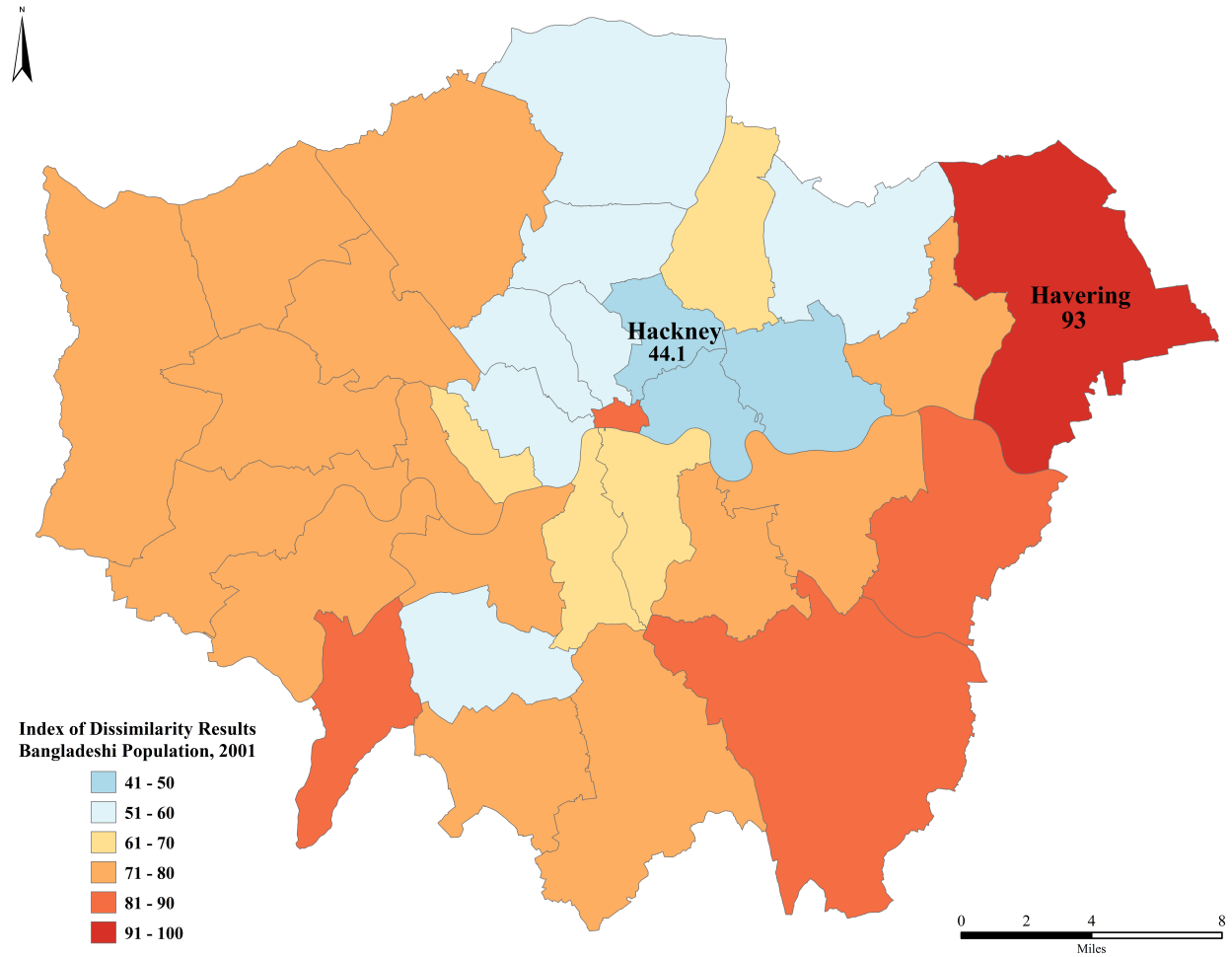

Figure 17a: Index of Dissimilarity Results for the Bangladeshi Population, 2001

Source: Office of National Statistics, Contains National Statistics data (C) Crown copyright and database right 2013, Contains Ordnance Survey data C Crown copyright and database right 2013

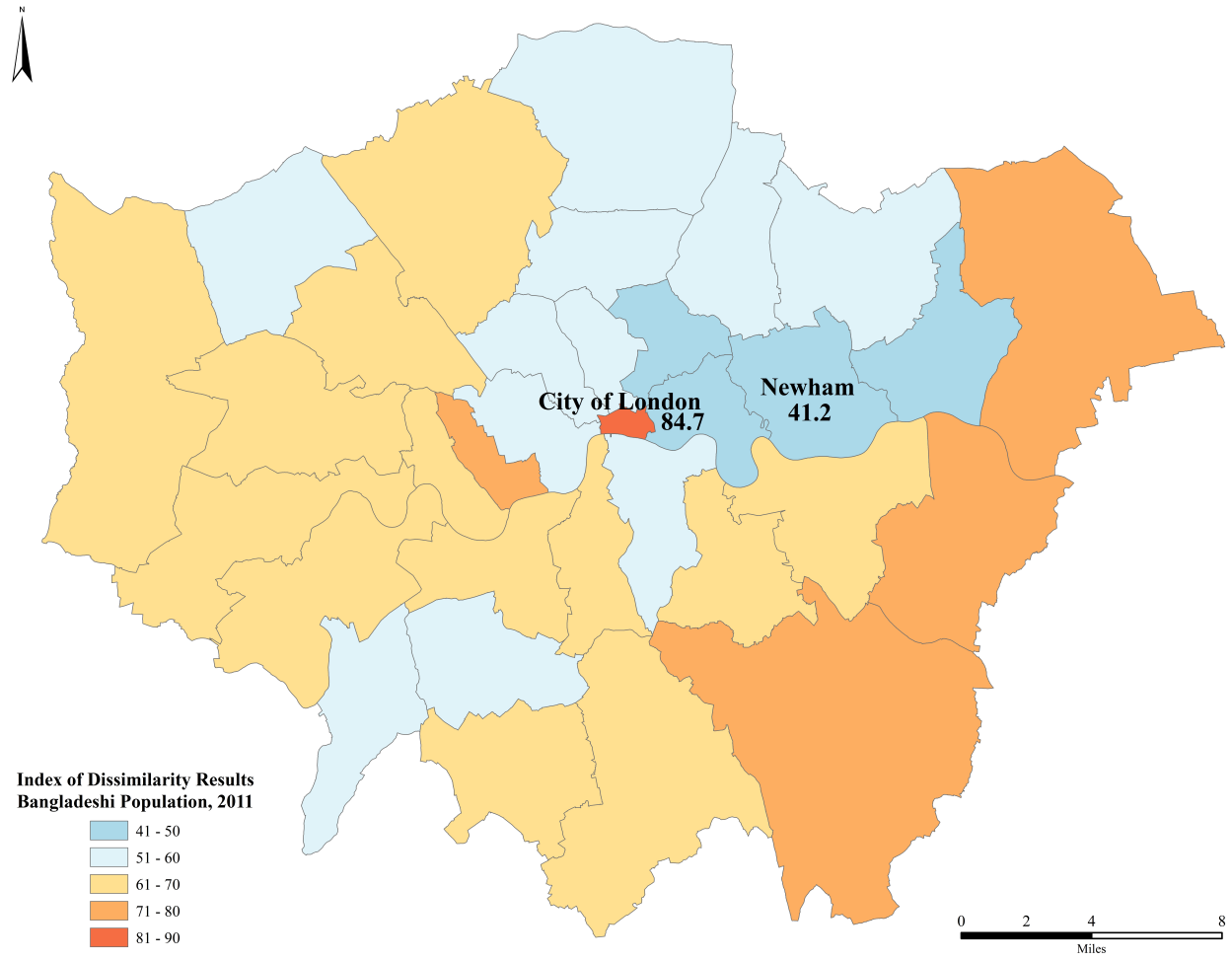

Figure 17b: Index of Dissimilarity Results for the Bangladeshi Population, 2011

Source: Office of National Statistics, Contains National Statistics data $(\subset$ Crown copyright and database right 2013, Contains Ordnance Survey data (C) Crown copyright and database right 2013 
The local statistic results for the Bangladeshi population show in much starker detail the level of concentration of the group in the city. There was a general increase in the overall concentration within the Bangladeshi population between 2001 and 2011 (Figures 18a and 18b). Due to the condensed nature of the population distribution, it is easier to see how the population shifted and where areas of highest concentration grew or moved. One of the more interesting revelations of the local statistic results is the group of Low-High clusters in the center of the large Bangladeshi hot spot, which coincide with the central portions of the city. Perhaps more significant than the areas of high concentration was the increase in the density and coverage of areas with statistically low concentrations of Bangladeshi residents surrounding the large hot spot.

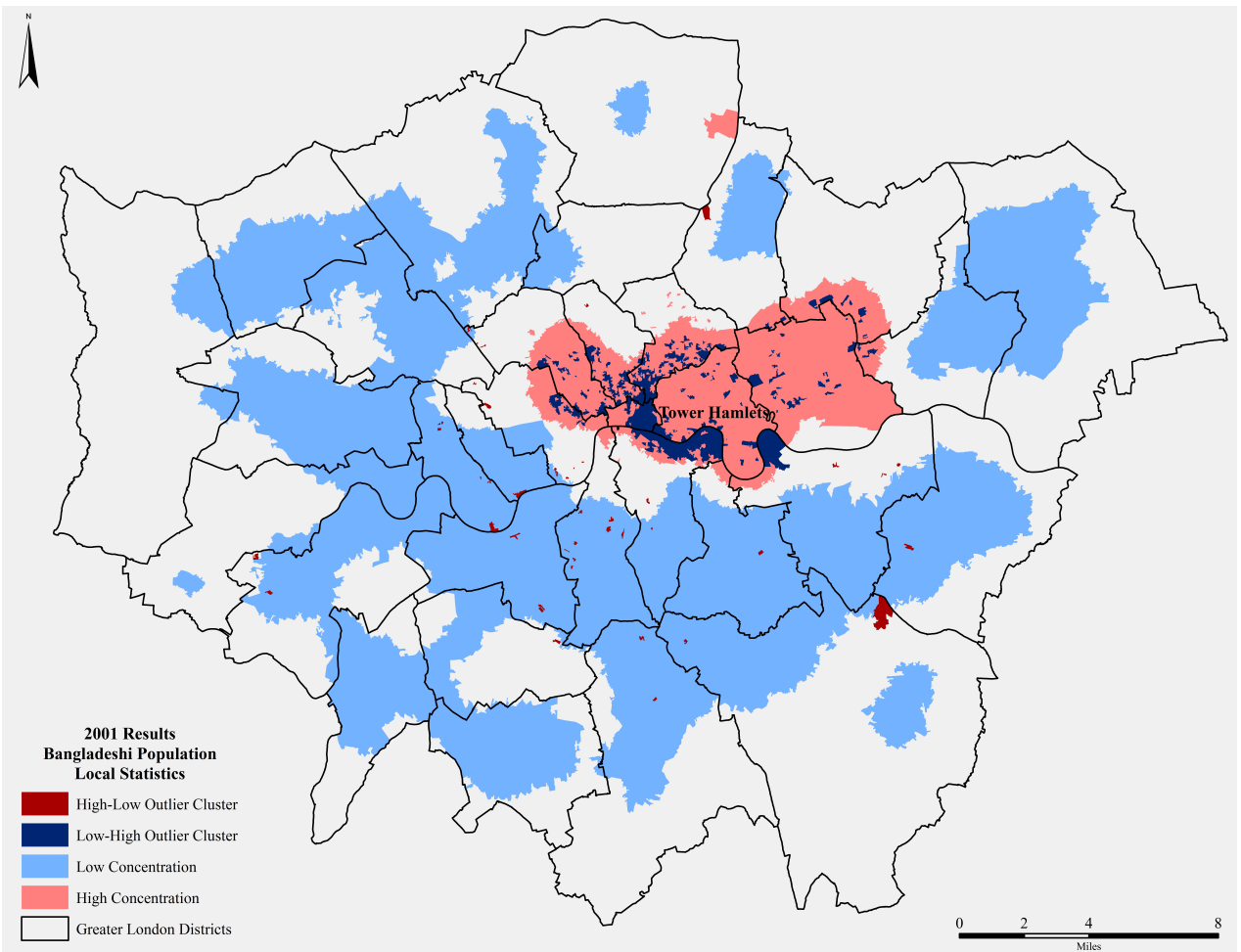

Figure 18a: Local Statistics Results for the Bangladeshi Population, 2001

Source: Office of National Statistics, Contains National Statistics data (C) Crown copyright and database right 2013, Contains Ordnance Survey data @ Crown copyright and database right 2013 


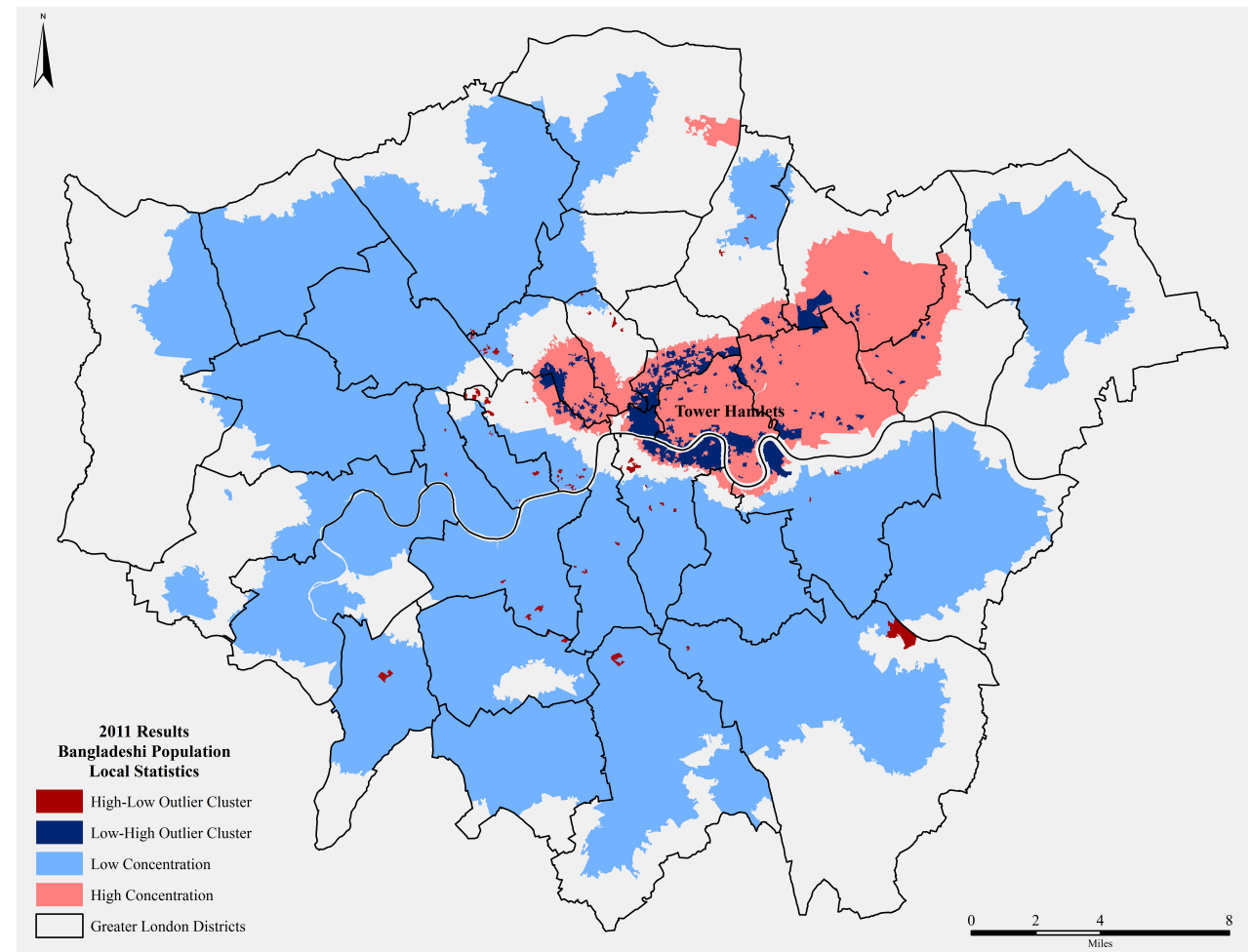

Figure 18b: Local Statistics Results for the Bangladeshi Population, 2011

Source: Office of National Statistics, Contains National Statistics data $($ Crown copyright and database right 2013, Contains Ordnance Survey data (C) Crown copyright and database right 2013

The tables for the Bangladeshi population confirm that there are more Bangladeshis living in areas of low concentration. There was also an increase in the number and percentage of the group living in highly concentrated areas, but the population change in high areas was not as significant proportionally as the population change in low areas. Interestingly, there were no Bangladeshi residents classified as living in Low-Low clusters in 2001 and only 35 in 2011 whereas there were approximately fourteen thousand and thirty thousand living in cold spots in that time frame (Tables 10a and 10b). 
Table 10a: Bangladeshi population in statistically significant Output Areas and change in population 2001-2011, Getis-Ord $G^{*}$

Source: Office of National Statistics, Contains National Statistics data

(C) Crown copyright and database right 2013

\begin{tabular}{|c|c|c|c|c|}
\hline & Hot Spot & \% Group Population & Cold Spot & \% Group Population \\
\hline $\mathbf{2 0 0 1}$ & 106,509 & 69.20 & 14,097 & 9.16 \\
\hline $\mathbf{2 0 1 1}$ & 155,015 & 69.71 & 30,325 & 13.64 \\
\hline Change & 48,506 & 0.51 & 16,228 & 4.48 \\
\hline
\end{tabular}

Table 10b: Bangladeshi population in statistically significant Output Areas and change in population 2001-2011, Anselin Local Moran's I

Source: Office of National Statistics, Contains National Statistics data

(C) Crown copyright and database right 2013

\begin{tabular}{|c|c|c|c|c|}
\hline & High Cluster & \% Group Population & $\begin{array}{c}\text { Low } \\
\text { Cluster }\end{array}$ & \% Group Population \\
\hline $\mathbf{2 0 0 1}$ & 101,998 & 66.27 & 0 & 0.00 \\
\hline $\mathbf{2 0 1 1}$ & 149,258 & 67.12 & 35 & 0.02 \\
\hline Change & 47,260 & 0.85 & 35 & 0.02 \\
\hline
\end{tabular}

Taking all of the ethnic minority groups considered in the study together, there was an overall increase in the proportion of the ethnic minority population living in highly segregated areas throughout London between 2001 and 2011. Only two of the groups saw a decrease in segregation: the Black African and Black Caribbean populations both saw a decrease in the portion of their total population living in highly segregated areas.

In an effort to gain a more comprehensive understanding of how areas of concentration, clustering and evenness shifted over the study period, the results for all five ethnic minority groups were combined. First are the combined results for the Poulsen et al. typology (Figures 19a and 19b). According to these two maps, the portion of the city with high levels of ethnic minority segregation grew between 2001 and 2011 while the areas of highest segregation stayed relatively stable. 


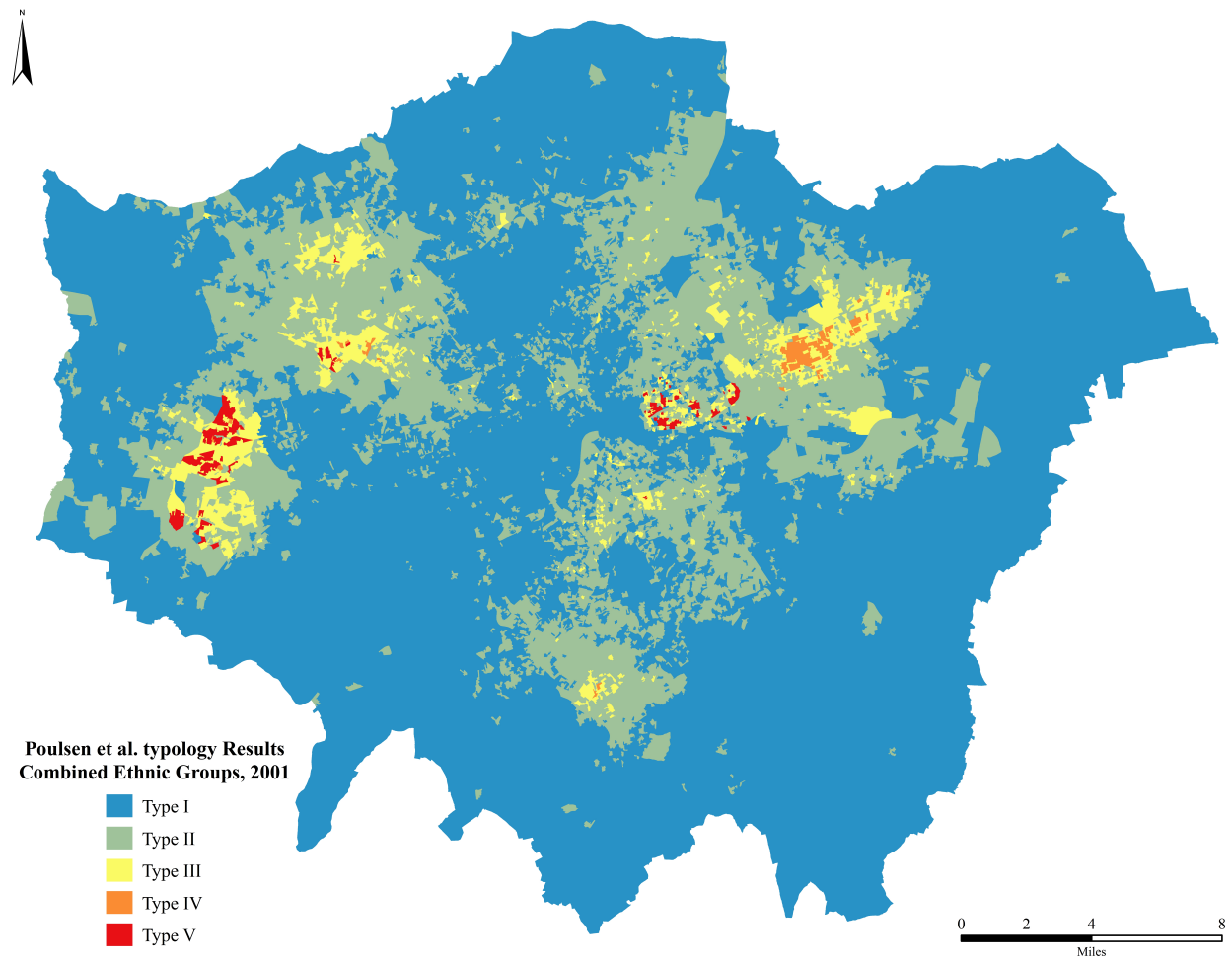

Figure 19a: Combined Poulsen et al. typology results, 2001

Source: Office of National Statistics, Contains National Statistics data $($ Crown copyright and database right 2013, Contains Ordnance Survey data (C) Crown copyright and database right 2013

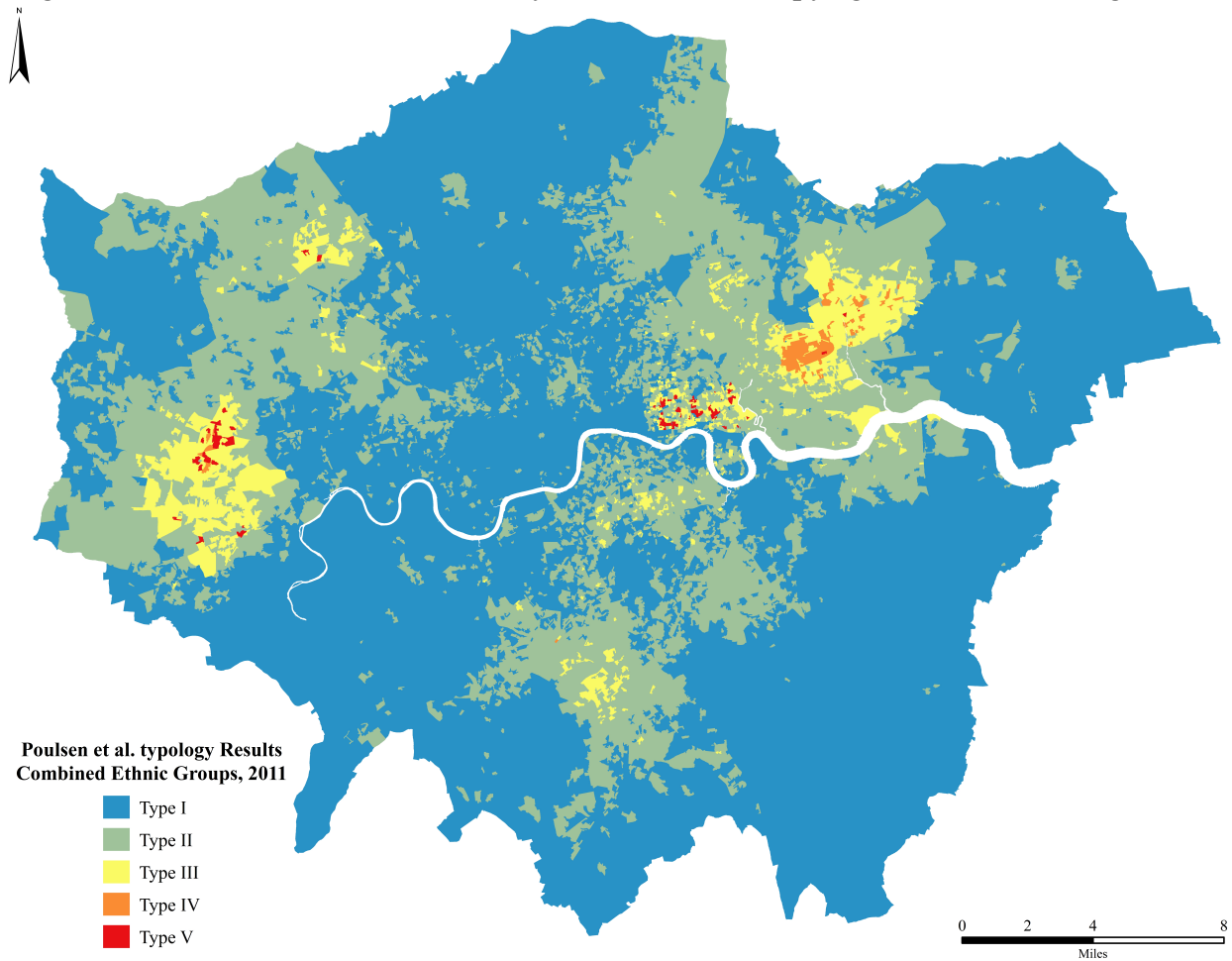

Figure 19b: Combined Poulsen et al. typology results, 2011

Source: Office of National Statistics, Contains National Statistics data (C Crown copyright and database right 2013, Contains Ordnance Survey data (C) Crown copyright and database right 2013 
The maps combining the areas of high concentration for the minority groups analyzed show an overall spreading out of the areas of highest concentration throughout the city. In 2001, these areas overlap to a considerable degree, but in 2011 , the individual ethnic groups can be seen more clearly, indicating something of a separation between the areas of high concentration amongst the minority groups being studied (Figures 20a and 20b).

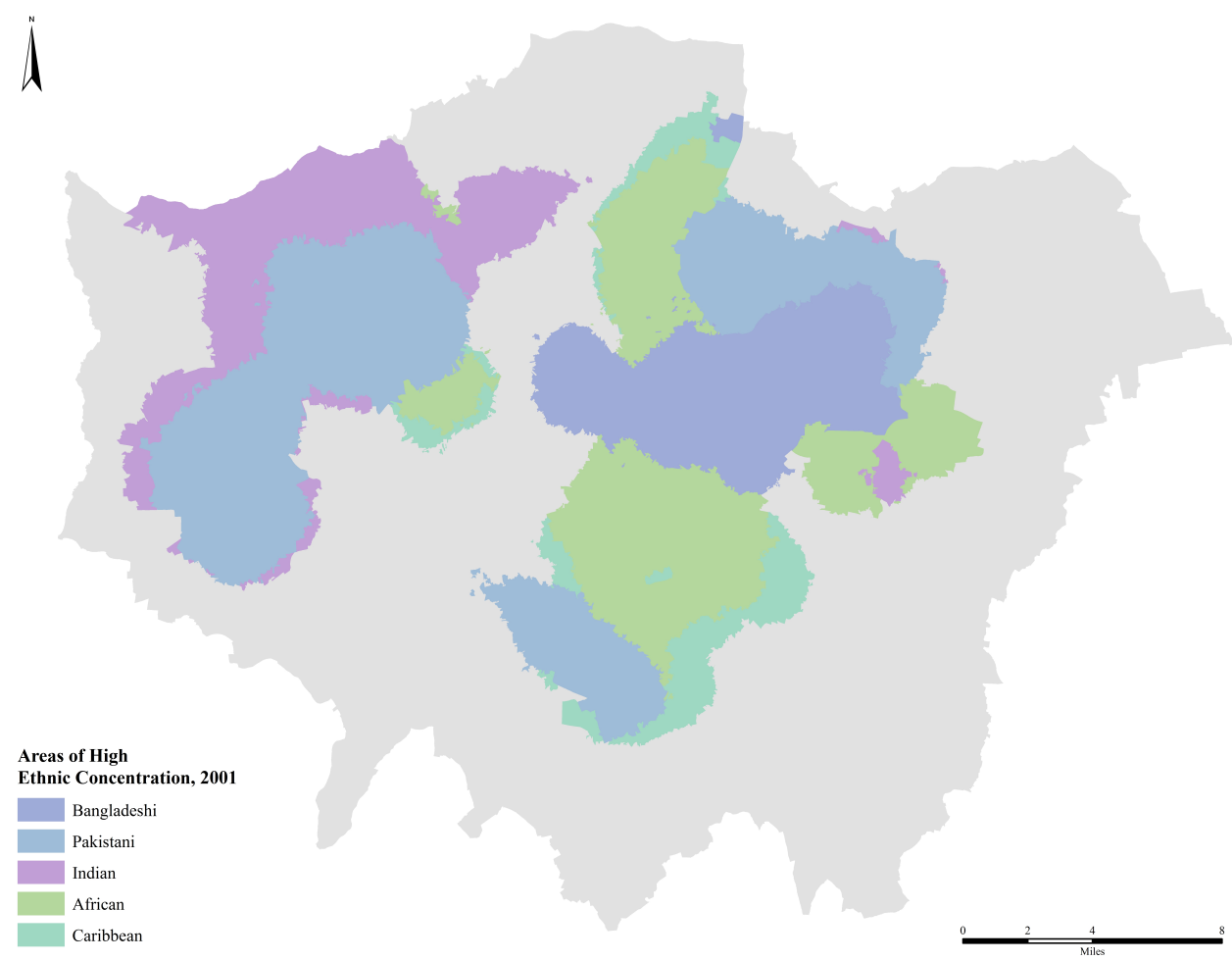

Figure 20a: Areas of high ethnic minority concentration, 2001

Source: Office of National Statistics, Contains National Statistics data $\odot$ Crown copyright and database right 2013, Contains Ordnance Survey data $@$ C Crown copyright and database right 2013 


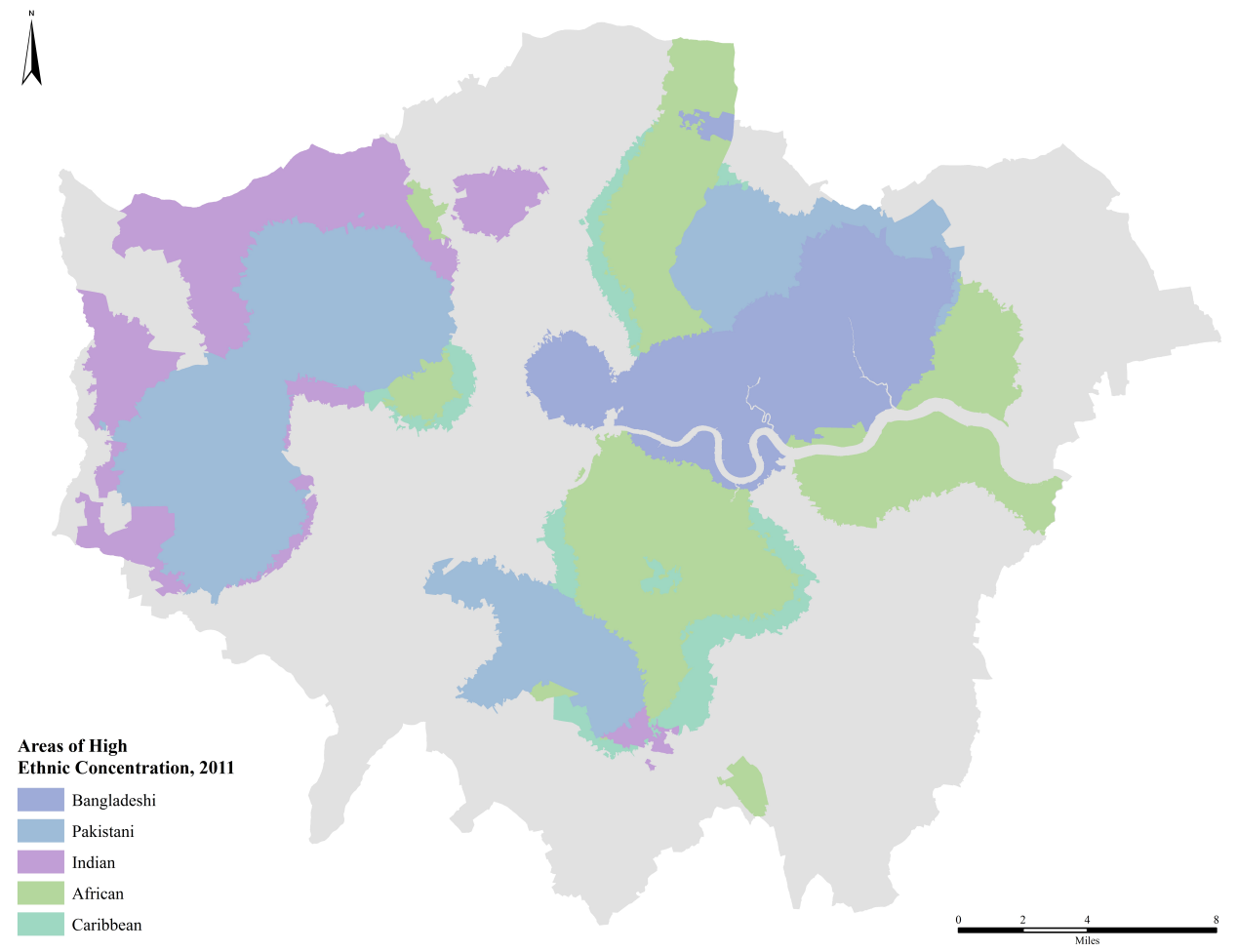

Figure 20b: All areas of high ethnic minority concentration, 2011

Source: Office of National Statistics, Contains National Statistics data $(C$ Crown copyright and database right 2013, Contains Ordnance Survey data (C) Crown copyright and database right 2013

Finally, for a quantitative understanding of how groups shifted in and out of areas or low concentration, the proportion of each groups population living in an area of high or low concentration for each census was calculated and then the difference between both years was found (Tables 11a and 11b). These tables show that the White/British and Pakistani populations saw a decrease in the portion of its population living in areas of low concentration and the Black African and Black Caribbean populations were the only groups to see a decrease in the portion of their populations living in areas of high concentration. 
Table 11a: Percent of group population living in areas of high or low concentration Source: Office of National Statistics, Contains National Statistics data

(C) Crown copyright and database right 2013

\begin{tabular}{|l|r|r|r|r|}
\hline & High 2001 & High 2011 & Low 2001 & Low 2011 \\
\hline White/British & 54.36 & 56.75 & 40.19 & 36.79 \\
\hline Indian & 66.25 & 66.69 & 20.77 & 23.38 \\
\hline Pakistani & 70.73 & 74.00 & 18.49 & 17.36 \\
\hline Bangladeshi & 71.02 & 71.89 & 9.34 & 14.00 \\
\hline African & 70.57 & 70.34 & 18.31 & 24.82 \\
\hline Caribbean & 73.91 & 69.32 & 18.22 & 20.98 \\
\hline
\end{tabular}

Table 11b: Change in percentage of group living in areas of high or low concentration Source: Office of National Statistics, Contains National Statistics data

\begin{tabular}{|l|r|r|}
\hline & High Difference & Low Difference \\
\hline White/British & 2.39 & -3.40 \\
\hline Indian & 0.44 & 2.61 \\
\hline Pakistani & 3.27 & -1.13 \\
\hline Bangladeshi & 0.87 & 4.66 \\
\hline African & -0.23 & 6.51 \\
\hline Caribbean & -4.59 & 2.76 \\
\hline
\end{tabular}

\section{Comparing methods of measurement}

One of the aims of this research was to use GIS to compare the cartographic result of different measures of segregation. Maps are powerful tools for conveying information. Changing the method of measurement can drastically change the result and thus create an entirely different map, leading to contradictory interpretations of the same data. In order to provide a consistent comparison across all four measurements, the 2011 data for the Black African population was used in all comparisons. 
The first two methods compared are the Index of Dissimilarity and the Poulsen et al. typology. Any comparisons with ID in this case are problematic in the sense that while three of the four measures used in the study were done at the small Output Area scale, ID was calculated by district. However, it is possible to see just how much variation across space is hidden by the index. In the interest of readability, the comparison between the Poulsen et al. typology and the Index of Dissimilarity does not include those areas classified by the typology as Type I, or areas where the majority group dominates. It is difficult to discern with any amount of clarity the areas with the highest and lowest levels of segregation just by looking at these two measures (Figure 21). While the typology is more specific than the index, it is still calculated based on two different minority groups and thus cannot be used to look for changes in the segregation of a singular group, which is possible with the index as well as the two local statistics used here.

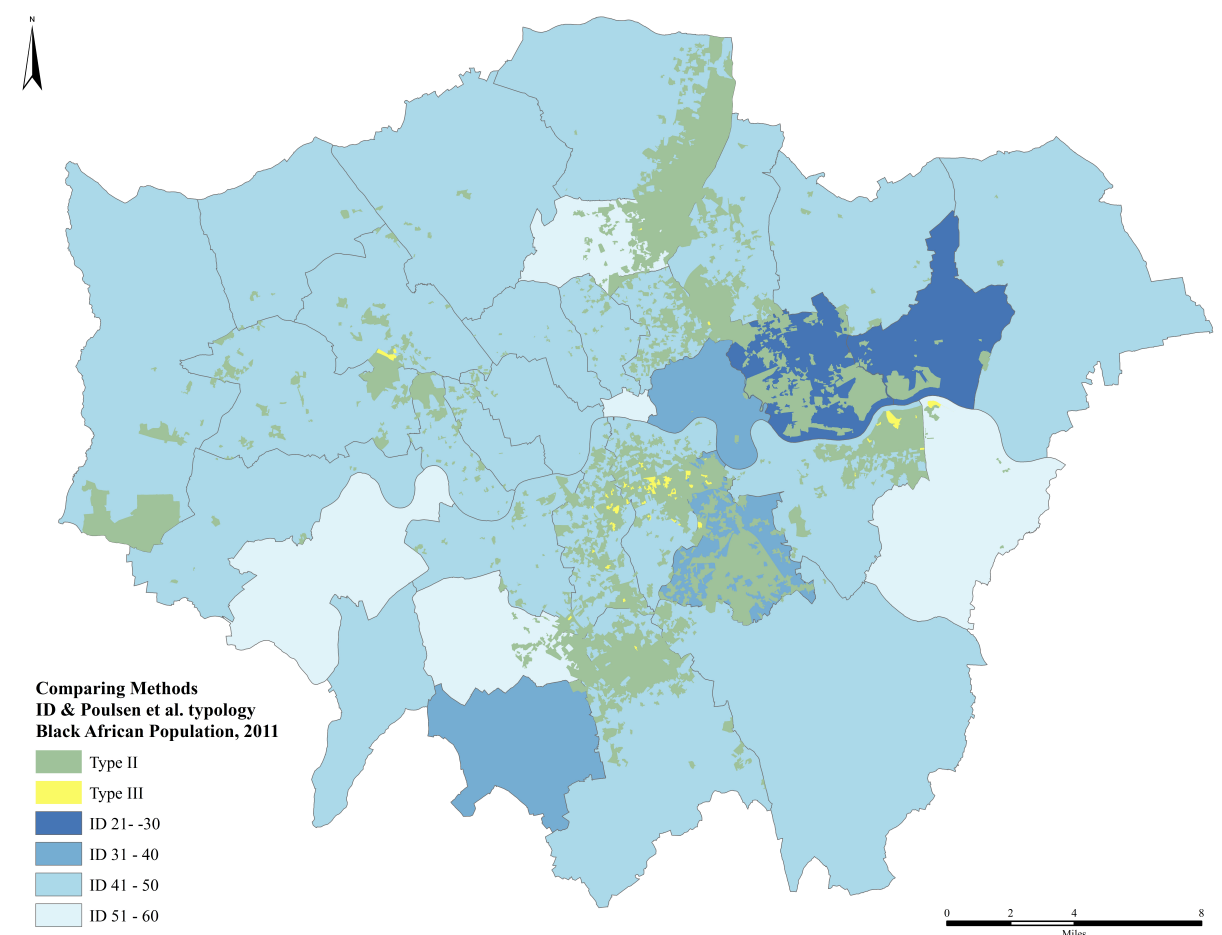

Figure 21: Comparing methods, Poulsen et al. typology \& Index of Dissimilarity Source: Office of National Statistics, Contains National Statistics data $(\mathcal{C}$ Crown copyright and database right 2013, Contains Ordnance Survey data (C) Crown copyright and database right 2013 
The next comparisons are between the hot and cold spots highlighted by GetisOrd $G^{*}$ and the High-High or Low-Low areas according to Anselin Local Moran's $I$ and the values for the Index of Dissimilarity. One of the many difficulties in interpreting maps using ID in any context is the fact the values cover a large range and do not account for the fact that there are no areas in the city with a perfectly even distribution of the minority and majority across space. In the case of London, all of the ethnic minorities are to some degree segregated across the city due to the fact that the British/White population is such an overwhelming majority. This means that even in districts with high populations of an ethnic minority group or groups, they are still not the in the majority. Thus, when trying to interpret results for the Index of Dissimilarity, one needs to look at degrees of segregation, not whether or not the area is in fact segregated. This contrast is seen clearly in the following maps showing areas of high and low concentration for each statistic overlaid on the results for ID (Figures 22 and 23). 


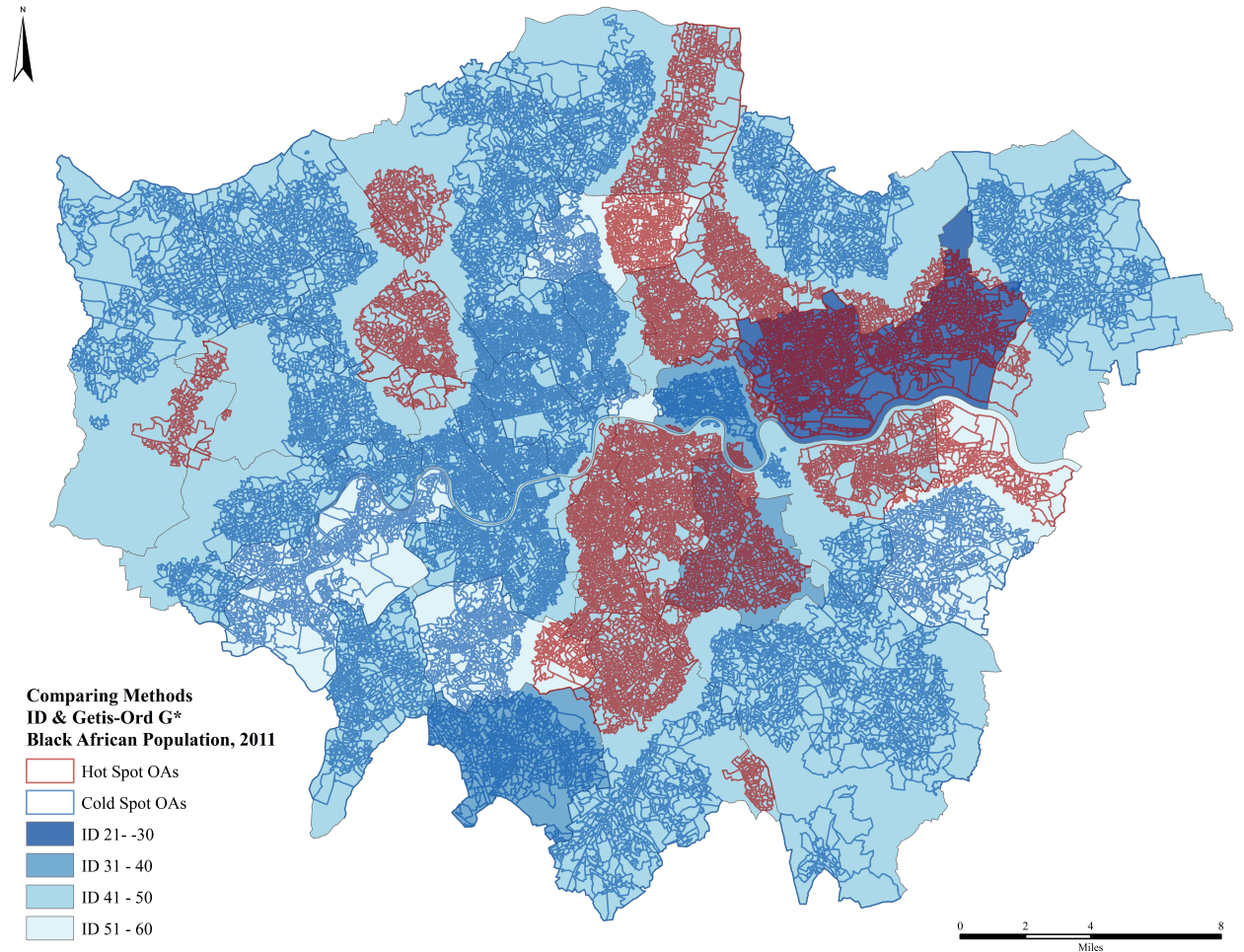

Figure 22: Comparing methods, Getis-Ord $G^{*} \&$ Index of Dissimilarity

Source: Office of National Statistics, Contains National Statistics data (C) Crown copyright and database right 2013, Contains Ordnance Survey data (C) Crown copyright and database right 2013

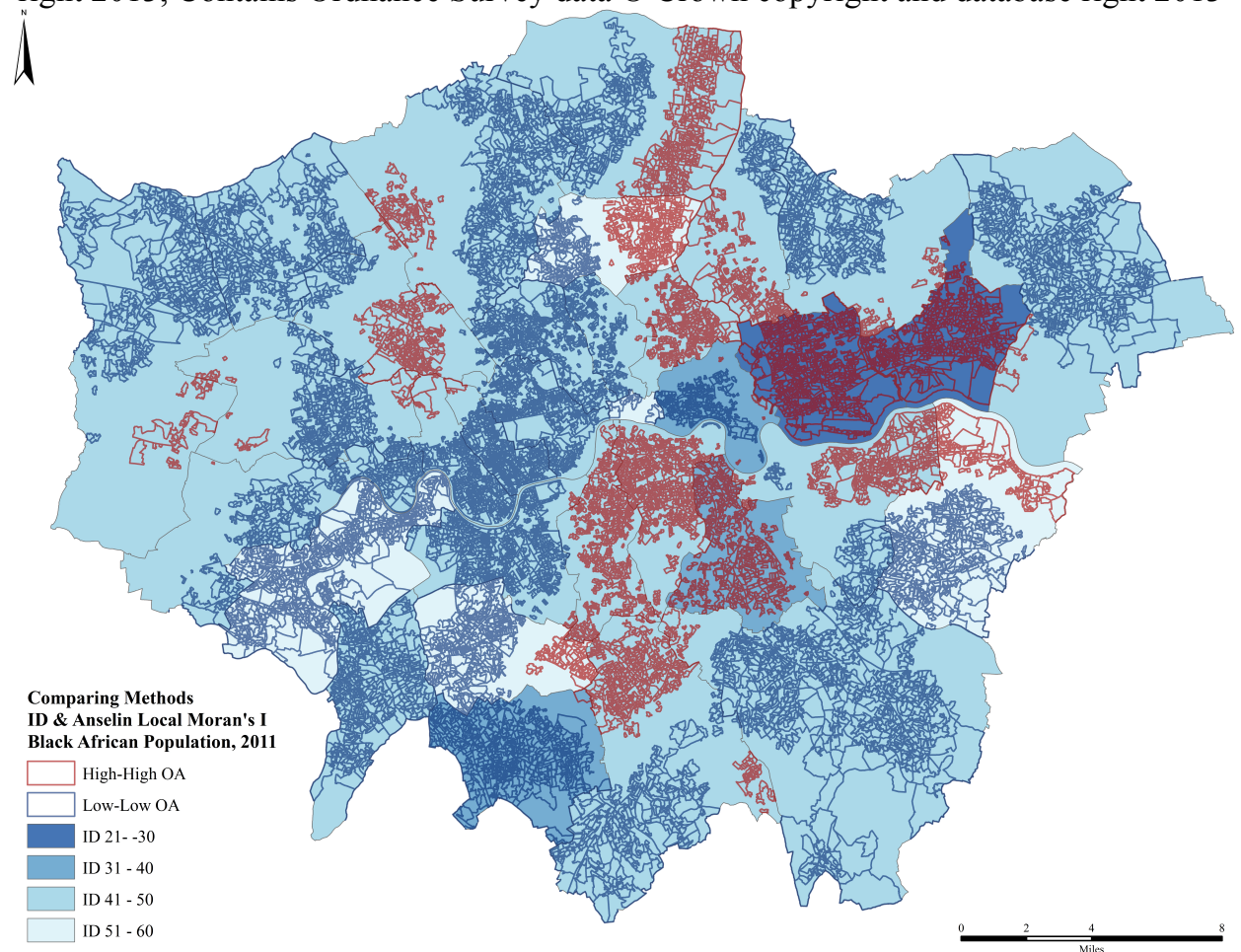

Figure 23: Comparing methods, Anselin Local Moran's I \& Index of Dissimilarity

Source: Office of National Statistics, Contains National Statistics data $\subset$ Crown copyright and database right 2013, Contains Ordnance Survey data (C) Crown copyright and database right 2013 
In both of the local statistic/ID maps, there are areas with low ID values classified as a hot or HH spot as well as areas with high ID values classified as a cold or LL spot. In some cases there are districts that are classified as both. This is a more detailed example of how the Index of Dissimilarity hides variation across space. Because it is a measure that must be performed across a large area, any differences within the individual districts are not seen, the same value is applied for the entire district.

The results comparing the Poulsen et al. typology and Anselin Local Moran's I match fairly well, with the areas classified as having significant minority populations matching with some consistency with the High-High areas as classified by I (Figure 24). The problem is the lack of distinction between the two minority groups used for the typology classification. There may be areas where the Black Caribbean population is greater than the Black African population, but those differences are not discernable in the measure. 


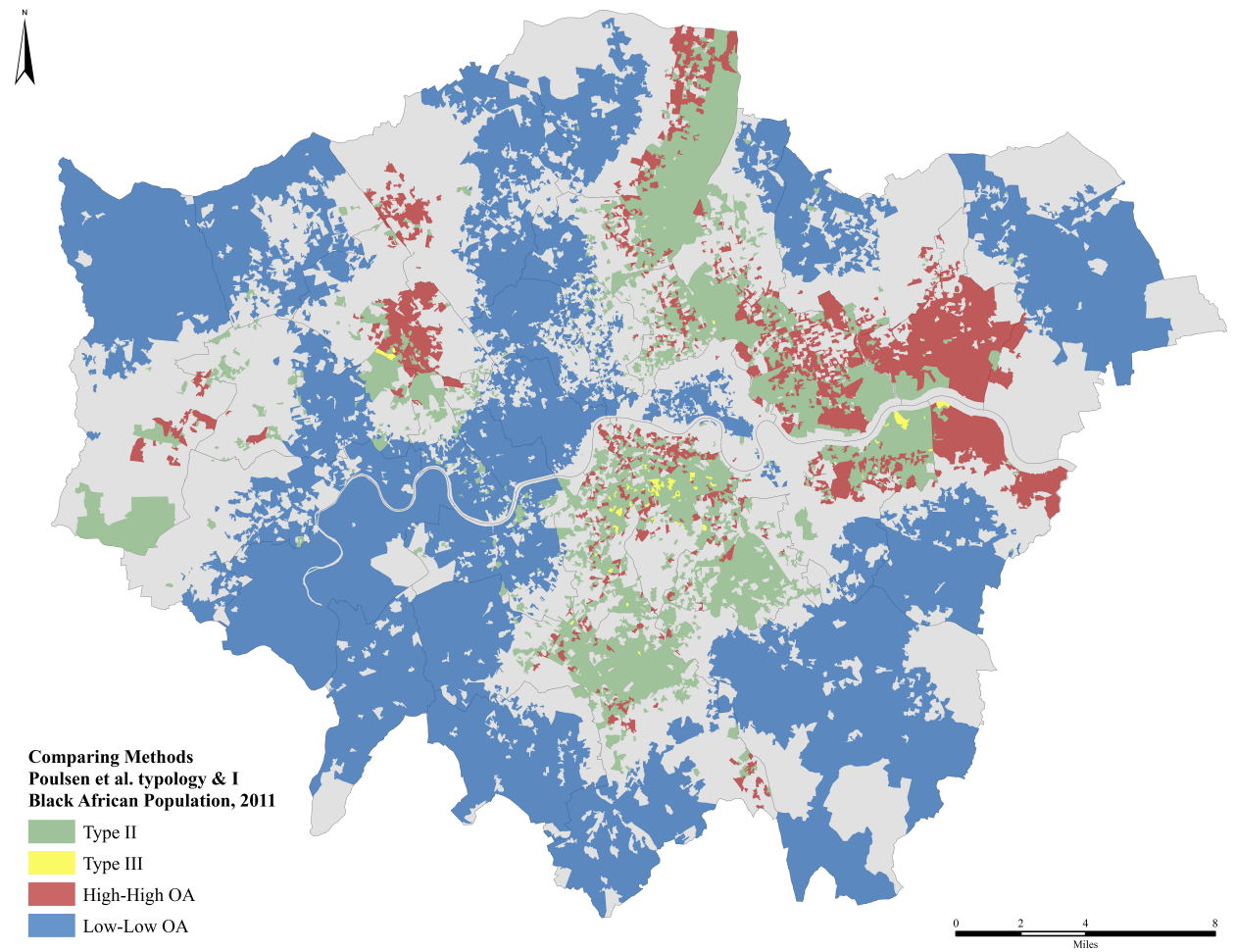

Figure 24: Comparing methods, Poulsen et al. typology \& Anselin Local Moran's I

Source: Office of National Statistics, Contains National Statistics data $\odot$ Crown copyright and database right 2013, Contains Ordnance Survey data (C) Crown copyright and database right 2013

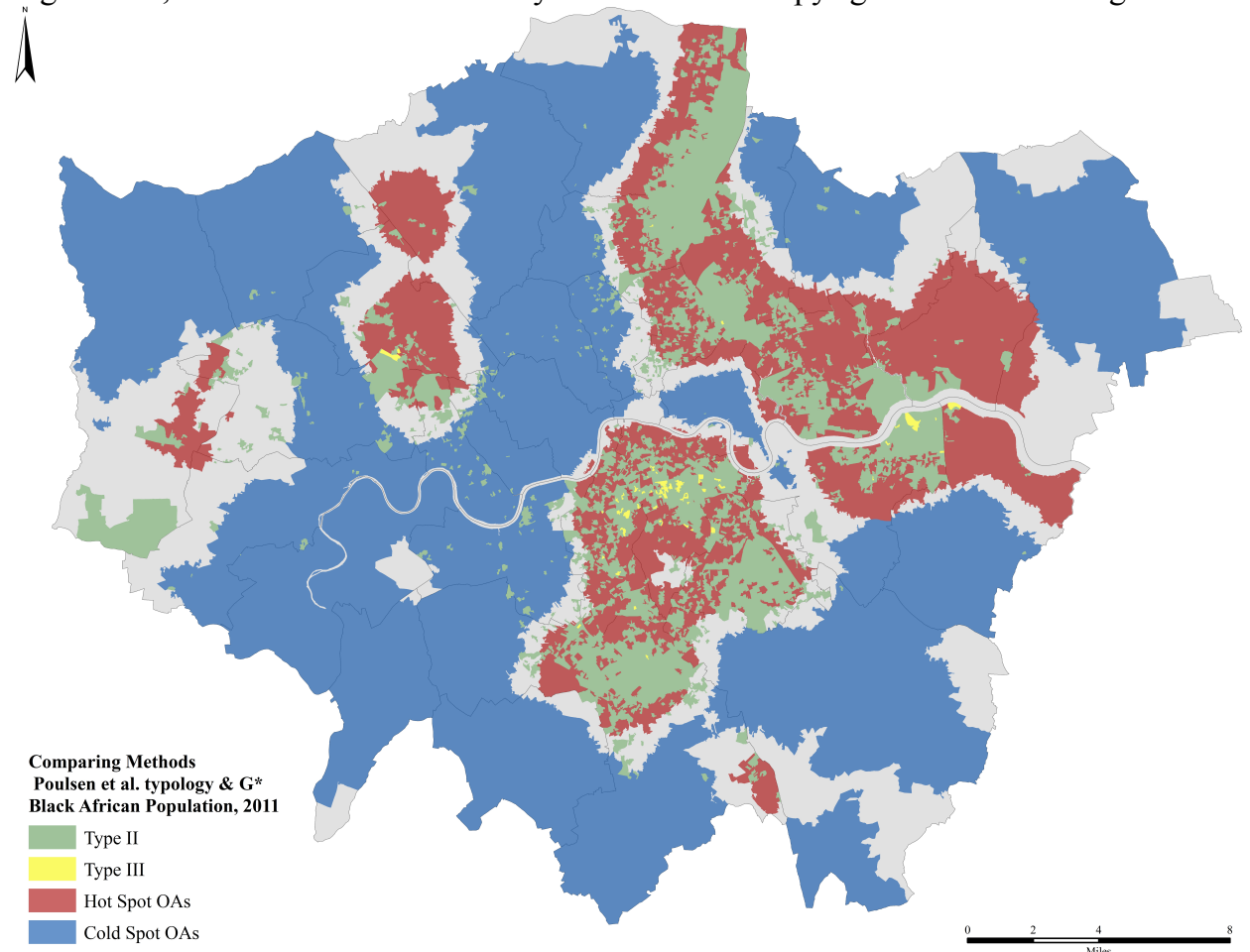

Figure 25: Comparing methods, Poulsen et al. typology \& Getis-Ord $G^{*}$

Source: Office of National Statistics, Contains National Statistics data (C) Crown copyright and database right 2013, Contains Ordnance Survey data (C) Crown copyright and database right 2013 
The final methodological comparison is between the two local statistics used for this study, Anselin Local Moran's $I$ and Getis-Ord $G^{*}$. The map shows the differences between the two results and is based on areas of high concentration and areas of low concentration (Figure 26). Due to the nature of the statistics, the result for $G^{*}$ is much more consistent across space while $I$ gives the only indication of true variation in small areas. The patterns for both statistics are remarkably consistent and there are only a few departures between the two within the classifications shown below.

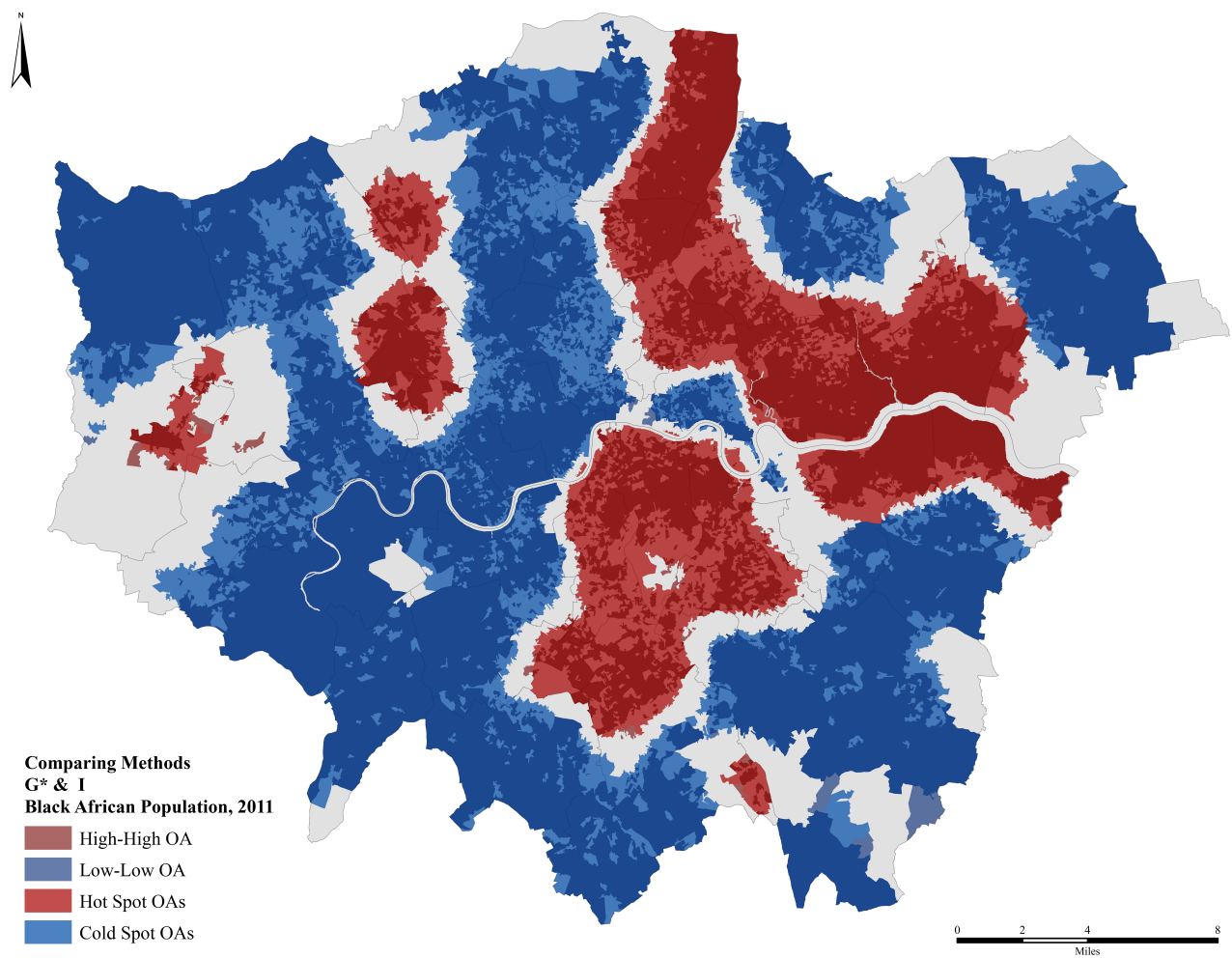

Figure 26: Comparing methods, Getis-Ord $G^{*} \&$ Anselin Local Moran's $I$

Source: Office of National Statistics, Contains National Statistics data $(\mathcal{C}$ Crown copyright and database right 2013, Contains Ordnance Survey data (C) Crown copyright and database right 2013 
After calculating and evaluating four different measures of segregation/spatial concentration, it is clear that there is not one definitive measure of segregation. There are, however, measures that provide a much more detailed and accurate portrayal of how populations are distributed across space. Most traditional measures of segregation, such as the Index of Dissimilarity used here, hide as much as they reveal about the settlement patterns of minority groups in a given city. With the growing availability of GIS technology, it is now possible to use more advanced local statistics to discern ethnic residential patterns. While the Getis-Ord $G^{*}$ statistic gives a statistically sound result of areas of significant high and low values, the Anselin Local Moran's I gives the most nuanced result by showing outliers. The allowance for outliers provides for areas within what may be considered a hot or cold spot that in fact have significantly high or low numbers of the population group being examined. 
Chapter 5: Discussion

\section{Answering research questions}

After reviewing the results of the four measures of segregation used for this analysis, I am able to answer my initial research questions with a fair amount of confidence. The first question I sought to answer was: How have levels of ethnic residential segregation in the greater London area changed since the introduction of ethnicity to the British census in 1991 ?

Due to changes in geometry and uncertainty with assuming distribution for new geography, the analysis was only performed comparing 2001 and 2011. To avoid issues of continuity between Output Areas, the quantitative analysis for this research question was done using only population figures and the associated proportions of the individual ethnic minority groups. Subsequently it was determined that two of the five ethnic minority groups considered saw a decrease in the overall portion of its population living in highly segregated areas: Black African and Black Caribbean. The three South Asian minority groups saw small increases in their overall levels of segregation, with the Pakistani population experiencing the greatest increase in terms of the percentage of its total population living in highly segregated areas.

Have policies promoting "community cohesion" been successful in their goal of decreasing levels of segregation? The idea of creating mixed communities that promote social integration does not seem to have significantly changed the ethnic residential landscape of London during the first decade of the twenty-first century. Only the Black Caribbean population saw a decrease in the overall level of highly segregated Output Areas in the city between 2001 and 2011, the remaining four minority groups all 
experienced an increase in the level of highly segregated OAs in that time. This would suggest that, contrary to the assertion of the government's report on the impacts of choice-based letting, the relative levels of segregation among the ethnic minority population as a whole have not significantly decreased with time.

How does changing the method of measurement change a map of residential segregation and do different the methods used produce maps that may lead to different interpretations of segregation in a city?

When examining maps of ethnic residential segregation measures, there are some distinct differences to be seen. The Poulsen et al. typology (2001) produces a very generalized map of segregation among broad population groups across the study area, but does not allow for the analysis of shifts of individual ethnic groups. It also does not allow for analysis of how the different minority groups differ in areas that are considered highly segregated in the typology. If an area is classified as minority dominant, which group of the minority groups being used is not revealed? The Index of Dissimilarity produces only a very general map and relies on large areal units for its calculations. This results in a map that hides most of the variety of segregation levels across space that is shown by other methods. A significant challenge in interpreting ID results comes in the fact that it is an inherently aspatial measure. It does not allow for any variation across space. It also tends to hide as much as it reveals; in the case of this study, the Bangladeshi population has very high ID values, but this is a result more of there being a very small Bangladeshi population in that district than segregation.

The two local statistics used in this study produce similar results but distinct results. The general shape and size of areas classified as having the highest and lowest 
concentration of the ethnic group in question is consistent for both measures. The Anselin Local Moran's I statistic shows a more fragmented result with much smaller pockets of clustering than Getis-Ord $G^{*}$, which results in a much more continuous and smooth result across space. This is due in large part to Moran's I's allowance for outliers in its classification scheme. The ability to discern areas of high values surrounded by low values or low values surrounded by high is why in my view the Moran's I statistic is the most valuable of the four measures used.

This value lies in the ability of the statistic to show significant variation across space that is not revealed by any of the other statistics. When aiming to gain a truly comprehensive understanding of segregation in a city, a combination of measures would be recommended as each has its value, but the Anselin Local Moran's I stands out as the most encompassing of the measures used in this study. The four methods I used for this study are by no means all of the ways to evaluate segregation. I recommend that local statistics will become the standard in measuring segregation in urban areas.

The measurements used for this study contribute to a better understanding of the different dimensions of segregation. While the Index of Dissimilarity is a cursory measure of evenness, the Poulsen et al. typology provides a more detailed view of evenness. The results for the local statistics reveal two other dimensions of segregation. Getis-Ord $G^{*}$, in its hot and cold spot classifications, is inherently a measure of concentration either of high or low minority populations across space. Anselin Local Moran's I reveals areas of clustering across space, whether that be a large area of clustering of high and low values or small outlier areas of high or low values. 


\section{Personal observations of the study area}

In the midst of this research, I had the opportunity to go to London and explore some of the areas I was analyzing. I was able to see two neighborhoods with significant ethnic minority populations. The first was the district of Southwark, which is home to one of the cities most significant Afro-Caribbean populations. As I walked around the different neighborhoods in the district, the impact of social housing and redevelopment plans in the district were very clearly seen on the landscape. One of reasons studies such as this one are important is because they help to identify areas where the most vulnerable populations are housed, which in many cases means that they are areas with the highest levels of deprivation. Seeing the state of the council housing in the Elephant and Castle neighborhood created a stark picture of the juxtaposition of new development and old social housing. The following image is a representation of how many residents in the area feel about current development trends (Figure 27).

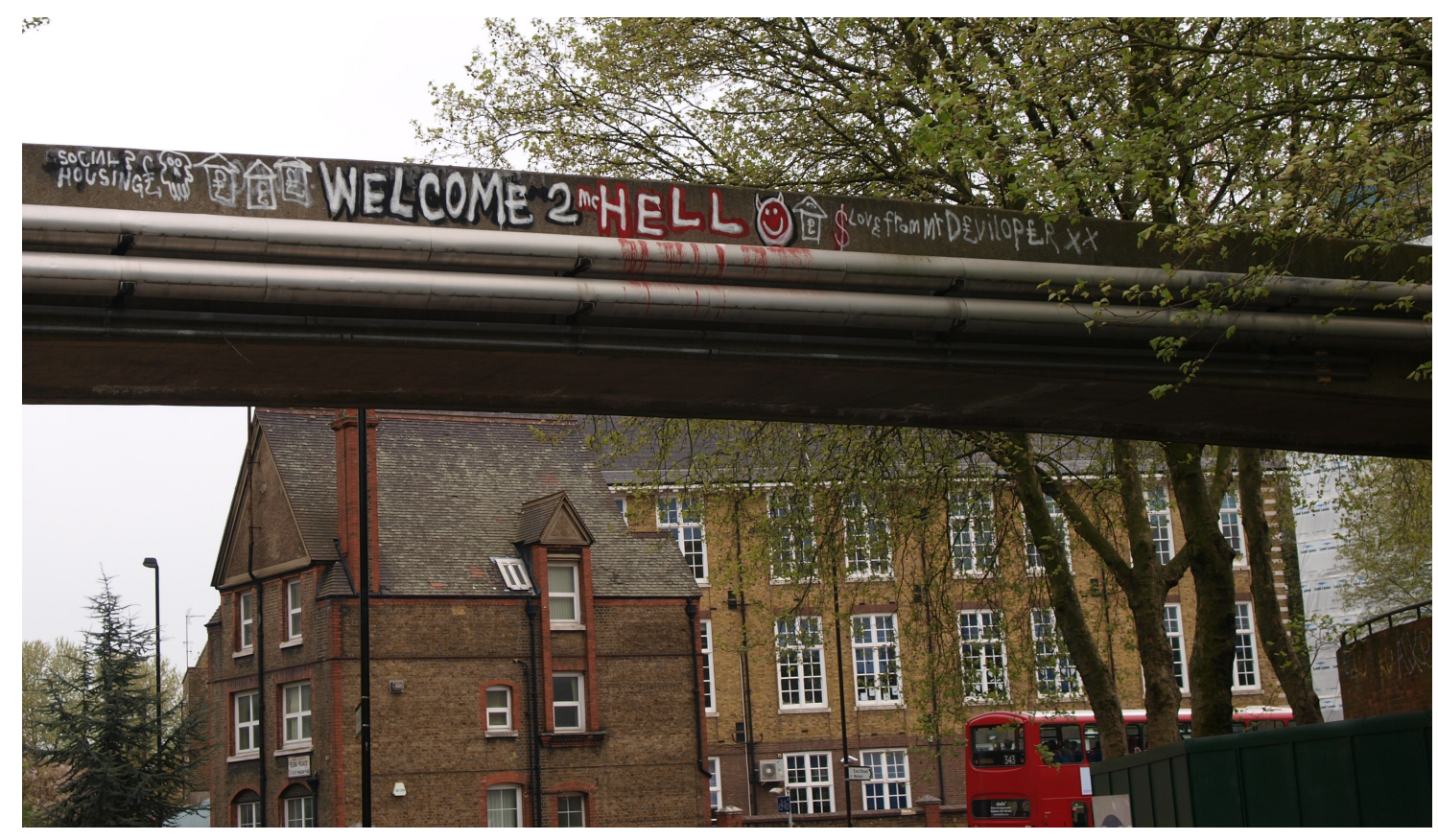

Figure 27: Graffiti in Elephant and Castle, Southwark, London. Photo taken by the author 
It was very apparent that much of the social housing in the area was either neglected or being torn down in favor of new gentrifying development (Figure 28).

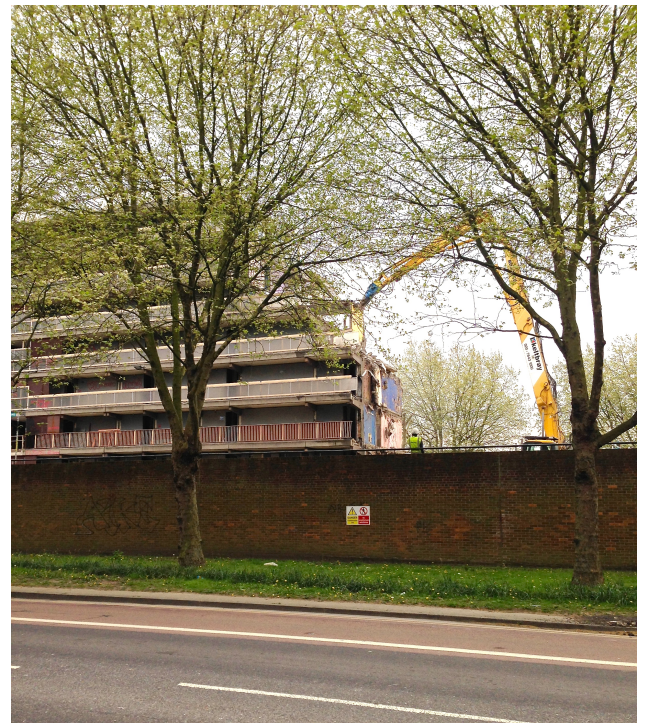

Figure 28: Demolition of a council housing facility in Elephant and Castle, Southwark, London. Photo taken by the author

As I moved further south into the district, the influence of the Afro-Caribbean population became very apparent. Walking through the Peckham neighborhood, the presence of the ethnic community there marked the landscape in very distinct ways. The high street in Peckham is full of shops selling Afro-Caribbean foods and barber shops tailored to the black community (Figure 29). 


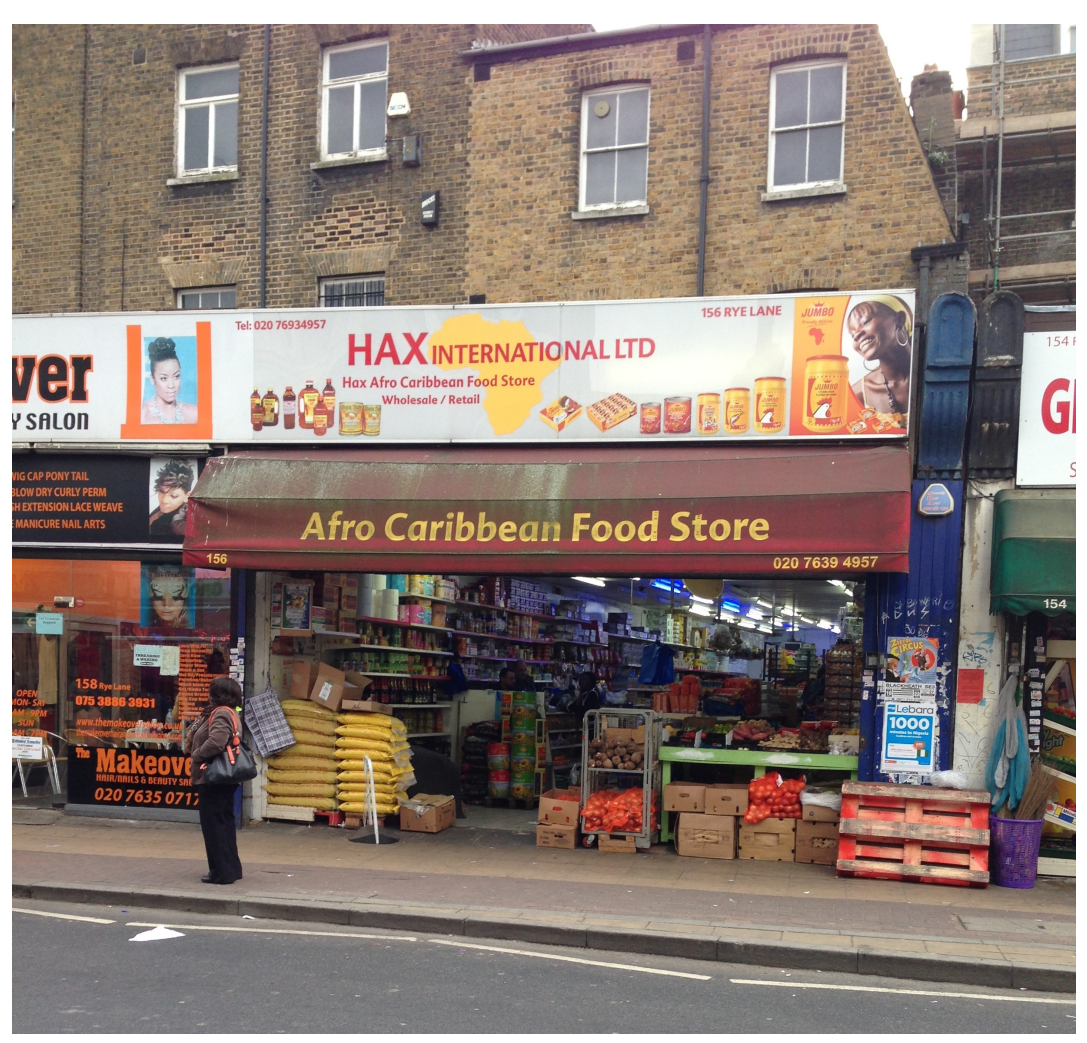

Figure 29: Afro-Caribbean centric high street in Peckham, Southwark, London. Photo taken by the author

Later in my trip, I visited the Tower Hamlets area of London, which is home to

over a third of the Bangladeshi population in England. Knowing that this district had such a high ethnic minority population, I was very interested in seeing how that translated onto the landscape. I also went to Barking, which is another area north of the river with a prominent South Asian community. One instance of the visibility of the minority population came here where, instead of public service advertisements portraying White/British individuals, the ads include people of South Asian descent (Figure 30). 


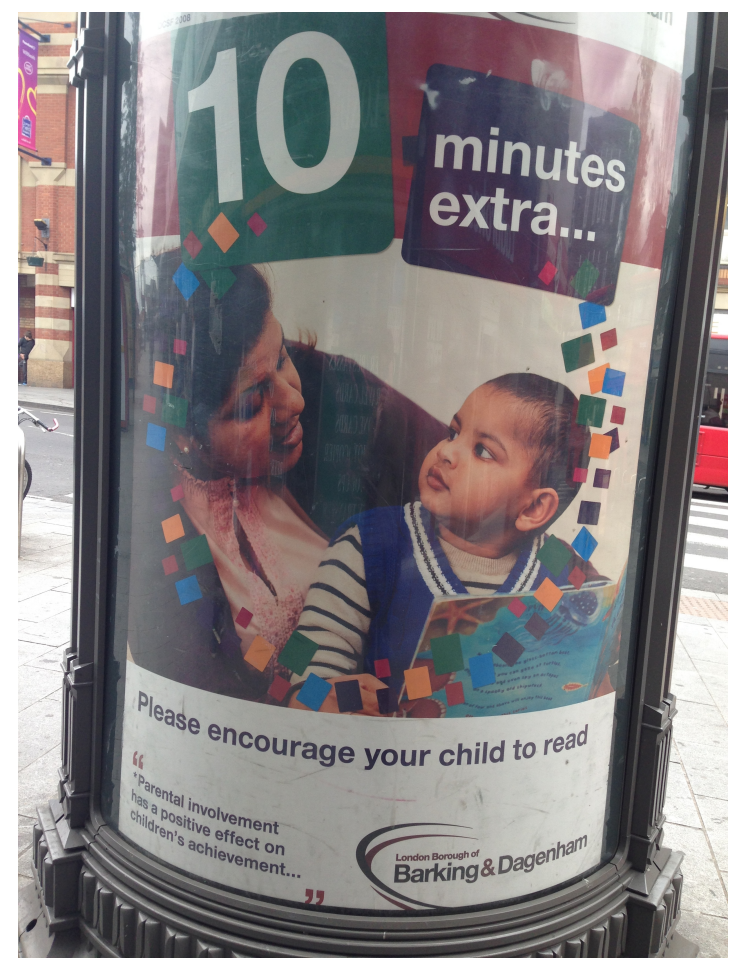

Figure 30: Public service advertisement in Barking and Dagenham, London. Photo taken by the author

Despite the limited duration and scope, I was able to see how prominently the ethnic minority population is seen in areas classified as having the highest ethnic minority concentrations. The sense of community in these areas is apparent and lends itself to the notion that not all segregation is harmful and in some cases it is actually intentional.

\section{Broader Implications}

In many ways the results of this study raise many more questions than it answers, which made this type of study very appealing. The idea of using quantitative research to point to areas where qualitative research might be most effective is of great interest to me as a human geographer, and using a study of this nature to provide more accurate questions for research in the future is a way to combine the sociocultural aspects of geographic study with some of its more technical methods. As the discipline of 
geography continues to evolve, it will become increasingly important that geographers use multiple tools to gain a truly comprehensive understanding of the questions posed. The ways in which immigrant and ethnic minority populations settle across space and the impacts of that settlement on the landscape are incredibly important when seeking to discern the why of where, otherwise known as geographic research.

Studies looking at the different causes and effects of segregation are bound to elicit many avenues for further research. In the case of this study, these questions tend to involve the role of individual choice in segregation as well as factors other than race that may lead to changes in segregation across an urban area. How much of the segregation seen in London is a result of different ethnic minorities choosing to live in communities with similar cultural and/or religious characteristics and how much is a result of housing practices and policies? Is the presence of segregation in a city always negative? What other characteristics do areas of high segregation share? Is it in any significant way related to income? What are the levels and types of deprivation associated with areas with large ethnically segregated populations? 


\section{Chapter 6: Conclusion}

The research presented in this paper provides some insight into how ethnic residential segregation has changed in the London area from 2001 to 2011 in light of new government policies aimed at discouraging ethnic minority segregation. The results of the study show that the first ten years of efforts by the government to encourage integration rather than segregation have not made a significant impact on the landscape of the city. There are many areas of the city with significant levels of ethnic clustering, and while they have shifted and changed in size, they have not lessened in population.

In addition to gaining further perspective as to how segregation has changed (or not) throughout the city, this is also a study of how changing the method of measurement changes the result. It highlights the value in using Anselin Local Moran's I to see small scale changes over time and to reveal some of the variation across space that is inherent in segregation yet hidden by its more traditional measures. The ability of the statistic to reveal outliers, or very small clusters of either high or low values makes it a powerful tool for policy makers and community leaders to pinpoint small areas of ethnic minority clustering in order to evaluate them as possible locations of social exclusion and disadvantage.

Moving forward, it is important to add more qualitative efforts to studies of segregation. Much of the work done in this field involves purely quantitative analysis, but it is important to recognize that there is a very real human impact resulting from high levels of segregation. In the areas where change occurred between 2001 and 2011, questions must be asked about why those areas were affected. Are the minority populations in those areas moving away by choice or it is a result of further racism or 
gentrification? The UK's history of institutionalized racism must be recognized and addressed in any study of ethnic minority segregation in London.

It would be useful to utilize the results of a study such as this one to then go to areas with high levels of segregation with the aim of involving the populations of those areas in an examination of how residing in a highly segregated area affects living conditions. There is also the question of why areas of ethnic concentration have shifted and what drives individuals in each ethnic group to move to a different area of the city. One of the benefits of a study such as this one is that it enables us to look at a very complicated situation through a broad lens in order to find more narrow avenues for future research that will then add to our collective understanding of different cities and societies.

There are many implications for studies of segregation, yet very few answers for how to address the serious problems facing those living in areas of high segregation, which are often areas with high levels of deprivation as well. Finding the most accurate methods for highlighting areas of significant segregation will enable researchers and policymakers to find locations with the most need in order to then work to alleviate deprivation and eradicate social exclusion in urban areas. The life of an immigrant is full of enormous challenges and finding ways to address the needs of this extremely vulnerable community can be aided in the smallest way through the development and use of quantitative measures, those measures should be pursued with vigor. As a geographer, my main pursuit is to find ways to gain a better understanding of the how complexities of modern life create and maintain space. 
The other looming question raised by quantitative segregation research is how levels of segregation affect levels of social exclusion and deprivation among the most segregated communities. What are the factors that might cause one area of segregation to have low levels of deprivation and another to have high levels? How does the ethnic group one belongs to contribute (or not) to levels of social exclusion when examined in tandem with residential segregation? There are any number of questions raised by this and other ethnic residential segregation research, and my hope is that more researchers will begin to use advanced methods of measurement such as local statistics to provide a comprehensive understanding of how and why different ethnic groups are segregated in urban areas around the world. This study provides a thorough examination of several dimensions of ethnic residential segregation in London, which can only be done using a combination of measurements, highlighting once again the that attempts to simplify something as complex as segregation only serves to diminish its impact on cities. 


\section{References}

Anselin, L. 1995. Local Indicators of Spatial Association - LISA. Geographical Analysis. 27(2): 93-115.

Brimicombe, A. 2007. Ethnicity, religion and residential segregation in London: evidence from a computational typology of minority communities. Environment and Planning B: Planning and Design. 34: 884-904.

Burnett, J. 2007. Britain's 'civilising project': community cohesion and core values. Policy \& Politics. 35(2): 353-357.

Coleman, D.A. 1995. International Migration: Demographic and Socioeconomic Consequences in the United Kingdom and Europe. International Migration Review. 29(1): 155-206.

Department for Communities and Local Government (DCLG). 2006. Monitoring the Longer Term Impact of Choice Based Letting. London: Department for Communities and Local Government.

ESRIa. 2014. Modeling spatial relationships. Redlands: ESRI, ArcGIS Resources. Available at http://resources.arcgis.com/en/help/main/10.1/index.html\#/Modeling_spatial_relat ionships/005p00000005000000/ (last accessed 20 March 2014).

b. 2014. How Hot Spot Analysis (Getis-Ord Gi*) works. Redlands: ESRI, ArcGIS Resources. Available at http://resources.arcgis.com/en/help/main/10.1/index.html \#/How_Hot_Spot_Analysis_Getis_Ord_Gi_works/005p00000011000000/ (last accessed 20 March 2014).

c. 2014. Cluster and Outlier Analysis (Anselin Local Moran's I) (Spatial Statistics). Redlands: ESRI, ArcGIS Resources. Available at http://resources.arcgis.com/en/help /main/10.1/index.html\#/Cluster_and_Outlier_Analysis_Anselin_Local_Moran_s_ I/005p0000000z000000/ (last accessed 20 March 2014).

Fangen, K. 2010. Social exclusion and inclusion of young immigrants: Presentation of an analytical framework. Young. 18(2): 133-156.

Getis, A. and J.K. Ord. 1992. The Analysis of Spatial Association by Use of Distance Statistics. Geographical Analysis. 24(3): 189-206. 
James, W. 2004. The Black Experience in Twentieth-Century Britain. In Black Experience and the Empire, ed. P. Morgan and S. Hawkins, 347-386. Oxford: Oxford University Press.

Johnston, P. 2007. Brown's Manifesto for Britishness. London: Telegraph. Available at http://www.telegraph.co.uk/news/uknews/1539369/Browns-manifesto-forBritishness.html (last accessed 22 May 2014).

Johnston, R., M. Poulsen and J. Forrest. 2005. On the Measurement and Meaning of Residential Segregation: A Response to Simpson. Urban Studies. 42(7): 12211227.

Johnston, R., M. Poulsen and J. Forrest. 2009. Research Note - Measuring Ethnic Residential Segregation: Putting Some More Geography In. Urban Geography. 30(1): 91-109.

Johnston, R., M. Poulsen and J. Forrest. 2010. Moving on from Indices, Refocusing on Mix: On Measuring and Understanding Ethnic Patterns of Residential Segregation. Journal of Ethnic and Migration Studies. 36(4): 697-706.

Kaplan, D. and K. Woodhouse. 2004. Research in Ethnic Segregation I: Causal Factors. Urban Geography. 25(6): 579-585.

Kaplan, D. and K. Woodhouse. 2005. Research in Ethnic Segregation II: Measurements, Categories and Meanings. Urban Geography. 26(8): 737-745.

Knox, P. 1989. The Vulnerable, the Disadvantaged, and the Victimized: Who They Are and Where They Live. In Social Problems and the City: New Perspectives, ed. D. Herbert and D. Smith. 32-47. Oxford: Oxford University Press.

Layton-Henry, Z. 1994. Britain: The Would-be Zero-Immigration Country. In Controlling Immigration - A Global Perspective, ed. W. Cornelius, P. Martin and J. Hollidfield, 273-295. Stanford, CA: Stanford University Press.

Manley D. and van Ham, M. 2011. Choice-based Letting, Ethnicity and Segregation in England. Urban Studies. 48(14): 3125-3143.

Massey, D. 1999. International Migration at the Dawn of the Twenty-First Century: the Role of the State. Population and Development Review. 25(2): 303-322. 
Massey, D. and N. Denton. 1988. The Dimensions of Residential Segregation. Social Forces. 67(2): 281-315.

Money, J. 1997. No Vacancy: The Political Geography of Immigration Control in Advanced Industrial Countries. International Organization. 51(4): 685-720.

Office of the Deputy Prime Minister (ODPM). 2004. Tackling Social Exclusion: Taking stock and looking to the future: Emerging findings. London: Office of the Deputy Prime Minister, Social Exclusion Unit.

Pacione, M. 2005. The changing geography of ethnic minority settlement in Glasgow, 1951-2001. Social Geographical Journal. 121(2): 141-161.

Pawson, H. and K. Kintrea. 2002. Part of the Problem or Part of the Solution? Social Housing Allocation Policies and Social Exclusion in Britain. Journal of Social Policy. 31(04): 643-667.

Peach, C. 1999. London and New York: Contrasts in British and American Models of Segregation. International Journal of Population Geography. 5: 319-351.

Phillips, D. 2006. Parallel lives? Challenging discourses of British Muslim selfsegregation. Environment and Planning D: Society and Space. 24: 25-40.

Phillips, D. 2010. Minority Ethnic Segregation, Integration and Citizenship: A European Perspective. Journal of Ethnic and Migration Studies. 36(2): 209-225.

Phillips, D. and V. Karn. 1991. Racial Segregation in Britain: Patterns, Processes and Policy Approaches. In Urban Housing Segregation of Minorities in Western Europe and the United States, ed. E. Huttman, co-ed. W. Blauw and J. Saltman, 63-91. Durham: Duke University Press.

Poulsen, M., R. Johnston and J. Forrest. 2001. Intraurban ethnic enclaves: introducing a knowledge-based classification method. Environment and Planning A. 33: 20712082.

Poulsen, M., R. Johnston and J. Forrest. 2011. Using local statistics and neighbourhood classifications to portray ethnic residential segregation: a London example. Environment and Planning B: Planning and Design. 38: 636-658. 
Taket, A., B. Crisp, A. Nevill, G. Lamaro, M. Graham and S. Barter-Godfrey, eds. Theorising Social Exclusion. London: Routledge.

Trudeau, D. and C. McMorran. 2011. The Geographies of Marginalization. In $A$ Companion to Social Geography, ed. V. Del Casino Jr, M. Thomas, P. Cloke and R. Panelli, 437-453. West Sussex: Wiley-Blackwell.

Schierup, C., P. Hansen and S. Castles. 2006. Migration, Citizenship and the European Welfare State. Oxford: Oxford University Press.

Stewart, E. 2005. Exploring the Vulnerability of Asylum Seekers in the UK. Population, Space and Place. 11: 499-512.

Stillwell, J. 2010. Ethnic population concentration and net migration in London. Environment and Planning A. 42: 1439-1456.

van Ham, M. and D. Manley. 2009. Social housing allocation, choice and neighbourhood ethnic mix in England. Journal of Housing and the Built Environment. 24: 407422 .

van Ham, M. and D. Manley. 2012. Segregation, choice based letting and social housing: How housing policy can affect the segregation process. Discussion paper series, Forschungsinstitut zur Zukunft. 6372: http://nbn-resolving.de/urn:nbn:de:101:1201206146479.

White, M. 1983. The Measurement of Spatial Segregation. American Journal of Sociology. 88(5): 1008-1018.

Wolton, S. 2006. Immigration Policy and the "Crisis of British Values." Citizenship Studies. 10(4): 453-467. 
Appendix A

England Census Questionnaire, Ethnicity question 2001 \& 2011

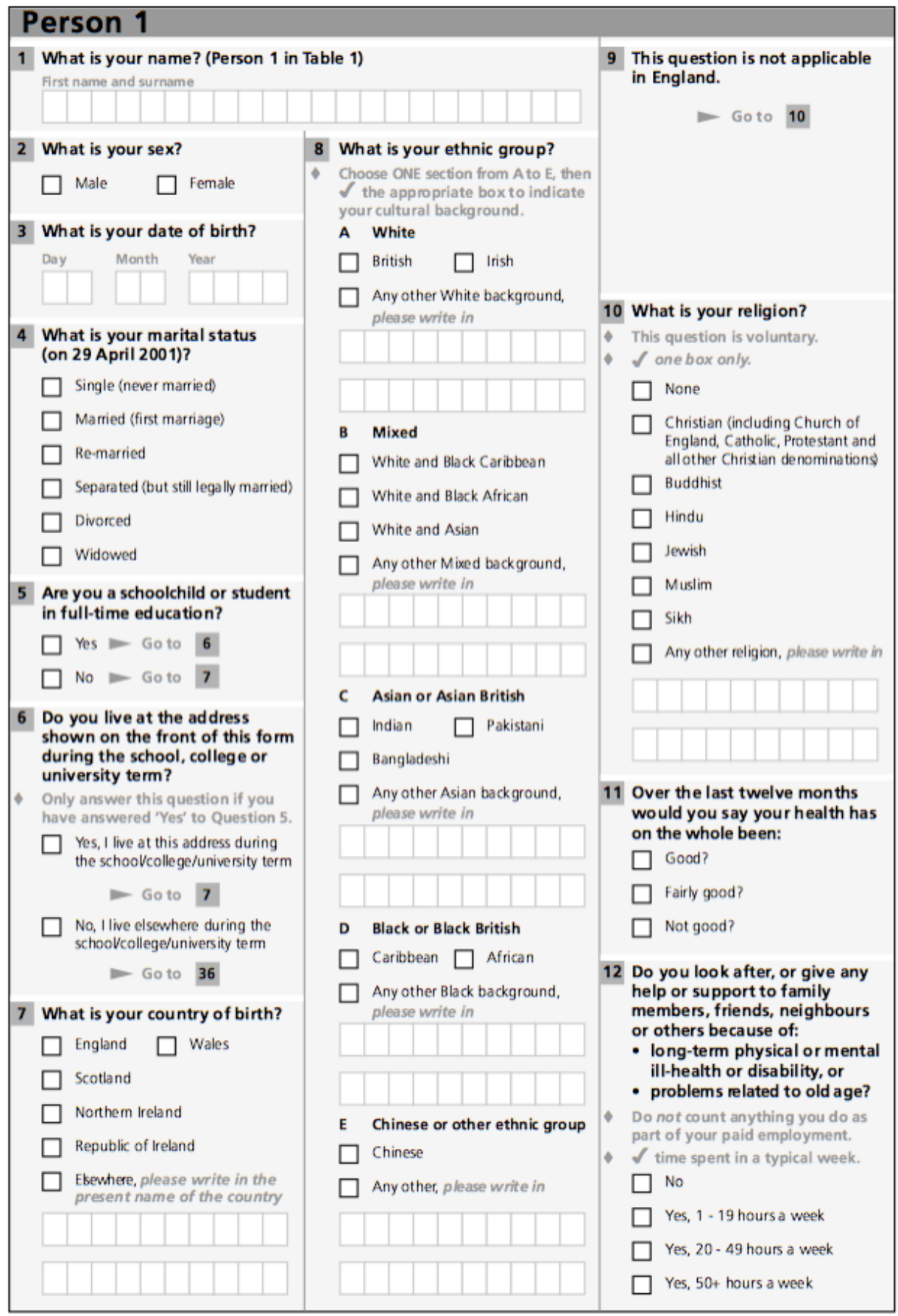

Page 6

Source: Office of National Statistics. 2001. "England Household Questionnaire - H1" Contains National Statistics data (C) Crown copyright and database right 2013 


\section{Person 1 - continued}

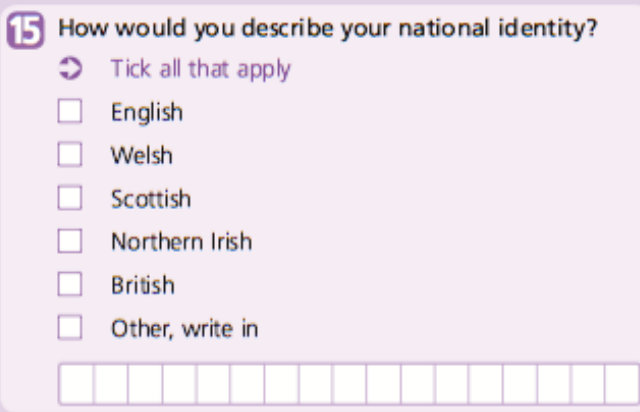

16 What is your ethnic group?

(2) Choose one section from A to $E$, then tick one box to best describe your ethnic group or background

\section{A White}

English/Welsh/Scottish/Northern Irish/British

Irish

Gypsy or Irish Traveller

Any other White background, write in

B Mixed/multiple ethnic groups

White and Black Caribbean

White and Black African

White and Asian

Any other Mixed/multiple ethnic background, writein

c Asian/Asian British

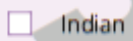

$\square$ Pakistani

Bangladeshi

Chinese

Any other Asian background, write in

D Black/African/Caribbean/Black British

African

Caribbean

] Any other Black/African/Caribbean background, write in

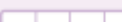

E Other ethnic group

Arab

Any other ethnic group, write in
17 This question is

intentionally left blank $\Rightarrow$ Goto 18

18 What is your main language?

$\square$ English $\rightarrow$ Go to 20

$\square$ Other, write in (including British Sign Language)

19 How well can you speak English?

Verywell Well Notwell Not at all

20 What is your religion?

(2) This question is voluntary

No religion

Christian (including Church of England, Catholic, Protestant and all other Christian denominations) Buddhist

Hindu

Jewish

Muslim

Sikh

Any other religion, write in

21 One year ago, what was your usual address?

D If you had no usual address one year ago, state the address where you were staying

$\square$ The address on the front of this questionnaire

$\square$ Student term time/boarding school address in the UK, write in term time address below

$\square$ Another address in the UK, write in below
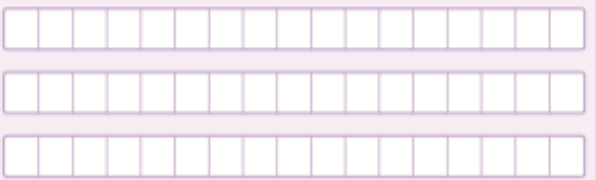

Postcode

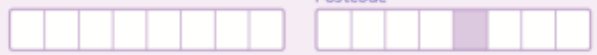

OR

Outside the UK, write in country

Page 8

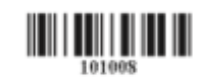

Source: Office of National Statistics, 2011 "2011 Census questionnaire for England"

Contains National Statistics data (C) Crown copyright and database right 2013 